\title{
Joint Systems in the Watchung Basalt Flows, New Jersey
}

GEOLOGICAL SURVEY PROFESSIONAL PAPER 864-B

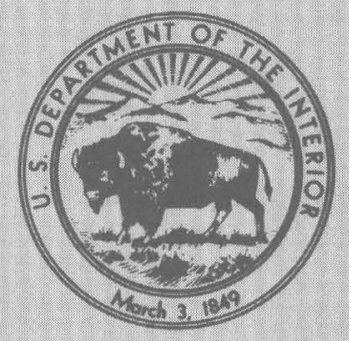





\section{Joint Systems in the Watchung Basalt Flows, New Jersey}

By GEORGE T. FAUST

STUDIES ON THE WATCHUNG BASALT FLOWS OF NEW JERSEY GEOLOGICAL SURVEY PROFESSIONAL PAPER 864-B

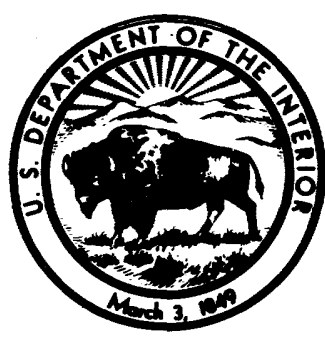




\section{UNITED STATES DEPARTMENT OF THE INTERIOR \\ CECIL D. ANDRUS, Secretary}

\section{GEOLOGICAL SURVEY}

V. E. McKelvey, Director

Library of Congress Cataloging in Publication Data

Faust, George Tobias, 1908-

Joint systems in the Watchung Basalt flows, New Jersey.

(Studies on the Watchung Basalt flows of New Jersey) (Geological survey professional paper ; 864-B)

Bibliography: p.

Includes index.

Supt. of Docs. no.: I 19.16:864-B

1. Joints (Geology) 2. Basalt-New Jersey. I. Title. II. Series. III. Series: United States. Geological Survey. Professional paper ; 864-B. QE605.F38 $551.8^{\prime} 4$

For sale by the Superintendent of Documents, U.S. Government Printing Office Washington, D.C. 20402

Stock Number 024-001-03023-3 


\section{CONTENTS}

Abstract

Introduction

Previous studies on jointing in the Watchung Basalt flows

Sampling of the jointing patterns in Third Watchung Mountain _-_-_-_-_-_-_-

Description of the joint systems

Cooling joints

Vesicular top

Columnar zone --_--_-_-_-_-_-_-_-_-_-

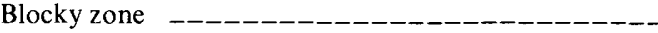

Curvilinear zone -_-_-_-_-_-_-_-_-_-_-_--

Geometric character of the curvilinear joints

Vesicular base _-_-_-_-_-_-_-_-_-_-_-_-_-

Occurrences of similar cooling joints in other basaltic provinces

Tectonic joints

Vesicular top

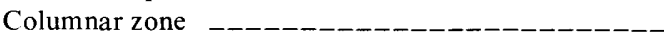

Blocky zone -- -

Curvilinear zone -_-_-_-_-_-_-_-_-_-_-_

Pseudocolumnar joints (type 1) - - - -

Pseudocolumnar joints (type 2)-platy-prismatic joints (fracture cleavage) _-_-_-_-_-

Basal platy joints

Sheeting joints

Weathering joints and associated phenomena

Spheroidal joints

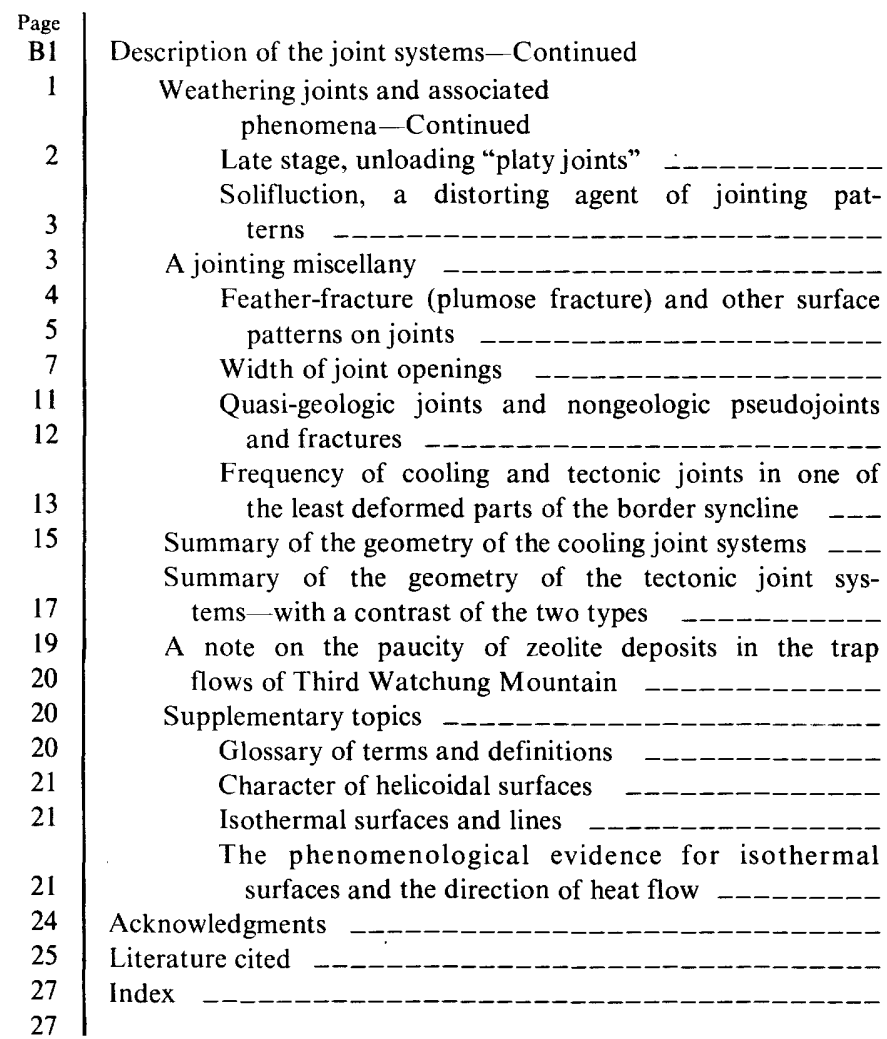

Page

\section{ILLUSTRATIONS}


Figure 7. Columnar joints, slightly curved and tapered, just below the vesicular top. Roadcut on the east side of Alps Road a short distance south of its intersection with Rockledge Terrace, northeast of Mountain View, on Packanack Mountain _-_-_

8. Remnants of the blasted and mechanically excavated trap in the roadcut at Lyons Station, Lyons, N.J., showing the mechanically disrupted columnar zone

9. Columnar joints in the upper flow unit of Second Watchung Mountain. Roadcut on U.S. Highway No. 287, near Liberty Corner

10. Inverted fan structure formed of columnar basalt. In roadcut for U.S. Highway No. 280 near West Orange, N.J

11. The ball end of "ball and socket" joints in columnar basalt. Ferguson's quarry, near Little Falls, N.J

12. The socket end of "ball and socket" joints in columnar basalt. Ferguson's quarry, near Little Falls, N.J _-_-_-_-_-_-

13. Exposure at the top of the "east" wall of the Millington quarry. The blocky zone juts out. The geologist is pointing to the base of the blocky zone. At the lower right hand side of the picture, well-developed curvilinear joints may be seen. This wall forms the dumping ramp of a stock pile: The apparent granular decoration on the top of the blocks and scattered over the faces is the remains of a former stock pile

14. Detailed view of the blocky zone on the "east" wall of the Millington quarry An enlargement of a portion of figure 13

15. A hackled block from the blocky joint system which has fallen and tumbled from its position in the overhanging ledge to the floor of the Millington quarry. It was battered by a steel ball dropped from a crane boom. Such blocks are used as jetty stone. Other large blocks may be seen near the base of the wall

16. Weathered blocky jointed trap. Roadcut near Blackberry Lane and James Street, New Vernon trap sheet near Morristown, N.J

17. Glacial pavement developed on basalt of the blocky zone. This glacially polished outcrop is on the north side of Chapel Hill Road and Highland Street, Hook Mountain, near Lincoln Park, N.J

18. Blocks of trap dislodged from their position at the top of the ridge. These were naturally quarried by alternate freezing and thawing which disrupted the jointed ledge to produce a jumble of blocks. When dislodged sufficiently or undermined, they tumble down the scarp slope. Northeast of the intersection of Pine Brook Road and Passaic Avenue Road, Lincoln Park, N.J

19. Curvilinear joints in trap. "East" wall of the Millington quarry. Note thin layer of the closely jointed blocky zone (upper left hand corner) overlying the curvilinear zone and above this the irregular and hackly broken masses of the blocky zone - - -

20. A close-up view of curvilinear joints in an old quarry wall. "South" wall Millington quarry. Note that the blocks that have dropped out from the wall are shield shaped and wedge shaped

21. Excellently developed curvilinear joints in the trap. The roadcut is approximately perpendicular to the strike. The joints across the face of the curved planes are sheeting joints and are not cooling joints. Roadcut on Bloomfield Avenue near its intersection with Hook Mountain Road, Pine Brook, N.J

22. Curvilinear joints in relatively fresh basalt. This rock is very tough and required extra blasting to excavate it. The curvilinear joints are outlined by the shades and shadows. They are elongate approximately perpendicular to the floor of the excavation. Near the surface of the triangular area on the right some checking of the minor joints is apparent. This locality is an excavation at the intersection of U.S. Highway 46 and Hook Mountain Road, Pine Brook, N.J _-_-_-_-_-_-_-_-

23. A strongly blasted mass of curvilinear jointed trap preserving its characteristic morphology. The picture represents a portion of the "north wall" at the Millington quarry, Millington, N.J

24. Weathered curvilinear joint masses having wedge shapes. This rock is similar to that in figure 22 except that it is from a strongly weathered zone. Excavation at the intersection of the U.S. Highway 46 and Hook Mountain Road, Pine Brook, N.J --

25. Curvilinear joints in the trap of Second Watchung Mountain. Geologist's hammer indicates the position of the trace of the helical path of the curvilinear joint. Gallo's quarry, Mt. Bethel, N.J

26. Two right helicoids with parallel but displaced directrices (helicoidal axes), with generators of slightly different length, with equal pitches and out of phase by about $155^{\circ}$

27. Portions of two steep right helicoids, moved parallel to one another graphically, until they intersect 28. Curvilinear jointed trap overlying the vesicular base of the upper flow unit in the Millington quarry. The hammer handle figure 4

29. Outcrop of flow breccia on south side of Oakland Valley Road, approximately abreast the dam, Packanack Mountain, at Pompton, N.J. This relatively thin layer of flow breccia lies just under the curvilinear jointed lava at the base of the flow

30. Curvilinear joints in the basaltic lava flow exposed on the Bay of Fundy at Canada Creek, near Black Rock Lighthouse, Nova Scotia

31. Tension jointed base of the blocky zone (so-called seam), overlying the curvilinear joint system. Excavation on Northfield Avenue below Valley Road, West Orange, N.J

32. Detailed view of the tension jointed base of the blocky zone overlying the curvilinear zone "East" wall of the Millingt on quarry

33. Typical pseudocolumnar appearance in the curvilinear zone produced by the superimposition of tectonic planar vertical joints on the curvilinear system. Excavation on Northfield Avenue, below Valley Road, West Orange, N.J

34. Pseudocolumnar joints produced by the superimposition of tectonic joints on the curvilinear jointing system in the north wall of the Millington quarry, Millington, N.J. The tectonic joints are very rare in the overhanging ledge of the blocky systems, in this photograph. This is the appearance of the pseudocolumns in a freshly blasted exposure

35. Platy-prismatic joints (fracture cleavage) in Second Watchung Mountain. Alward's quarry at the intersection of Pill Hill Road and Meeker Road almost $2 \frac{1}{4}$ miles west of Basking Ridge, N.J. These joints are close to the contact with the Triassic sedimentary rocks below 
Figure 36. A view of the zone of the platy-prismatic tectonic joints on Second Watchung Mountain. Musialowski's quarry on Washington Valley Road, northwest of Martinsville, N.J. Note the curvature of the sides, of the back joint face in profile. The fracture cleavage here shown in the walls of the quarry has its acute angle bisected by a line parallel to the axis of the major syncline

37. The platy surface of the curved platy-prismatic joints (fracture cleavage) developed in or near to the axial plane of the tightly folded syncline in the New Germantown trap sheet, 1.2 miles southwest of Oldwick, N.J N.J

39. Top view, showing the prismatic cross section of the curved platy-prismatic joints (fracture cleavage). New Germantown trap sheet, 1.2 miles southwest of Oldwick, N.J

40. Very abundant platy-prismatic joints on Second Mountain. The conjugate set of tectonic joints are so abundant that it is difficult to recognize the cooling joints. This section was formerly exposed in the cut for U.S. Highway No. 78 near Pluckemin, N.J. The outcrop is just above the contact with the underlying Brunswick Formation

41. Basal platy joints at the base of the curvilinear zone, just above the contact with the hornfelsized Brunswick Formation. In cut, in Second Watchung Mountain, on U.S. Highway No. 280 at its intersection with Pleasant Valley Way, West Orange, N.J

42. Sheeting joints in the transition zone between the blocky and the curvilinear zone of the basalt flow of Hook Mountain. This figure represents a view showing a section essentially at right angles to the strike. The roadcut, on Bloomfield Avenue in Pine Brook, is roughtly east-west

43. Sheeting joints in the blocky and curvilinear jointed trap of Hook Mountain. The steplike aspect is clearly evident. Quarry near the northern end of Hook Mountain near Mountain View, N.J

44. Spherical balls found in the deeply weathered columns of trap, near the surface. A ball 3 inches $(7.5 \mathrm{~cm})$ in diameter was cut and polished to show the "fresh" character of the minerals

45. "Spherical jointing" in basalt produced by weathering. Quarry $21 / 2$ miles south of Stirling, Second Mountain. Taken from Lewis (1908, pl. 38, fig. 1)

46. Late stage, unloading joints, probably developed in prestressed areas close to the surface of the earth. Their development may have been aided by weathering processes relieving stress, by man induced stresses inherent in blasting, excavating, and machine scraping or bumping operations. "North wall," Millington quarry and plant of the Houdaille Industries, Inc

47. Effects of solifluction are shown in the wall, which is essentially normal to the strike. This is shown in Tullo's quarry on Washington Valley Road, near Martinsville, N.J. The creep of the mantle down the slope has tilted the pseudocolumns, from their normal position shown at the base, to head downslope

48. Feather fracture developed on a curvilinear joint surface. Upper flow unit, Hook Mountain of Third Mountain, Pine Brook, N.J. The sharp end of the hammer is at the basal point of the feather

49. Fracture pattern on a joint wedge broken out of the curvilinear zone at the Millington quarry (Houdaille Industries, Inc.) Millington, N.J. The scale is $10 \mathrm{~cm}$

50. A, A string model of Oblique Helicoid prepared by Olivier of Paris " $\mathrm{A}$ helix and its axis as directrices; elements making an acute angle with the axis." B, A string model of Right Helicoid. "A helix and its axis as directrices; elements making a right angle with the axis." From Schumann (1946) (Published by permission of D. Van Nostrand Co., Inc.)

51. Two left-hand, right helicoids. The vertical distance $2 \pi q$ is the pitch of one helicoid where $q$ equals a constant and it represents the vertical distance traversed in one complete revolution $\left(360^{\circ}\right)$ of the generatrix. Scheffers $(1902$, v. 2, p. 60-61)

----

\section{TABLE}

TABLE 1. Joint frequencies in the Watchung Mountains along a line nearly normal to the strike and extending from Pine Brook on Third Watchung Mountain to near West Orange on First Watchung Mountain

\section{ERRATUM}

On page A23 of Professional Paper 864-A, "A review and interpretation of the geologic setting of the Watchung Basalt flows, New Jersey," the following items in table 2, column 1, were incorrectly cited:

$\mathrm{SrO} \quad 0.08$ should be corrected to $\mathrm{SrO} \quad 0.00$

$\mathrm{CO}_{2}----$ should be corrected to $\mathrm{CO}_{2} \quad 0.08$ 



\title{
STUDIES ON THE WATCHUNG BASALT FLOWS OF NEW JERSEY
}

\section{JOINT SYSTEMS IN THE WATCHUNG BASALT FLOWS OF NEW JERSEY}

\author{
By George T. FAust
}

\begin{abstract}
"Die Klüfte"
"Wir treten vor eine universelle Erscheinung. Kaum ein Vorgang, sei er vulkanischer oder tektonischer Natur, der nicht fähig wäre, Klüfte zu erzeugen."
\end{abstract}

\section{ABSTRACT}

The Watchung Basalt flows of New Jersey were jointed by four different geologic processes-the cooling of the lava flows, tectonic deformation of the graben, loading during glaciation, and weathering. After the lava flows were extruded to form sheets, they began to cool down, solidify, and joint. The developmental sequence of the joint systems was controlled by the character of the heat loss. The sequence, typical of the two flow units in Third Watchung Mountain, forms the basis of this study. The vesicular top formed first. It developed a system of joints which combined to form rectangular prisms with a slabby aspect. During the stage when the vesicular top was forming the base of the flow began to solidify, and for most of its length it formed a thin vesicular zone 6-8 inches thick $(15-20 \mathrm{~cm})$. The central portion of the flow between the vesicular top and bottom cooled very slowly and eventually solidified and jointed. The sequence of the joint systems, arranged in descending order, which developed in the central portion is as follows: the vesicular top changes gradually or abruptly into the columnar zone, this in turn forms an abrupt boundary with the blocky zone, and the blocky zone changes abruptly into the underlying curvilinear zone, the latter zone passes abruptly or gradually into the vesicular base.

The tectonic joints developed in the flows after graben development had ceased. These joints resulted from the deformation of the contents of the graben into a regional central arch with border synclines. In New Jersey weathering has removed all but the border syncline on the so-called "west wall of the graben." Tectonism produced transverse joints in the vesicular top, irregular or planar lateral joints in the columnar zone, a tension jointed base in the blocky zone, and three types of joints in the curvilinear zonepseudocolumnar, platy prismatic (fracture cleavage), and basal lateral joints.

Sheeting, the third type of jointing, postdated all the other joint systems. It is best developed in the curvilinear zone north of the terminal moraine of the last glaciation.

Weathering processes developed spherical joints.

Observations made on jointing systems elsewhere in the United States and in Iceland, Great Britain, and Germany are compared with those observed in the Triassic basin.

Cloos. Hans (1936, p. 214). "We are in the presence of a universal phenomenon. Scarcely an event, be it of volcanic or tectonic nature, that would not be capable of generating joints."

\section{INTRODUCTION}

Joints are the record, imprinted in the rocks, of past geologic processes whose stress fields were of such a magnitude that they caused the brittle rocks to rupture. Joints are omnipresent in rocks. They can be formed by several physical processes - thermal and mechanical. The magnitude of the stress fields developed in a given region is not constant throughout time and may reach magnitudes sufficient to produce rupture at several widely separated times in the geologic history of the region. Commonly, the several geologic events which produced the stress fields that caused rupture were themselves unrelated. Each of the geologic events, if it is capable of rupturing the rocks, will produce its own characteristic set of joints. From a study of joints in the field it should be possible to determine:

1. how many different joint systems are present,

2. the geometric morphology of each joint system, and

3. the relation of each joint system to some past geologic event.

Joints studied in this way may thus contribute in deciphering the geologic history of a region and provide an estimate of the minimum order of magnitude of some of the forces involved.

Joints are commonly paths along which ground waters flow in traversing rock masses. The amount of water moving along joint planes is dependent upon the width of the joint openings, and the frequency of joints. It also depends on the degree of interconnection between the various joint systems, and between these systems and other structural planes or depositional surfaces. The zones of most intense fracture will be the zones of higher permeability. The relation of joint frequency in rocks and the yield of water in wells in these rocks may serve as a valuable aid in hydrologic studies.

Joints may also be the paths along which mineralizing solutions flow, and they may themselves later become filled or coated with mineralized veins. By noting which of the sev- 
eral joint systems are veined and which are not and by determining the paragenetic sequence characteristic of each type of veined joint system, the relative ages of the mineralization and the direction of flow of the mineralizing solutions may be obtained. Such information can help in the search for ore deposits, or it may furnish diagnostic criteria in the interpretation of the petrologic history of igneous rocks.

A detailed knowledge of the joints present in rock masses that are traversed by, or compressed by superimposed constructional loads, is very important to engineering geologists and civil engineers. Joints in rocks affect the stability of slopes, walls, tunnels, and other types of excavation and they may greatly influence the hydrologic regime within such rock masses. Under water-saturated conditions and high pore pressure, walls may become so unstable that they collapse. Quarry operators may also make use of information obtained in the study of joints in selecting the volumes of rock to be quarried.

In order to answer some of the problems just posed to the reader, it is necessary to study joints in the field. The present study was undertaken to help in the interpretation of the geologic history of the region. This geologic history was needed as a background on which petrologic studies could be based. As a byproduct of this study, data were obtained and observations made on joints which may help scientists, engineers, and others working in the applied disciplines.

The treatment of jointing presented in this paper is phenomenological. The theory of jointing and other interpretive discussions are reserved for another contribution.

In the introductory paper of this series I described the circumstances which led to my study of the development of the joint systems in the basalts of the Watchung Mountains, Faust (1975, p. A1). About 1937 I had made very simplified calculations of the heat flow relations within a model sheet. By this means the probable direction of movement of the heat flow lines, within the model, was obtained. A geometrical method given by Awbery and Schofield (1929) and Schofield (1930, p. 495) showed that the heat flow lines could be taken as perpendicular to the isotherms at every point within a given body. In three dimensions, assemblies of adjacent heat flow lines will be normal to a common plane or to a portion of a common curved surface. It has been assumed, in petrologic studies, that at that temperature at which the joints form in a cooling igneous mass they form along surfaces perpendicular to the isothermal planes, Iddings $(1909, \mathrm{v}$. 1, p. 320-327). Tomkeieff (1940, p. 129) defined the "fracture isotherm" as that particular isotherm at which fracture takes place. Spry (1962) and Jaeger (1968) discussed the relations between isotherms and jointing in basalt.

It was clearly recognized, at the outset of my studies, that this simplified model that I developed could only furnish ideas for a preliminary skirmish with such a formidable natural geometrical problem. Accordingly, I decided to compare the model with the natural system and I had the opportunity to test it while visiting a number of quarries and outcrops, in the company of Dr. Alfred C. Hawkins, Professor of Geology in Rutgers University. Although any real agreement between the model and the natural system had not been expected, the abundance of different sets of planar joints and the unique character of the curvilinear surfaces was totally unexpected. Moreover, the unequal frequency of occurrence of the joint surfaces for the different joint systems needs explanation. These observations led me to abandon theoretical studies and to examine the joint systems in the field.

Subsequent studies of the field relations of the flows showed that there were at least two independent geologic processes which produced the joint systems. In Third Watchung Mountain the joints due to the cooling of the lava were found to be the most abundant. In Second Watchung Mountain the abundance of a new type of joints arising from a second geologic process, the tectonic deformation of the contents of the Newark graben varied with respect to the outcrop position in the synclinal basin. Once these distinctions were established the tectonic joints were readily differentiated from the cooling joints. A third type of jointing, sheeting, was observed in the northern portion of the synclinal structure north of the terminal moraine which extends from the vicinity of Morristown to the SummitShort Hills area. The jointing in First Watchung Mountain, in certain outcrops, as at and in the vicinity of the famous O'Rourke quarry at West Orange, described by Iddings (1886), showed a more complicated pattern with the greater development of the zone of columnar jointing, and this modified the magnitudes of the zones of the several joint systems.

Certain aspects of this study are mentioned in Geological Survey Research 1961, 1972, and 1973 (U.S. Geol. Survey, 1961, p. A97; 1972, p. A27; 1973, p. A36).

A qualitative description is given herewith of the various jointing systems in the basalt flows, and of the interrelationships amongst them. Most of the examples will be chosen from outcrops in Third Watchung Mountain, but in addition examples of joint systems, well developed or more prevalent in Second Watchung Mountain and First Watchung Mountain, will be included.

The several jointing systems are described first in an overall manner, showing the relationships between the several systems, and then in detail for each system. Emphasis is placed on describing as far as possible, the appearance of a particular joint system in a freshly exposed outcrop, a weathered outcrop, and in glacially abraded exposures.

\section{PREVIOUS STUDIES ON JOINTING IN THE WATCHUNG BASALT FLOWS}

In earlier geologic studies of the Newark basin, some of the geologists made observations on joints in selected parts of the Watchung Basalt flows. The columnar fan structures in the basalt of First Watchung Mountain at O'Rourke's 
quarry just south of Llewellyn Park, West Orange, N.J., were made famous by the classical theoretical study of Iddings (1886, 1909). Fenner (1908) made observations on the character of the basal part of the lower flow unit of First Watchung Mountain. Lewis $(1909,1915)$ briefly described jointing patterns in the Watchungs and mentions columnar, platy, planar, irregular, and "sphenoidal or wedge-shaped" types of jointing. Bucher (in Bucher-Kerr, 1948) briefly described the jointing patterns in the lower flow unit of First Watchung Mountain and compared the section with that described by Tomkeieff (1940) at the Giant's Causeway, County Antrim, Ireland. Bucher's broad use of the term columnar makes difficult the comparison of his studies with those of other investigators.

Most of this early work consisted of observations made at one or a few outcrops. None of these geologists studied the distribution of joints in both the upper and lower flow units of any of the three sheets nor made any attempt to investigate the distribution of joint systems over the whole outcrop area.

Sosman (1916) carefully evaluated the results of the experimental data obtained in the study of the formation of polygonal structures. He developed criteria for recognizing contraction and convection prisms and applied them to the interpretation of the data on the frequency of $n$-sided prisms (where $n=3,4,5,6,7$ ) in columnar jointed basalts.

\section{SAMPLING OF THE JOINTING PATTERNS IN THIRD WATCHUNG MOUNTAIN}

The outcrop area of the several parts of Third Watchung Mountain is about 18 square miles along an outcrop scarp of approximately 41 miles length. In this area about 250 exposures were studied in detail. Four active and 16 inactive or abandoned quarries were studied.

Fortunate for this investigation was the rather extensive building development which occurred during the course of this research. Attractive scenic views along the scarp slope of Long Hill, Hook, and Packanack Mountains caused this area to open up quickly for homes for the commuting suburbanites. Cellars excavated and occasionally blasted out of the trap rock offered excellent exposures. Ditches for the utilities, gas, water and electricity, permitted checking the continuity of observations along the strike, and drilling for water wells, commonly through the basalt to the red shale below, permitted checks on the thickness and attitude of the flows. It should be emphasized that many of the outcrops described herein were open only during periods of excavation or building operations and cannot be seen today. The same is true for old and abandoned quarries which have had their floors leveled, and their walls graded, and have had apartments, dwellings, and factories built in them, or they have been converted into parking lots. For these some of the photographs included here are the only evidence.

It is of course not possible to see all of the trap rock present in Third Watchung Mountain. On the basis of what is observable, it is possible to state that, the bottom of the lower flow unit most commonly rests directly on the red shale and sandstone, which were baked; less commonly it formed a flow breccia resting on the shale and sandstone.

The description and the discussion of the minor zones of the flow units-agglomerate, pillow lavas, and tuff that occur locally - will be given in a subsequent part of this series.

\section{DESCRIPTION OF THE JOINT SYSTEMS}

The preliminary examination in 1936-37 showed that the jointing patterns were more distinct and apparently less complicated in the quarries and exposures in Third Mountain than in either Second Mountain or First Mountain. Further observations in 1946 showed that mineralization was chiefly confined to the joints and to a lesser extent to breccia zones as at the Millington quarry (then part of the North Jersey Quarry Co., now Houdaille Industries, Inc.). The large zones of "green rock," present in parts of First Mountain, were also absent from Third Mountain. Accordingly, it was decided to set up a standard section for study in the Millington quarry. The reasons for doing this were as follows: first, the jointing systems observed in Third Watchung Mountain appeared to be the least complex; second, the quarry at Millington was a very large excavation which exposed almost the entire section of the upper flow unit and a portion of the lower flow unit; and third, the possibility existed that the lower flow unit might be core drilled sometime in the future. Although the lower flow unit was exposed nearby in the weathered outcrops, the obvious advantage of obtaining fresher material from the core was also a decisive factor. In addition, in this quarry, the quarry faces had remained essentially dormant since large-scale quarrying operations temporarily closed down in 1930 , and the jointed surfaces had acquired a reddish patina which stood out in striking contrast to the yellowish-brown color of the subsurface alteration of the uppermost portion of the flow. Most of the cooling joint patterns described herein were first observed and later delineated at this locality. An overall photograph of this quarry taken in 1952 is given as figure 1.

In order to relate the various outcrops, described herein, to their position in the synclinal basin which they in part form, a sketch map is given here, see figure $2 A$. An index to the U.S. Geological Survey topographical quadrangle maps, scale $1: 24,000$, covering the exposure area of the Watchung Basalt flows is given in figure $2 B$.

Joints are commonly defined as the cracks which divide rocks into separate volumes and along whose surfaces no significant movement has occurred. In the field, joints are observed to occur in sets which usually have a directional parallelism. The frequency of occurrence of a given joint set in the Watchungs may vary from a few inches to many tens of feet. The area of the different joint surfaces is also quite variable, ranging from a few square inches to many tens of 


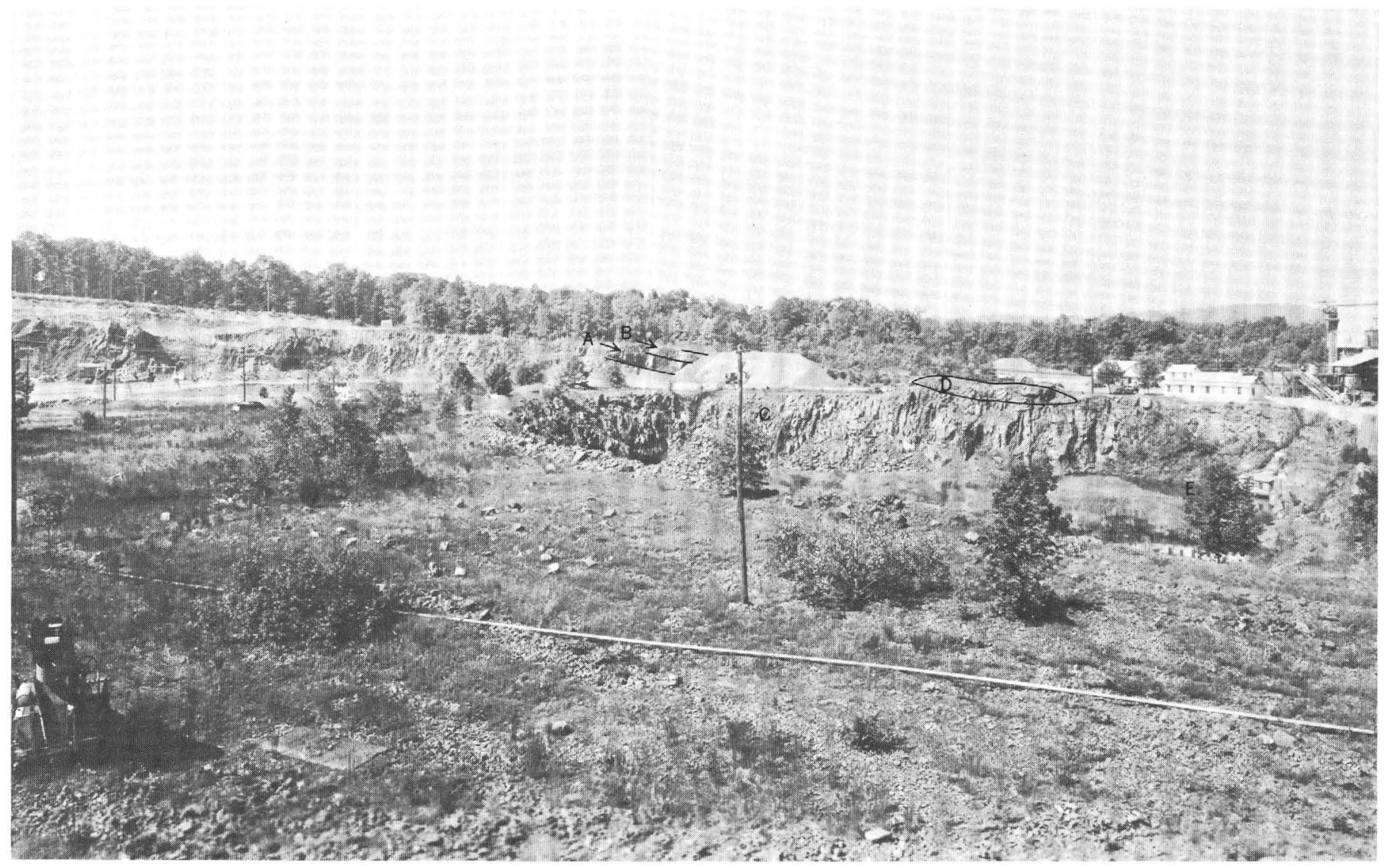

FIGURE 1. A photograph of the Millington quarry taken in 1952. The picture was taken looking in an easterly direction. Photograph courtesy of the Houdaille Industries, Inc., and Mr. Thomas Stewart, formerly superintendent of the Millington operations. A-B is the blocky zone, C is in the curvilinear zone, D is a remnant of the curvilinear just under the closely jointed base of the blocky zone, $\mathrm{E}$ is the pond just above the vesicular base.

square feet. The joint surfaces may be plane or curved surfaces. These characteristics define, in part, the geometrical relations of joints and joint surfaces, but by themselves they do not indicate the geologic process which produced the joints.

The jointing developed in a given area may be the result of one or more geologic processes. When several geologic processes have each developed their own joint sets, the combined sets of joints are very complicated, and it is necessary to identify the joint sets arising from each process. It is sometimes possible to note that a combination of several joint sets produces a symmetrical pattern and that these individual joint sets appear to be related. Thus three mutually perpendicular joint sets may be combined to form a rectangular parallelepiped. Such a combination of genetically related joint sets which encloses space and forms a more symmetrical pattern is here referred to as a joint system. The recognition of joint systems leads to an understanding of their genesis.

This usage of joint set and joint system is essentially the same as that described by Cloos (1936, p. 219) for use in the study of intrusive igneous, metamorphic, and sedimentary rocks. I have tried to avoid introducing new terminology, and I have followed Geike (1893, p. 529-530), in the use of transverse joints, those that "are oblique to the sides of the prism (referring to columnar joints)" and extended this term to cover joints that form as diagonal planes in an idealized orthogonal system.

\section{COOLING JOINTS}

The Watchung Basalt flows were formed by three volcanic episodes. Each volcanic episode poured out lava in two successive eruptive events. During each eruptive event, lava flowed out of the fissures and spread laterally until it reached the bounding "fault walls." Continuous discharge of lava built up accumulations from 100 feet $(30.5 \mathrm{~m})$ to perhaps 500 or 600 feet $(152.5$ or $183 \mathrm{~m})$ thick. The flood of lava tended to attain a level surface. The upper surface of a flow cooled relatively rapidly and formed a vesicular top. This surface was gently undulating and relatively smooth in character, of the pahoehoe type. The bottom of the flow cooled much more slowly and formed, in general, a thin vesicular base. The central portion of the flow cooled very slowly. After the various parts of the central portion had cooled sufficiently, they too jointed. The resulting sequence of zones of joint systems owe 
their origin solely to the cooling process which took place in the lava sheet. The sequence of zones of cooling joint systems observed in both the upper and the lower flow units of Third Watchung Mountain are, in descending order, as follows: a vesicular top that changes gradually or abruptly to the columnar zone; this in turn forms an abrupt boundary with the underlying blocky zone; this in turn forms an abrupt boundary with the curvilinear zone, and the curvilinear zone passes abruptly or gradually into the vesicular base.

A schematic diagram of the jointing relations in Third Watchung Mountain as exposed in the quarry at Millington, see figure 2, is shown in figure 3. The vesicular top is overlain to the east by the Brunswick Formation ( $\mathrm{kb}$ ), and an outcrop of Brunswick appears on South Maple Avenue just above the Davis Bridge, Basking Ridge. When I first examined the quarry in 1946, the vesicular top and the columnar zone were only remnants left after scraping and bulldozing the upper surface. The upper flow unit rests directly on the lower flow unit, and there is no intertrappean layer of sediments exposed in the quarry nor in the many drill cores that penetrate this boundary. The boundary surface between the two flow units is a pahoehoe surface, figure 4 , and it shows no evidence of any erosion, an indication that the two flow units were the results of two volcanic events not widely separated in time.

The lower flow unit was only partially exposed as the vesicular top in the quarry, but it was well and more completely exposed as weathered outcrops and as fresher rock in roadcuts, nearby. I have also examined the fresher rock of the drill cores, and they show the vesicular base of the lower flow unit rests on a very thin hornfels zone which grades almost imperceptibly into the unmetamorphosed sedimentary layers below.

A part of the sequence of the jointing systems and the interrelationships between them in the Millington quarry is shown in figure 1. The arrow " $\mathrm{A}$ " indicates the position of the blocky layer which juts out as a ledge. Atop it, arrow "B," is the remnant of the columnar layer which has been badly shattered by quarrying operations. In the quarry face, marked "C," located in the picture between the stock pile and office building, the lower part of the section is exposed. Here the curvilinear layer is shown cracked by vertical tectonic joints. The promontory, at the top of this section, marked "D," was 15 feet higher than the roadway and contained the lower part of the blocky layer. At the edge of the pond, marked "E," the lower vesiculate zone of the upper flow unit and the upper vesiculate zone (top) of the lower flow unit were encountered in quarrying operations probably about 1890-1900. More detailed views of the various boundary zones between the jointing systems are given in appropriate sections that follow.

\section{VESICULAR TOP}

Particularly fresh occurrences of the vesicular basalt are not very abundant on Third Watchung Mountain. The scar- city of such outcrop arises, in part, from the glacial erosion which removed much of this zone. It is still encountered in drilling wells for water; or in localities where it has been protected from erosion, it may appear in the top walls of quarries or in roadcuts. On Second Mountain at an exposure in a roadcut located on the east side of the Liberty Corner Road between Mountain View Avenue (Dead River Road) and Mountain Road, near Liberty Corner, a relatively fresh outcrop can be seen. The surface appears to be an original top; in places the gloss of the original surface has been dulled by weathering. The exposure probably lay beneath a red shale knoll, which has since been removed by erosion and excavation. Such red shale knolls in the Watchungs are not infrequent and usually offer good exposure. Some of them have been used as local quarries for brownstone and were apparently abandoned when the vesicular zone of the trap was encountered in quarry operations.

The vesicular zone is characterized at the top by a rectangular aspect. Weathering along the joints produces rectangular slabs. With depth, this zone may show a jointing pattern that appears to be pseudocolumnar.

The vesicular top, in the vicinity of the Millington quarry, has been largely removed in stripping operations, because it was much weathered and easily excavated. Nearby, at Davis Bridge, Basking Ridge excavations for the gas utility line starting in red shale penetrated through the contact with the vesicular trap and yielded relatively fresh samples of the latter. At some localities the vesicles are filled with minerals, chiefly calcite, but some prehnite and pectolite may be present. The rock is then part of an amygdaloidal top.

The characteristic appearance of a good exposure in the vesicular zone is shown in figure 5, where the rectangular (slabby) aspect of the top of the zone can be seen. This exposure is approximately 30 feet long and 6 feet high. In addition to the rectangular joint system, two sets of transverse joints at about $45^{\circ}$ to the principal joints are present. The rectangular joint system, which represents cooling joints, consists of the flat surface (the basal plane) and the rectangular prism. The transverse joints are interpreted as tectonic joints. This exposure represents the upper surface of the flow, and its change in character with depth cannot be followed here but elsewhere as at several exposures on Alps Road, northeast of Mountain View on Packanack Mountain, a part of Third Mountain, the lower portion of this vesicular zone may be observed.

The vesicular layer as it appears in a roadcut on Alps Road just a short distance south of its intersection with Rockledge Terrace, northeast of Mountain View, is very instructive. Here one can see the change from the vesiculate layer (here amygdaloidal in part) into the columnar layer below, see figure 6.

The weathering of the vesicular layer at some outcrops takes place so that the whole rock exposure has decomposed throughout to yield a soft product. At other outcrops it appears that the bridging rock between the vesicles, at the 


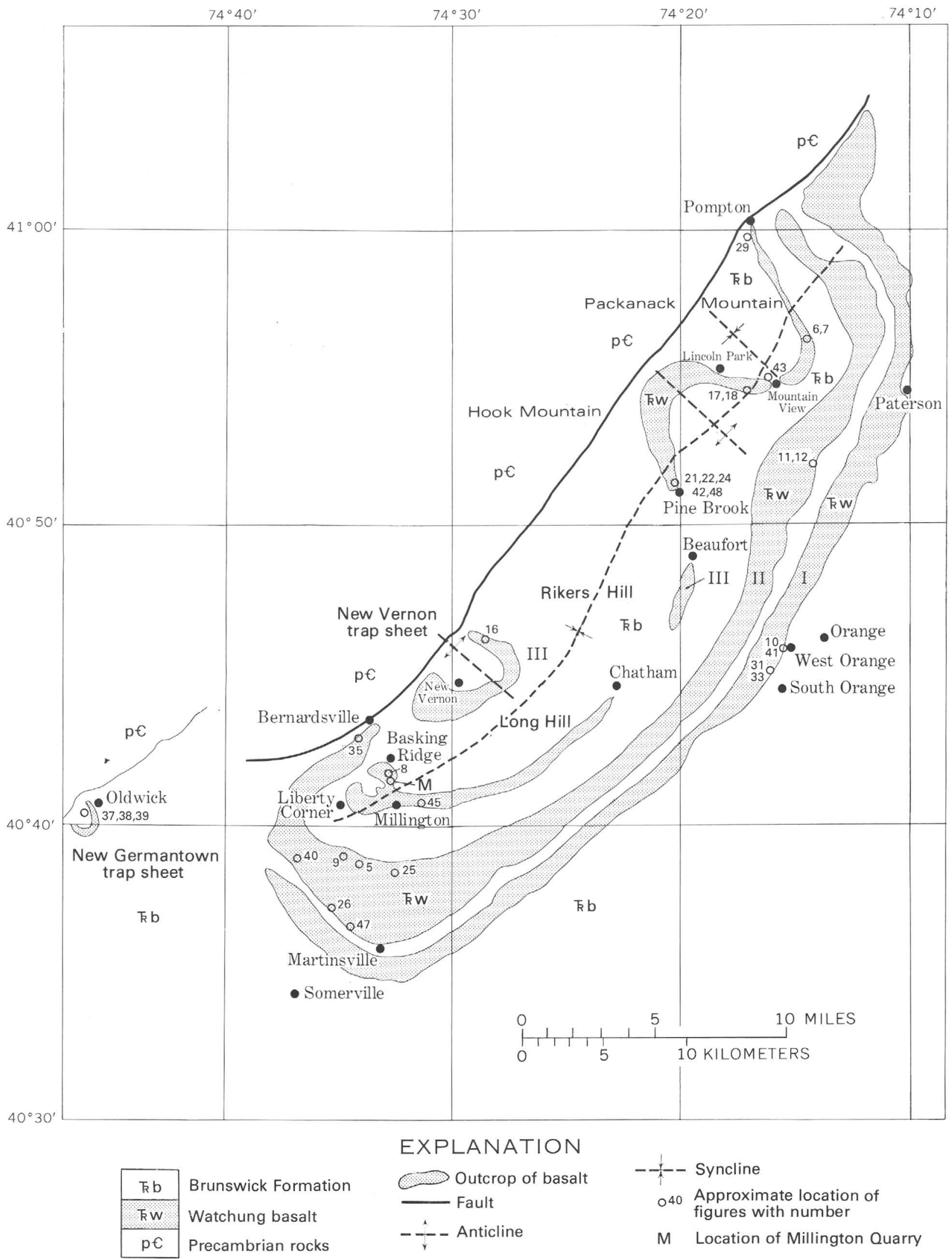




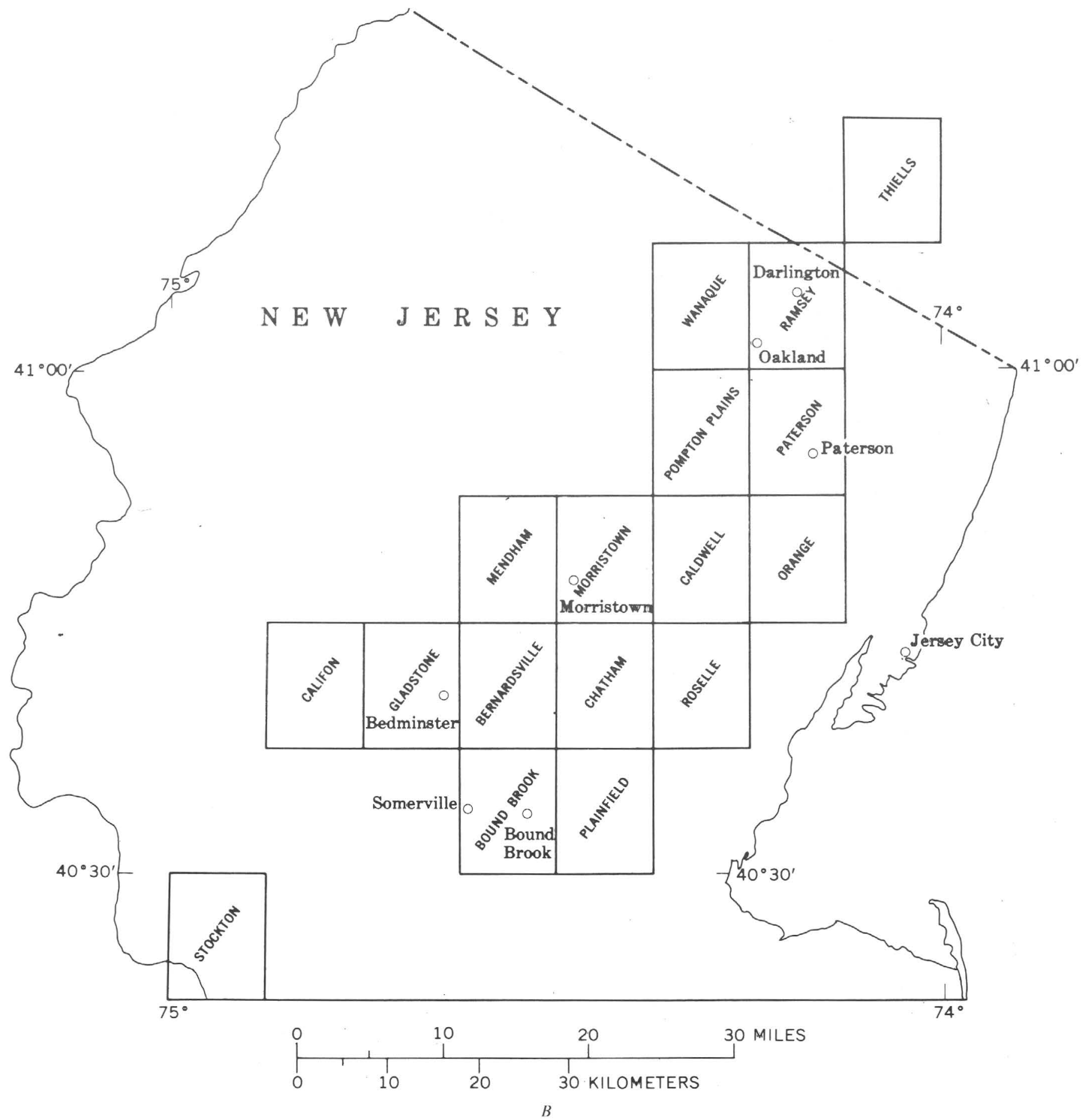

FIGURE 2. A, Sketch map showing outline of the three Watchung Mountains and the New Germantown trap sheet (modified from Lewis, 1908, pl. 10). I, II, and III refer to First, Second, and Third Watchung Mountains. B, An index to the U.S. Geological Survey topographical maps, scale 1:24,000, covering the exposure area of the Watchung Basalt flows.

position of least volume, weathers more rapidly so that crude polyhedral volumes of less altered rock result. If the finer material of such a deposit is winnowed and washed away a coarse gravelly deposit having the appearance of weathered pyroclastic material forms. This type of alteration is made more obvious to the eye if the rock was an amygdaloid, for the light colored minerals stand out by contrast, and the more insoluble minerals such as quartz and prehnite are particularly conspicuous.

\section{COLUMNAR ZONE}

The columnar zone is characterized by columns, com- 


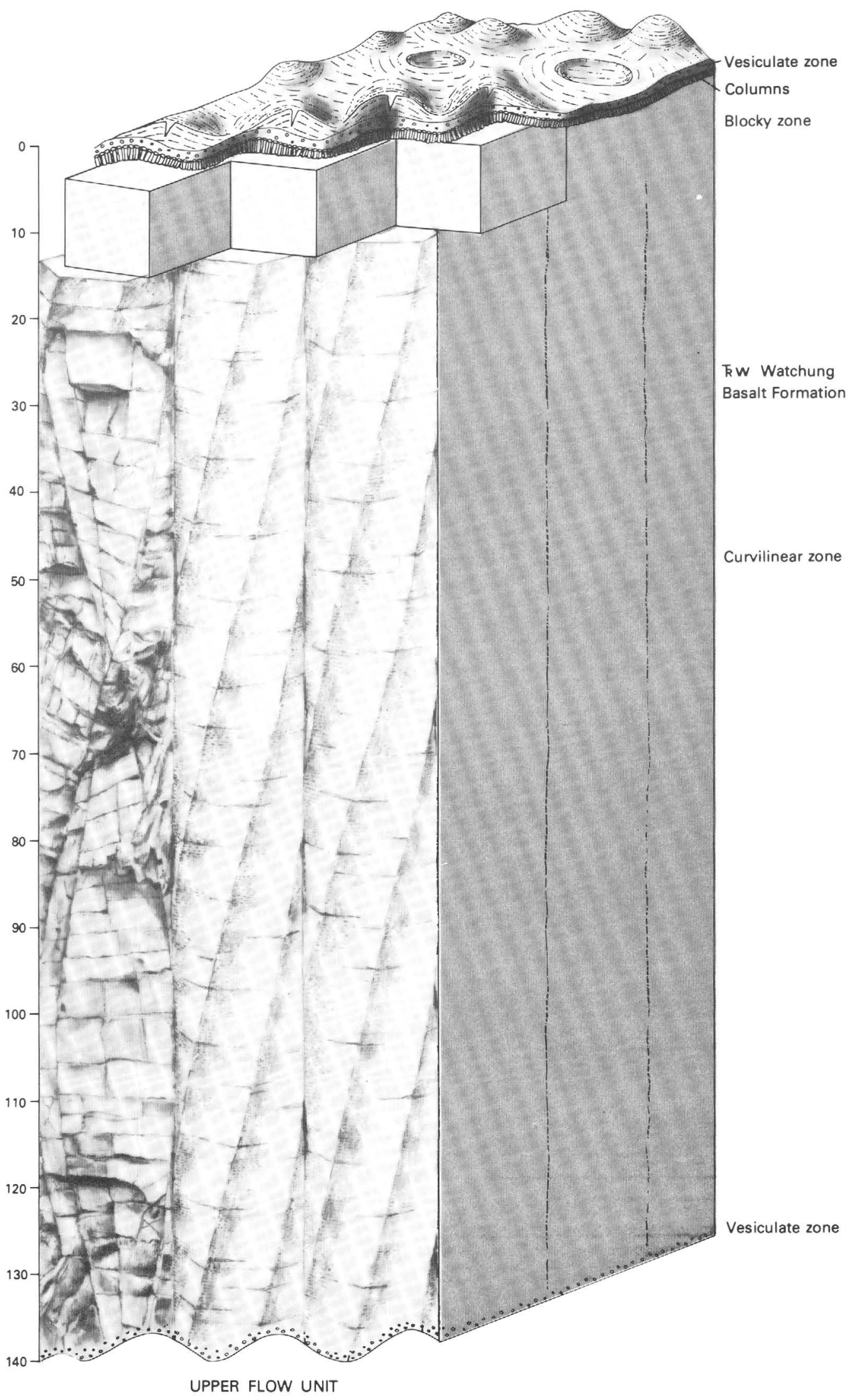

FIGURE 3. Schematic diagram of the cooling joint systems in Third Watchung Mountain as observed in the quarry at Millington for the upper and lower flow units. The curvilinear joints are enclosed within the bounding surface of the convection cells. These cells are drawn as hexagonal prisms in torsion, see p. B 14. The amount of torsion has been exaggerated for purposes of illustration. Three patterns of curvilinear joints corresponding to figures 20,21 , and 25 are schematically illustrated within the convection cells. The columnar and blocky zone of the lower flow unit were not exposed, but they are shown here. They do appear in other outcrops of the lower flow unit. 


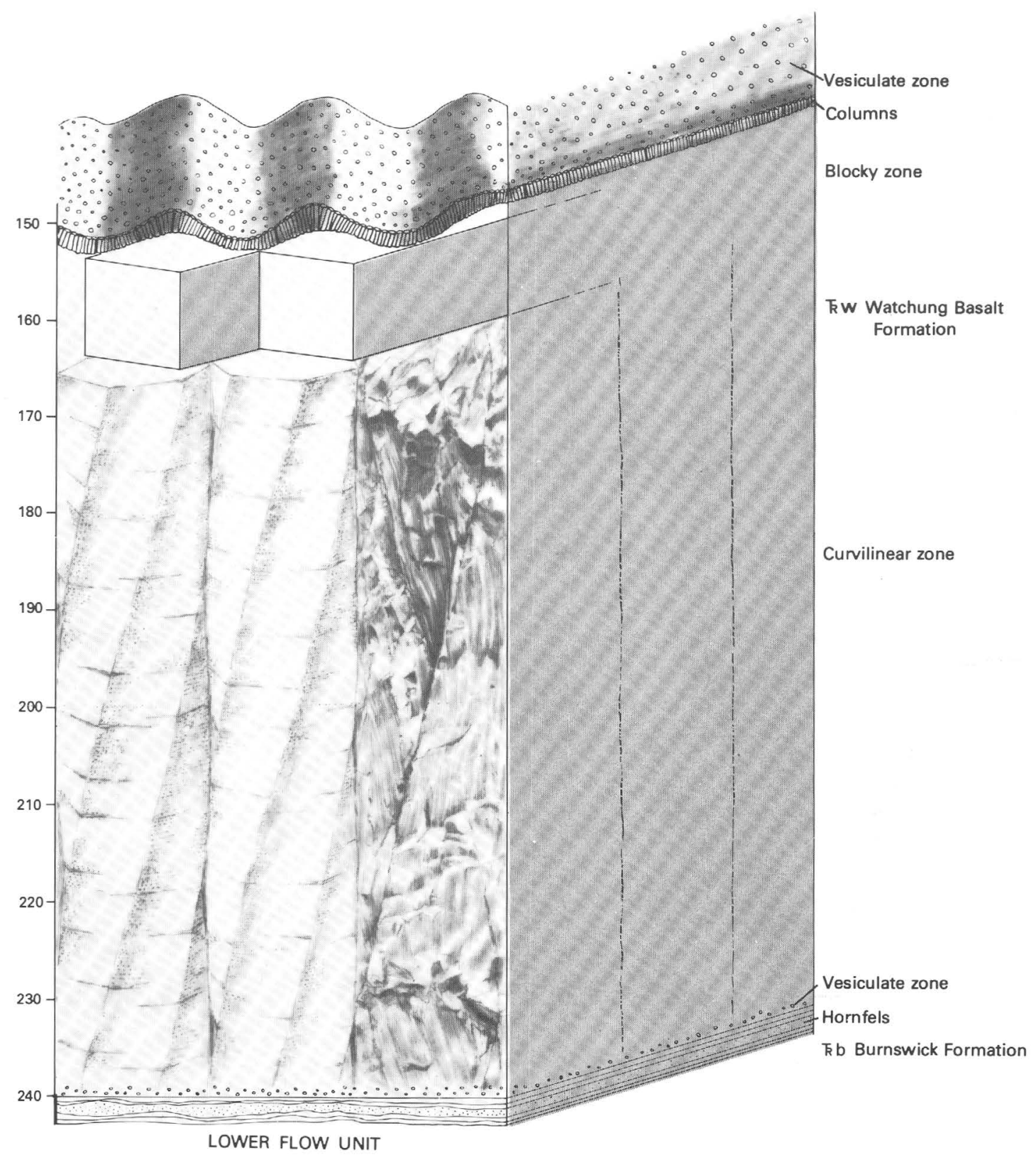

monly six-sided but also five-sided, and best described as polygonal in outline to allow for the variations observed locally. Figure 6 shows the upper vesiculated surface with curved columns appearing with depth. The crude columns at first are curved and swirly in nature. Some appear to flare out from points in the upper rectangular joint system. The columnar joints are commonly nestled under the vesicular zone and if this zone is thin, then the columns will radiate, or fan out, under the undulating pahoehoe top. Vesicles appear to be common in the top of the curved columns. Weathering accentuates the curved columns. Well-developed columns are illustrated in figure 7.
The columnar zone at the Millington quarry was well represented when the section was measured in 1949. It stood out in marked contrast from the blocky zone on which it rested, for weathering had enlarged the space between the joints. The columns were polygonal, many were six and five sided, and a horizontal joint system formed the basal planes which closed the columns at both ends. In addition to the enlargement of the cooling joints, cross-joints are made more evident by weathering, or blasting. The columns at the Millington quarry were commonly 6 inches wide $(15 \mathrm{~cm})$, but some ranged up to a foot $(30 \mathrm{~cm})$ in width. Their height was about four feet $(1.2 \mathrm{~m})$ but some had been broken off and they 


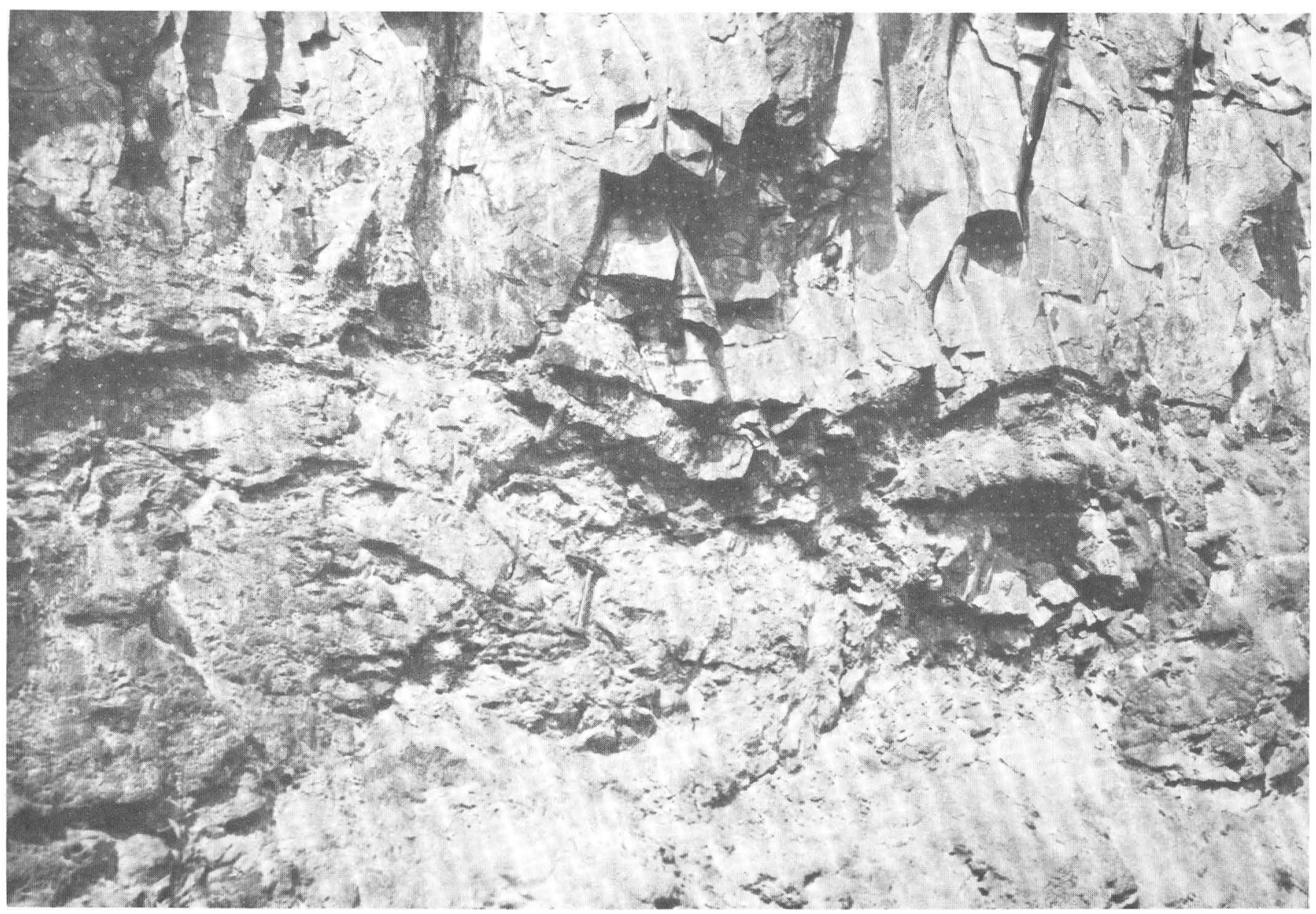

FIGURE 4. The pahoehoe surface between the lower flow unit and the upper flow unit. The curvilinear jointing system and the thin vesicular base of the upper flow unit rest atop the pahoehoe surface of the lower flow unit. South wall of the Millington quarry of Houdaille Industries at Millington, N.J. Scale is shown by hammer.

could have been in places up to 8 to 10 feet $(2.4$ to $3.1 \mathrm{~m}$ ).

Columnar cooling joints of the type described above are not commonly exposed on Third Watchung Mountain apparently because the advance of the North American ice sheet covered or beveled most of the outcrops. Nevertheless one may see the remains of eroded columnar cooling joints at a number of outcrops. At Lyons station, blasted and mechanically broken out exposures of the columnar layer resting on the blocky layer could be seen near the top of the roadcut, see figure 8 .

Columnar joints in the upper flow unit of Second Mountain are better developed than in Third Mountain, and they are much larger, as much as 15 to 20 feet (4.6 to $6.1 \mathrm{~m}$ ) long. They were better preserved from erosion so that they were excellently exposed during the excavations for U.S. Highway No. 287 in the vicinity of Far Hills and Liberty Corner, and on U.S. Highway 78 between Pluckemin and Mt. Bethel. A particularly fine exposure on U.S. No. 287 near Liberty Corner Road is shown in figure 9. The columns show the typ- ical pinch and swell structure of Spry (1962).

The columnar joints of the lower flow unit of First Watchung Mountain as exposed in the quarry near West Orange, N.J., and operated at the turn of the century by John O'Rourke, are world famous (Iddings, 1886, 1909). When the excavations of the cut for U.S. Highway No. 280 were made in the Oranges in the near vicinity of O'Rourke's quarry similar superb columnar structures were exposed. In mapping this cut it was found that the lower flow unit was cut by a dike. An example of an inverted fan structure, (in the terminology of Spry-1962, p. 195), is shown in figure 10.

The ball and socket type of jointing, in columnar basalt, made famous by its development in the Giants' Causeway, County Antrim, Ireland, Preston (1930), Tomkeieff (1940), is a relatively rare type of jointing in the Watchungs. In my fieldwork on Third and Second Watchung Mountain, I have only seen one good exposure of this type of jointing and that is present in the old Ferguson quarry, in Second Mountain near Little Falls, N.J., see figures 11 and 12. 


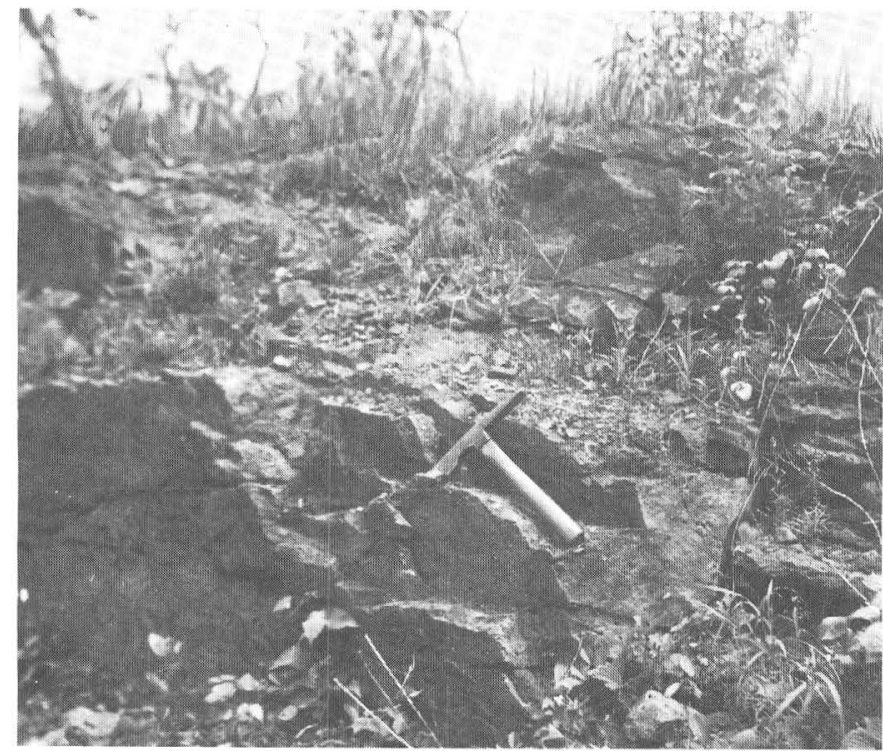

FIGURE 5. Exposure of the vesicular zone, showing the rectangular (slabby) aspect of the top and the jointing systems in this zone. Locality: Liberty Corner Road between Mountain View Avenue (Dead River Road) and Mountain Road, near Liberty Corner.

\section{BLOCKY ZONE}

The blocky zone forms a distinct ledge in the north wall of the quarry at Millington, N.J., where it juts out noticeably from the wall itself, see figure 1 (arrow marked "A"). A typical exposure of the blocky zone at Millington shows a ledge broken by a series of parallel joints which extend from the top to the bottom of the ledge and subdivide it into a set of large blocks which have the shape of rectangular parallelepipeds. Some of these large blocks have uninterrupted faces of as much as several tens of feet long. The blocky joints are remarkable for their planar quality and their surface area. A view of a well developed exposure of blocky jointed trap cropping out on the "east" wall is given in the upper part of figure 13 . The blocks had been badly battered by the crane shovels during removal of the overlying crushed rock. The typical system consists of a rectangular parallelepiped, faces of which are three sets of pairs of rectangles, each pair having a different area. The geologist is holding a hammer at the base of the blocky zone. A more detailed view of this system of joints is shown in figure 14, where the blocky aspect is clearly developed in an exposure of an old quarry wall from which the loose masses and fragments once part of it and the soil above it have been removed by the action of freezing and thawing, and rainfall over a number of years.

In the quarry walls the blocky zone may be seen jutting out from the other jointing zones. It does so by virtue of the great strength, toughness, and resistance to excavation of the basalt in this zone. Such overhanging ledges may remain for many years in unquarried walls. When active quarrying is resumed a succeeding blasting will tumble huge blocks almost unbroken to the quarry floor. The planar joint faces

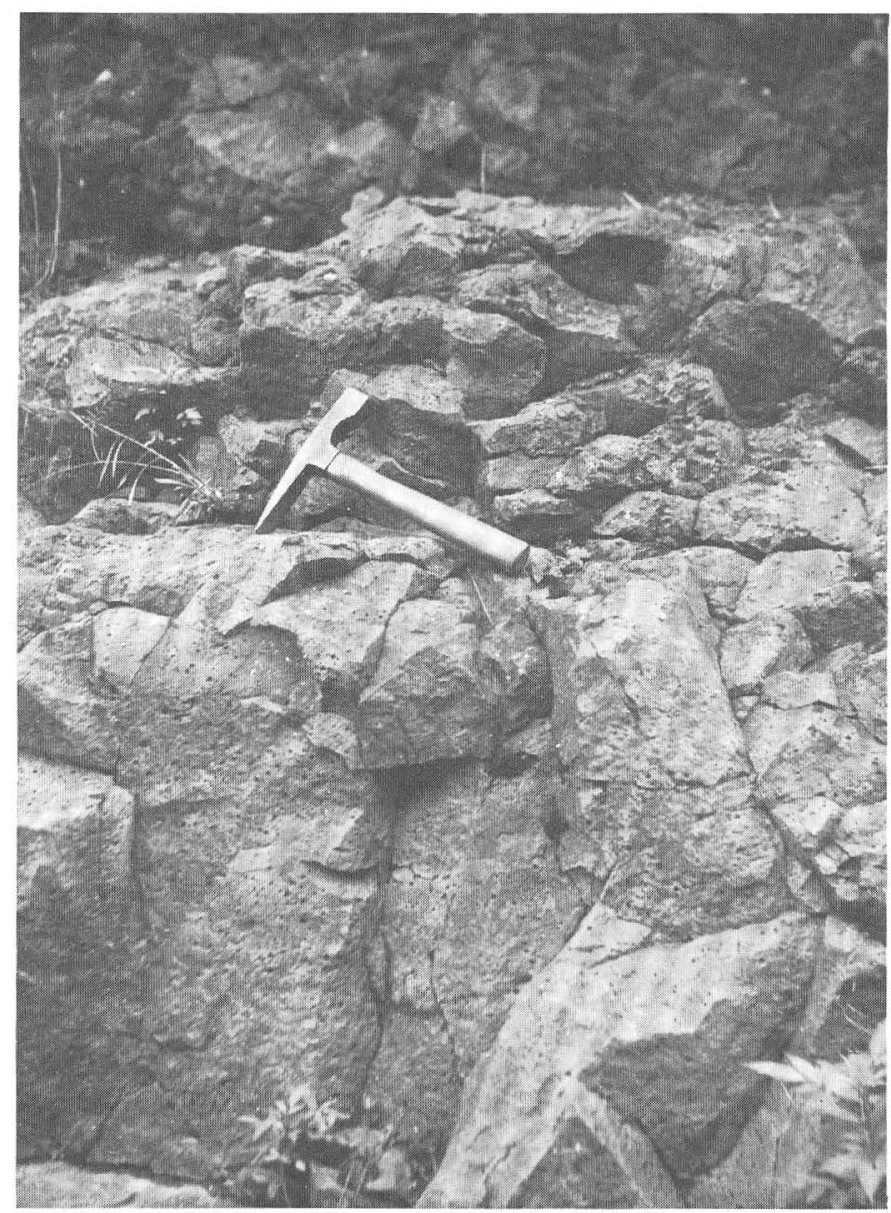

FIgURE 6. A part of the zone of vesicular trap grading into the columnar zone below. Roadcut on the east side of Alps Road a short distance south of its intersection with Rockledge Terrace, northeast of Mountain View, on Packanack Mountain. The hammer is near the boundary.

of such blocks may be partly defaced in the falling and tumbling over the loose blasted rock. Such hackled surfaces reveal an internal structure within the blocks which suggests an assemblage of closely packed elongate polyhedra. The longest axes of these polyhedra are randomly oriented. This characteristic random orientation serves to differentiate defaced "blocks" from battered columnar joints in small outcrops. Such a hackled block is shown in figure 15. An exposure of weathered blocky trap in the New Vernon trap sheet near Morristown illustrates the significance of this criteria. In figure 16 the randomly oriented elongate polyhedra are easily identified. This outcrop was exposed many years ago by pickaxe and crowbar and was recently enlarged. Despite erosion and excavation it is still recognized as part of the blocky zone.

In addition to defacing due to tumbling, the block in figure 15 was also battered with a large steel ball in an attempt to break it down to a size the crushers could accept. Such tough large masses are called "jetty stone" and are shipped, as quarried, to the New Jersey seashore for use in jetties, groins, and seawalls. 


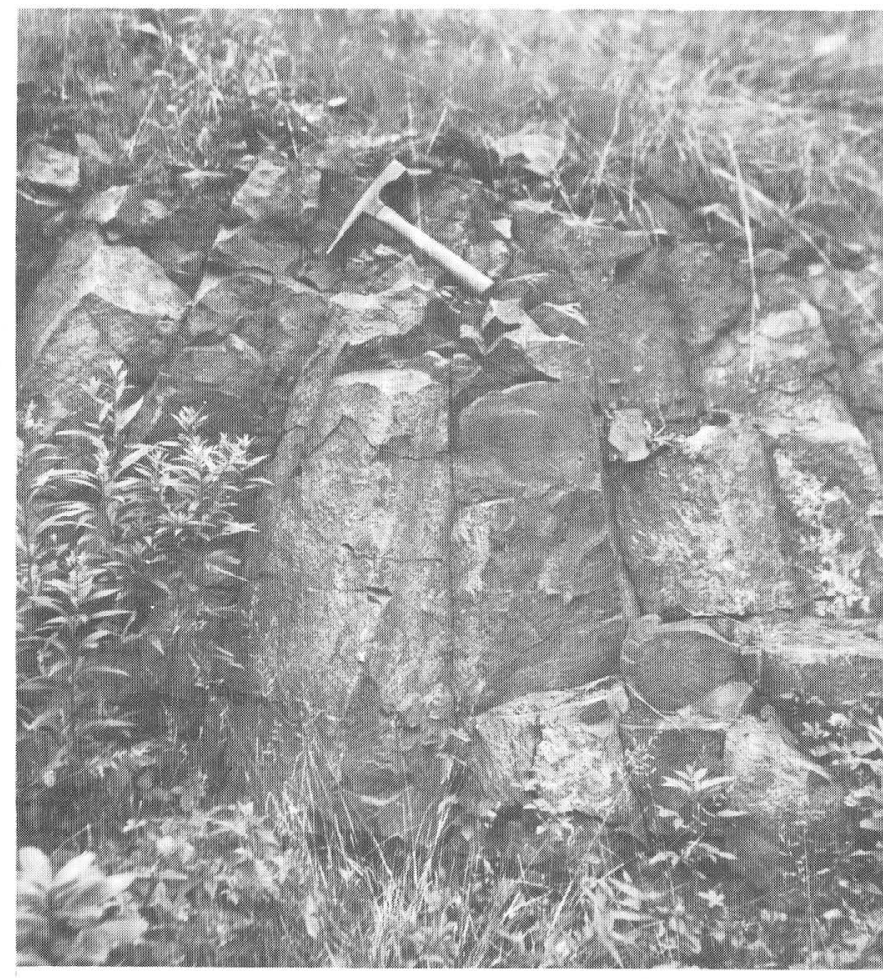

FIGURE 7. Columnar joints, slightly curved and tapered, just below the vesicular top. Roadcut on the east side of Alps Road, a short distance south of its intersection with Rockledge Terrace, northeast of Mountain View, on Packanack Mountain.

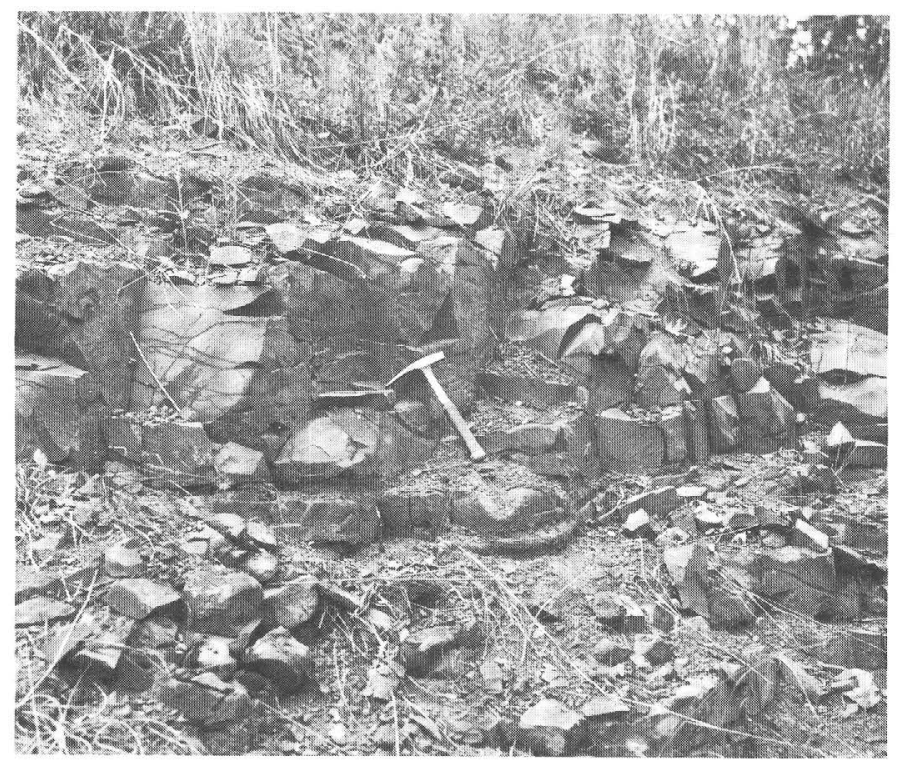

FIGURE 8. Remnants of the blasted and mechanically excavated trap in the roadcut at Lyons Station, Lyons, N.J., showing the mechanically disrupted columnar zone.

The outcrop of the basalt of Third Watchung Mountain appears as a ridge with a steep scarp slope and a gentle dip slope. During glaciation much of the scarp slope was parallel

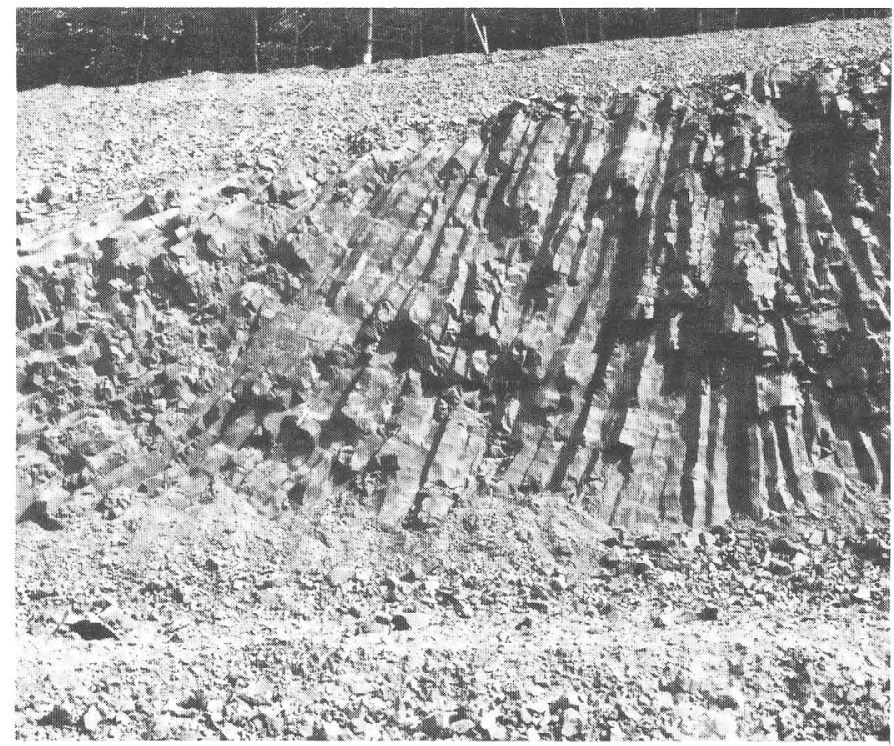

FIgure 9. Columnar joints in the upper flow unit of Second Watchung Mountain. Roadcut on U.S. Highway No. 287, near Liberty Corner.

to the direction of the oncoming ice of the North American ice sheet as it advanced. To the north of the terminal moraine and along the ridge the three units-the red shale above the flow, the vesicular zone, and the columnar zone, all of which are easily eroded by mechanical forces - were largely removed. The blocky jointed trap on the other hand was very resistant and was polished and in part striated and grooved by passage of the glacier. Surfaces of polished blocky basalt, the glacial pavement, are commonly observed as bosses on Hook Mountain, Rikers Hill, and Packanack Mountain, see figure 17. Salisbury (Salisbury and others, 1902, p. 540) gives data for striae measured on various exposures of glacial pavement.

The resistant blocky zone is visible in many outcrops along the ridge of Third Mountain, but there are sections where it cannot be seen. At many such sections the former presence of the blocky zone can be confirmed by examining the loose massive blocks at the base of the scarp slope, see figure 18. These blocks tumbled down from the ridge top where they were formerly exposed. Alternate freezing and thawing, oft repeated, spread open the blocky joints and jostled the blocks loose so that when they were undermined, they fell. The tumbled blocks commonly have been defaced so that they show the randomly oriented elongate polyhedra.

\section{CURVILINEAR ZONE}

The joints in this zone are bounded by curved surfaces. The typical appearance of this type of jointing in an old quarry wall in relation to the overlying blocky layer is seen in figure 14, and a close-up view is given in figure 19. Here the curved surfaces clearly differentiate this jointing system from its congeners. A block of curvilinearly jointed trap breaks out rather commonly in the form of a massive escut- 


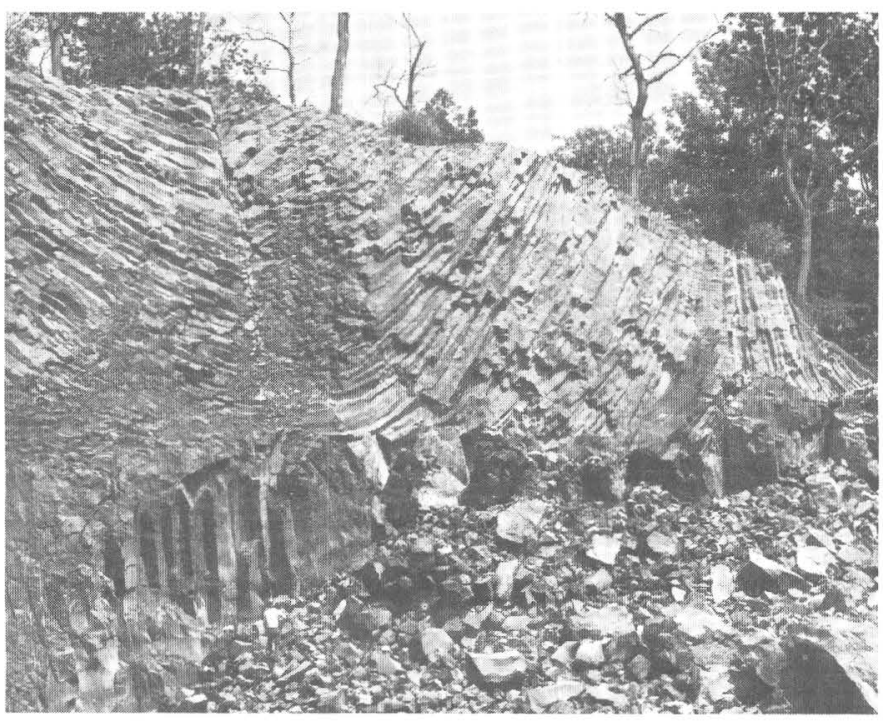

A

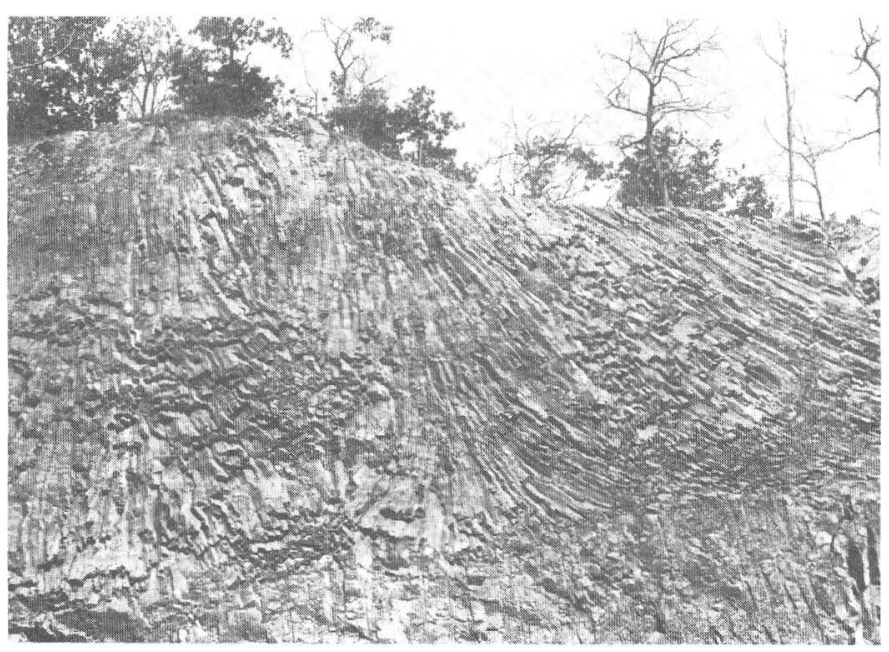

$B$

Figure 10. $A, B$, Inverted fan structure formed of columnar basalt. In roadcut for U.S. Highway No. 280 near West Orange, N.J.

cheon similar to those hewn from rock and used in the stone work decorating buildings. A close-up view of the curved joints in an old quarry wall, figure 20 , shows the wedge shape aspect of this type of jointing. When such wedge shaped masses weather out they produce shieldlike masses.

The pitch of the curved surfaces, as measured along the vertical extension of these curvilinear joints, varies from one exposure to another and a comparison of a recently weathered surface of a blasted excavation, figure 21 , shows a different curvature from the surfaces shown in the preceding figures 19 and 20 . In the outcrop shown in figure 22, a few of the shields were measured and found to average about 10 feet in height and 5 feet in breadth.

The toughness of this rock and its ability to preserve its characteristic curvilinear appearance is well shown in a strongly blasted mass located on the "north wall" of the Millington quarry, figure 23. Here the vertical tectonic joints have been emphasized by blasting and yet the shieldlike curved surfaces of the curvilinear joints can still be easily recognized.

The curvilinear joint system is the most commonly observed joint system on Third Mountain. It is usually very easily recognized. Weathering generally accentuates the joints producing wedge shaped masses of rock. That weathering has produced rather marked effects can be seen by comparing curvilinear joints in relatively unweathered and weathered zones, in a recently blasted excavation for a building. Those joints in the tough unweathered rock show clearly the curved surfaces with only a suggestion of the minor tectonic joints cutting normal to their vertical extension, figure 22 , whereas the weathered joints, belonging to the same original mass and approximately 15 feet $(5 \mathrm{~m})$ nearer to the outcrop surface in the weathered foreground, have separated into smaller parallel masses along the minor joints and produced wedges, figure 24 . Each face is a curvilinear polygon.

If a sufficient part of the joint system is preserved in a quarry wall, or other exposure, it may be possible to trace, with the eye, the curvature of the intersection of a curvilinear joint with its pseudocolumnar boundary and find that it follows a helical path. In figure 25 the geologist's hammer indicates the position of, and part of the path of, such a helical curve.

\section{GEOMETRIC CHARACTER OF THE CURVILINEAR JOINTS}

Field observations, made in this study, on the curvilinear system of joints provides us with the following geometrical properties of their surfaces and their limiting boundaries:

1 , the joint faces are all curved surfaces, see figures 19, 20, 21, $22,23,24,25$.

2 , the overall vertical extension of the curvilinear joints suggests that they are bounded by a surface which is pseudocolumnar, having almost a cylindrical aspect, see figures 20,21 .

3 , the curvilinear joints seem to consist of a curved surface which has combined with it an element of twist, see figures 19,21, 22 and 25, and photographs of curvilinear joints elsewhere in the text.

4 , where the curvilinear joints are viewed perpendicular to the principal axis of the joint, that is perpendicular to the direction of their pseudocolumnar aspect, the line of intersection of the curvilinear joints conveys the appearance of a helix, see figure 25 .

5 , along the "helix" the curvilinear joints may show a repeat distance for a given point on the "helix." This distance, the pitch of the helix, may vary from outcrop to outcrop. It may be manifested in the steepness of the slope of the face of the joint. The pitch will be most easily recognized in right helicoids and much less so in oblique helicoids, see the section in supplementary topics on "character of helicoidal surfaces." 


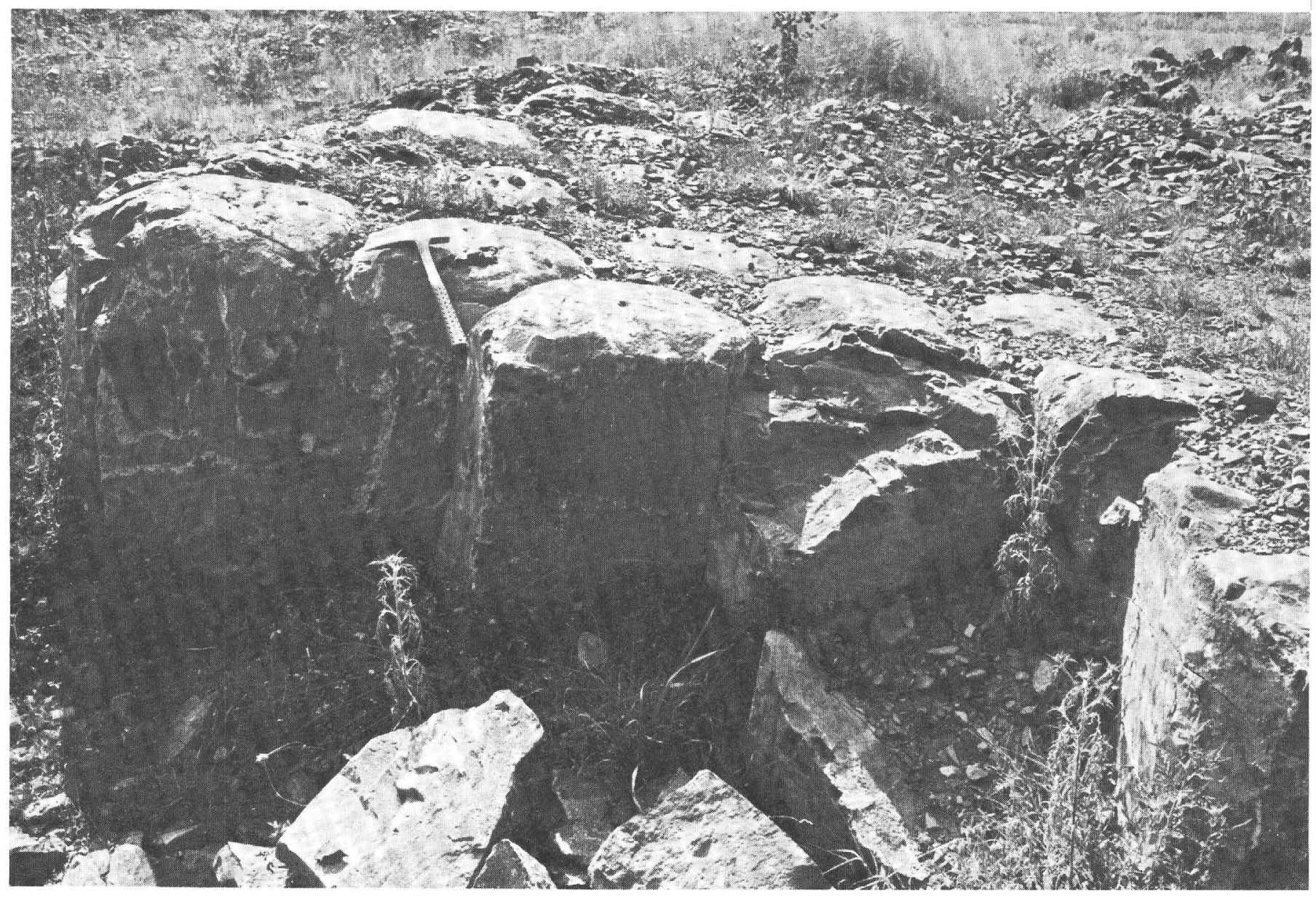

Figure 11. The ball end of "ball and socket", joints in columnar basalt. Ferguson's quarry, near Little Falls, N.J.

6 , the set of apparently parallel horizontal joints crossing the curvilinear joint system shown in figure 21 are not cooling joints but sheeting joints and have no genetic relation to the curvilinear joints. They do however suggest a ruled property to the curvilinear joint faces and that is a geometric property of helicoids.

7 , joints occur in groups and the closeness of the several parallel, subparallel, or otherwise geometrically related surfaces will be a measure of the spacing of a given joint system. For the curvilinear joint systems I have found that they are bounded by a pseudocolumnar surface and that these bounding surfaces will range from a few feet to about 15 feet (about $5 \mathrm{~m}$ ) in lateral extent (diameter).

In the list of observations on the helicoidal joints just given, reference is made to a boundary surface that contains the helicoidal joint surfaces (Nos. 2 and 7). Those bounding surfaces are a form of pseudocolumns and are so called here in contradistinction to the columnar joints described in the section "Columnar zone." The later joints are those normally called columns. I consider that these columnar joints have been produced by a conductive heat transfer process. When such columns are fractured they usually show a hackly surface. The pseudocolumns which enclose the helicoidal surfaces I consider, on the other hand, to have formed by a convective heat transfer process. When these pseudocolumns are broken they show helicoidal surfaces. The bounding surfaces are thus the former convection cells. The helicoidal character of the joints suggests that they reflect something of the nature of the former convective process. Detailed field and other studies will be given in a subsequent part of this series.

These observed geometrical properties of the curvilinear surfaces are the criteria to be used in identifying and selecting analogous geometrical models. The combined criteria numbers 3, 4, and 5 eliminate identification with quadric surfaces, see supplementary topics the section on "Glossary of terms and definitions." They show that the surfaces to which they belong are the warped, or skewed, surfaces. Criterion 6 suggests that these surfaces are also ruled surfaces. In particular the curvilinear joints are related to the class of surfaces known as helicoids (schraubenflache of the Germans, helicöide of the French). 


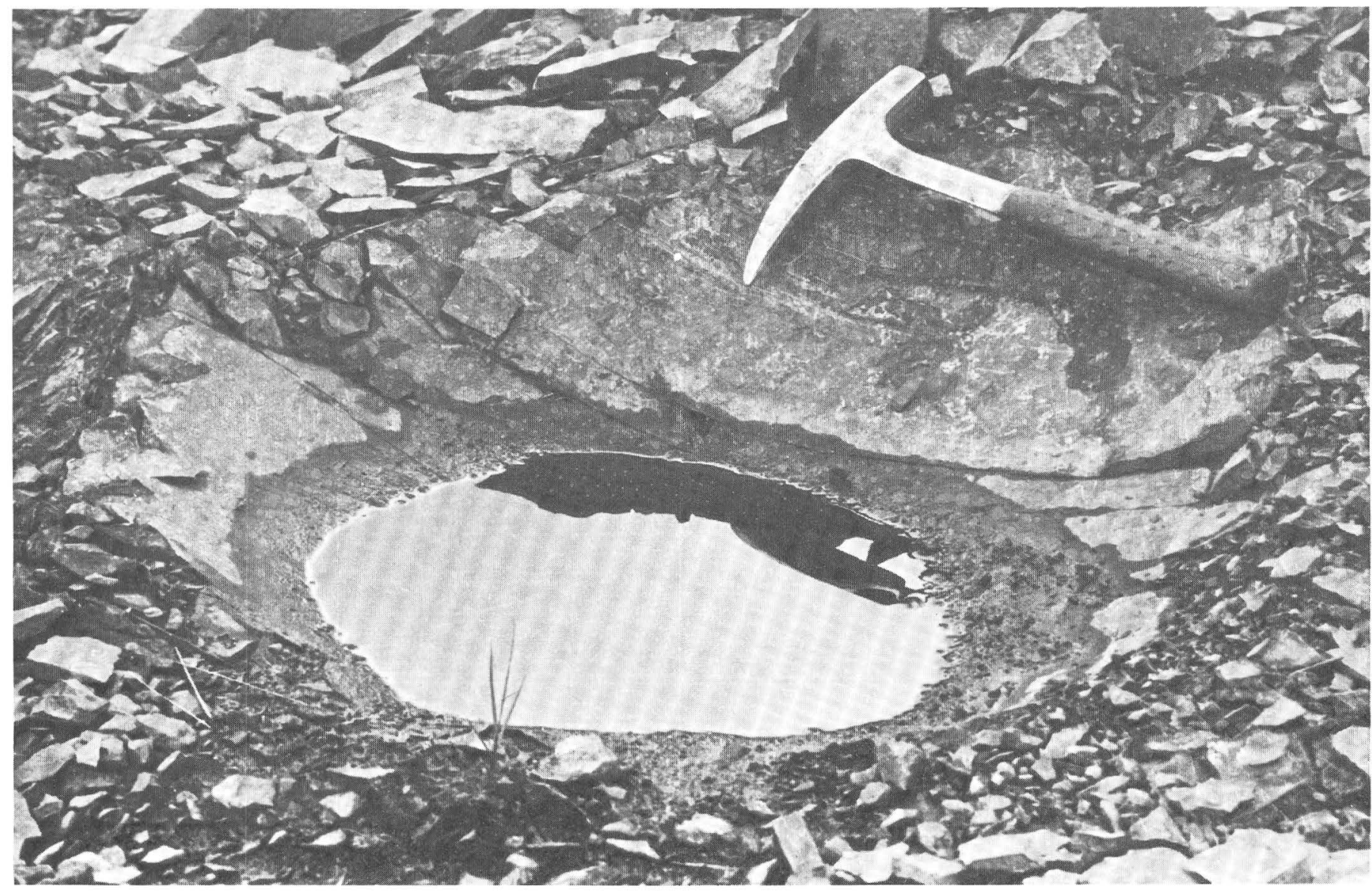

Figure 12. The socket end of "ball and socket" joints in columnar basalt. Ferguson's quarry, near Little Falls, N.J.

When the probable relationship between the geometry of the curvilinear system of joints as deduced from field relations, and the geometry of the helicoidal surfaces was realized many of the outcrops were reexamined to verify the correspondence. Unfortunately it is not always possible to see the full developments of the helicoids in natural outcrops or in the walls of quarries and excavations. Outcrops that have been exposed long enough for weathering to remove the loose blocks and form long continuous surfaces usually yield sufficient surface to identify their geometry. It was also found at many outcrops that the various shieldlike surfaces of the curvilinear joints, in unrelated pseudocolumns, show surfaces suggesting a considerable variation in pitch.

This reexamination and subsequent observations showed that some curvilinear joints appeared to be parts of the surface of a right helicoid, others appeared to correspond to oblique helicoids, still others appear to be more irregular and yet they still convey an indentity with helicoidal surfaces. These latter surfaces suggest an indentity with helicoids of varying pitch or varying length of the generatrix (sometimes referred to as the radius when the limiting surface is a cylinder). These geometric relations can be grasped from an inspection of the parametric equations of helicoids, see supplementary topics the section on "Character of helicoidal surfaces." Wellman (1948, p. 219) has discussed this type of helicoid as he observes that "helicoids of varying pitch and varying radius, although uncommon, are also feasible, and in such cases the angle between the generatrix and the axis is also variable. ${ }^{2}$ Screw propellers are frequently of variable pitch." It also became apparent that some of the joints could be represented in terms of the curves formed by the intersection of helicoids.

My colleague, Howard T. Evans, Jr., carefully considered the correspondence between the field observations, as portrayed in the photographs, and my sketches, and the geometrical theory of helicoids and drew two relevant illustrations. Figure 26, shows the intersection of two right helicoids which have parallel but displaced directrices, generators of slightly different length, equal pitches, and are out of phase by $155^{\circ}(+)$. The intersection edge is similar to some of those seen in some outcrops. Figure 27 , shows parts of two steep right helicoids moved parallel to one another until they intersect.

\section{VESICULAR BASE}

The vesicular base of the flow units are of two kinds, the base of the upper flow unit overlying the vesicular top of the

Htalies by G. I. F, 


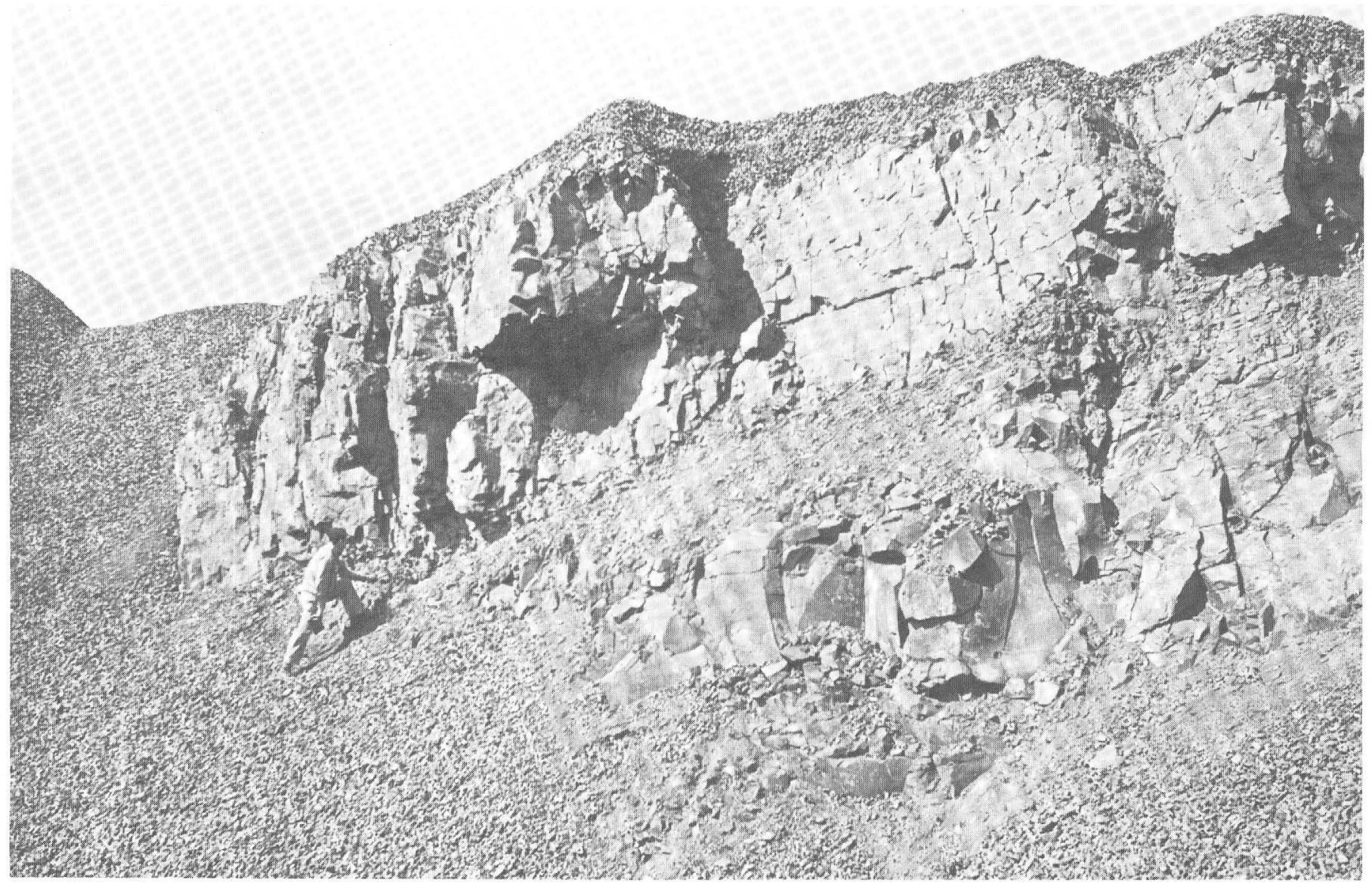

FIGURE 13. Exposure at the top of the "east" wall of the Millington quarry. The blocky zone juts out. The geologist is pointing to the base of the blocky zone. At the lower right hand side of the picture, well-developed curvilinear joints may be seen. This wall forms the dumping ramp of a stock pile. The apparent granular decoration on top of the blocks and scattered over the faces is the remains of a former stock pile.

lower flow unit and the vesicular base of the lower flow unit overlying the sedimentary rocks of the Brunswick Formation ( $k b)$.

The vesicular base of the upper flow unit overlying the vesicular top of a lower flow unit is a relatively thin layer, commonly 6 to 8 inches ( 15 to $20 \mathrm{~cm}$ ), and it is illustrated in figures 3 and 4 . The base is uneven and conforms directly with the pahoehoe surface of the lower flow. The relations between the curvilinear zone and vesicular base are shown in figure 28. Here the passage between the two zones appears to be transitional.

The character of the vesicular base overlying the sedimentary rocks in the Watchung Mountains is quite variable. This variability arose from a nonuniform distribution of water in the sedimentary floor. For most of the area the sediments were dry or slightly moist; parts of the areas, after storms, were moist, and scattered throughout the basin were playa lakes under which the sediments were saturated. Hot lava pouring out onto sediments with the above water contents would produce, respectively, breccias, thin layers of vesiculation, heavy layers of vesiculation, and pillow lavas. The thickness of the pillow lavas would depend on the depth of the playa lakes. Areas with braided drainage would produce alternate zones of pahoehoe toes (lobes) and pillow lavas.

In Third Watchung Mountain the base is almost uniformly a thin zone with only a very rare development of a flow breccia as in the vicinity of Oakland, N.J. In contrast, Second and First Watchung Mountains have more variable vesicular bases. In part they have the thin vesicular zone above a hornfelsized zone and in part they show the development of pillow lavas and (or) pahoehoe toes (lobes).

The most common type of bottom of the basalt flows of Third Mountain, where they rest conformably on the Triassic sedimentary rocks, is a vesiculated base.

Flow breccia is present as a very thin zone at the bottom of the lowest flow unit at the upper end of Packanack Mountain at Pompton, figure 29. The mass consists of fragments of basalt and of a lesser amount of sedimentary material, that were picked up as the lava flow rolled forward, and it is held together by interstitial lava to form a firm unit. This breccia is of limited areal extent.

Geologists making field studies in the Triassic Lowland in an earlier time when the sandstone was quarried for dimen- 


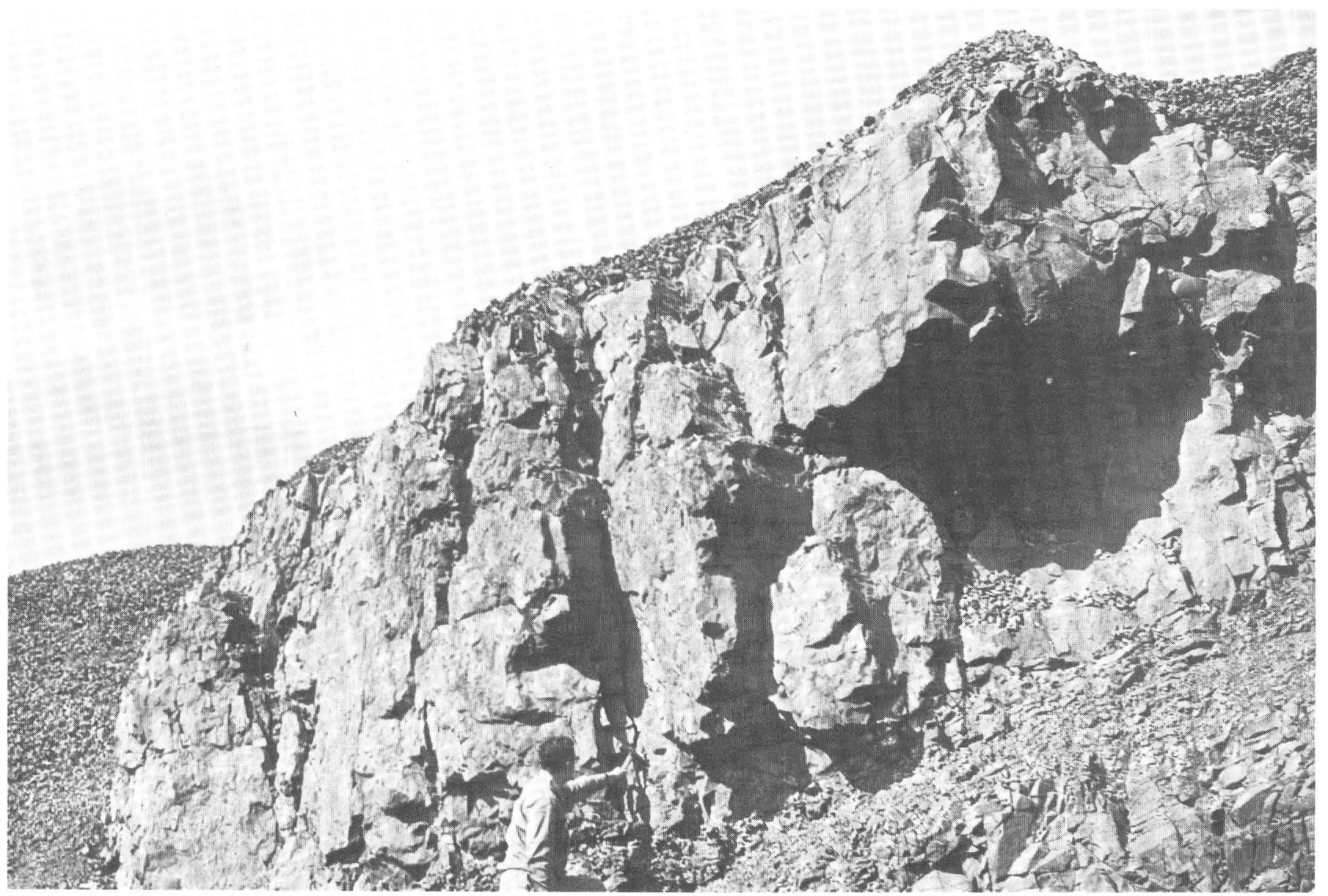

FIGURE 14. Detailed view of the blocky zone on the "east" wall of the Millington quarry. An enlargement of a portion of figure 13 showing the blocky joint system.

sion stone and the more easily quarried vesicular basalt was used as riprap to prevent erosion and as road metal for paving, had unusually good opportunities to study the physiographic conditions of the floor prevailing at the time of the eruption of the basalts in New Jersey, Connecticut, and Massachusetts. Fenner $(1908$, p. 310-311, 326) has made a detailed study of these relations in New Jersey, and Krynine $(1950$, p. $169,195-196)$ has similarly examined the broader relations of the environment and landscape of the Newark epoch in Connecticut.

These studies both agree that the intermontane valley onto which the Triassic lavas flowed was essentially flat land. In New Jersey my study of the scarp of Third Mountain, exposing the bottom of the flow for so great a distance, affords additional field evidence.

Excavations of the vesicular base of the lower flow unit of the basalt were also more easily studied, and the unique observation of Lewis (1908, p. 152-153) is pertinent. Lewis had the opportunity to examine the dumps made during the tunneling operations through Hook Mountain, north of Pine Brook, and he found a very small amount of tuff. He was uncertain of the stratigraphic position of this tuff in the base of the flow. This is the only evidence for basalt tuff in Third Mountain.

\section{OCCURRENCES OF SIMILAR COOLING JOINTS IN OTHER BASALTIC PROVINCES}

My field studies of jointing systems in basalt have been confined to the Watchung Basalt flows of New Jersey. As time and occasion have permitted I have examined the various cooling joint patterns in other basaltic provinces to see if the same kind of cooling joint systems are present. Visits to these provinces have been brief, and extended study of the jointing systems at any one outcrop was not possible, so that my observations were cursory in nature. In the fissure type eruptions of the Triassic of Connecticut, Massachusetts, and the Bay of Fundy area of Nova Scotia, as would be expected, I have seen jointing patterns identical with those in New Jersey. The curvilinear joint system because it is the thickest zone is the most frequently observed. In the vicinity of Canada Creek, near Black Rock Lighthouse, Bay of Fundy, Nova Scotia, several of the joint systems were observed. In figure 30 two joints systems are to be seen. 


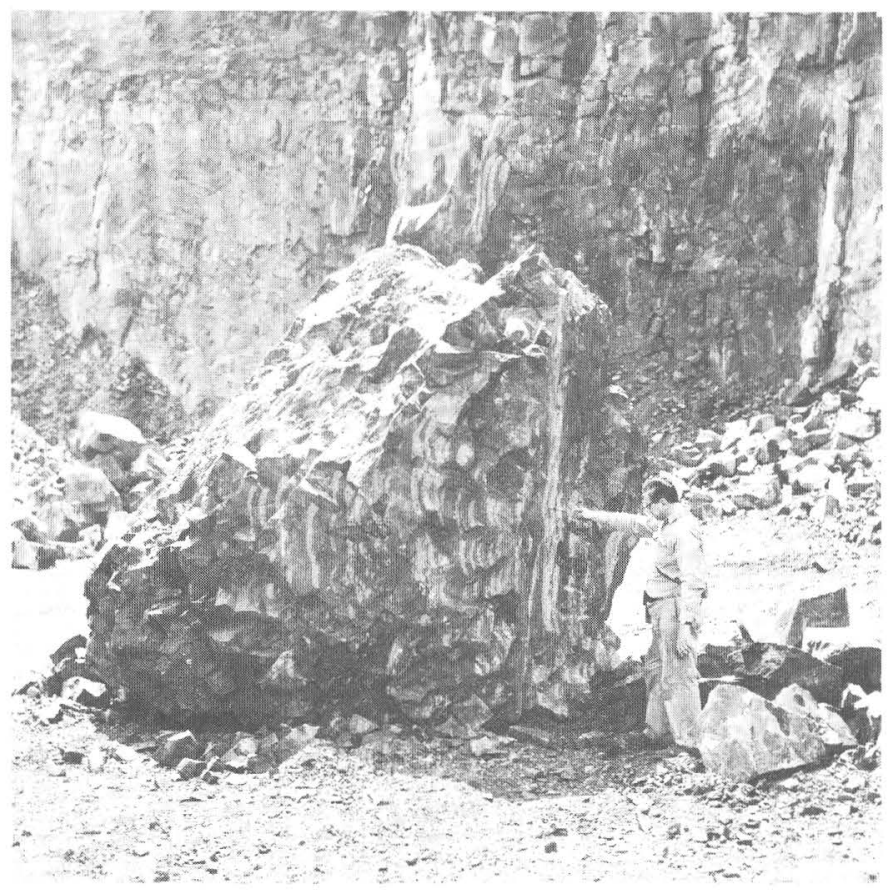

FIGURE 15. A hackled block from the blocky joint system which has fallen and tumbled from its position in the overhanging ledge to the floor of the Millington quarry. It was battered by a steel ball dropped from a crane boom. Such blocks are used as jetty stone. Other large blocks may be seen near the base of the wall.

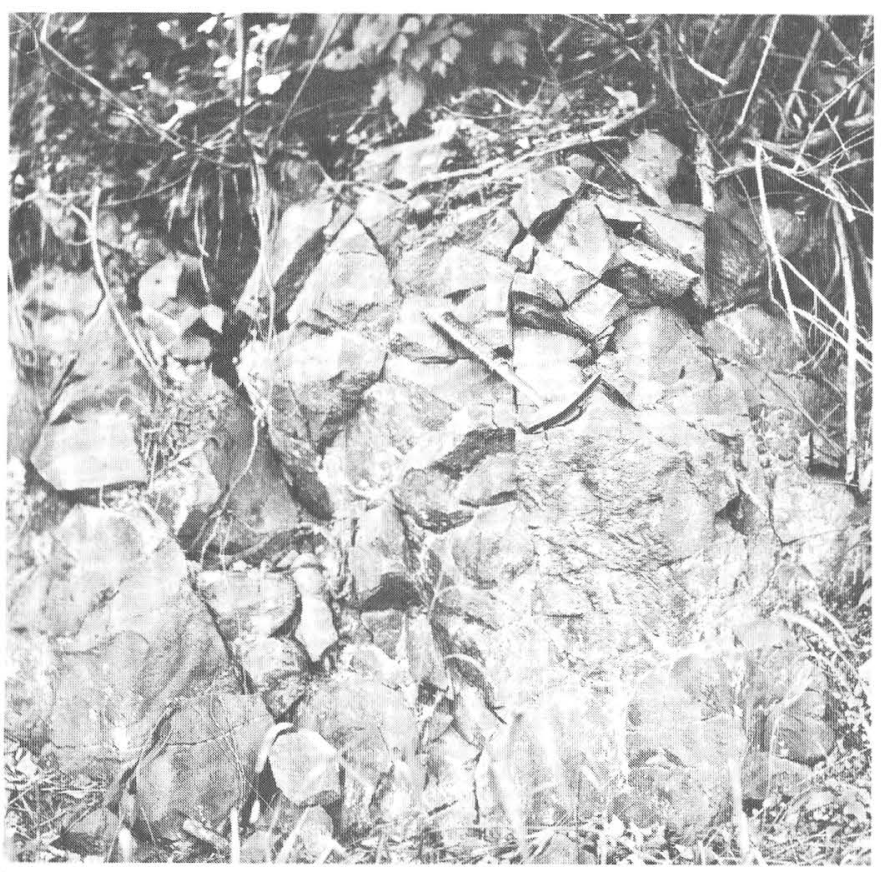

FIGURE 16. Weathered blocky jointed trap. Roadcut near Blackberry Lane and James Street, New Vernon trap sheet near Morristown.

The geologist is standing on the columnar zone of the lower flow unit; behind him the base of the curvilinear zone of the upper flow unit can be seen. The columns of the lower flow unit have a larger diameter ( 25 inches \pm ) than the

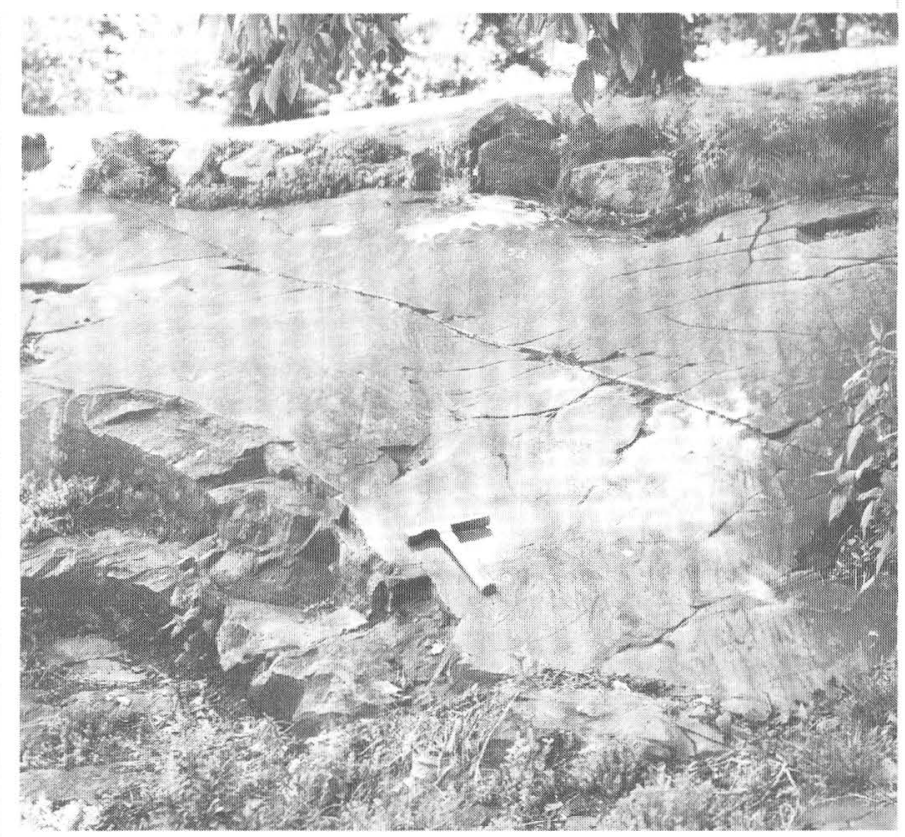

FIGURE 17. Glacial pavement developed on basalt of the blocky zone. This glacially polished outcrop is on the north side of Chapel Hill Road and Highland Street, Hook Mountain, near Lincoln Park, N.J.

columns occurring under the pahoehoe tops of the upper flow units in Third Watchung Mountain. The vesicular base of the upper flow unit and the top of lower flow unit are covered. At a locality nearby the base of the curvilinear zone and the vesicular base of the upper flow unit could be seen. Evidence of the blocky and columnar zones of the upper flow unit were observed as blocks and columns lying at the foot of the cliff.

Columnar jointing in the vast fissure eruptions of the Columbia River Basalt Group is a well-known phenomenon. The abundance, size, and arrangement of the joints in tiers has been described by Mackin (1961), Bond (1963), and Bingham and Grolier (1966). My visit to the Columbia River Basalt Group was limited to a very small area in the vicinity of the Grand Coulee, Wash., and there I saw, in addition to the excellent columns, areas where blocky and curvilinear joints were well developed.

At the Hoher Meissner, in Nordhessen, Germany, the basalt plateau overlies brown coal beds. Here a thick zone of very well developed curvilinear joints occurs above a thin vesicular base which in turn overlies a baked brown coal layer. In the very large central type volcano, the Vogelsberg, in West Germany I have observed some very large helicoidal surfaces. Some of these surfaces appeared to be oblique helicoids.

In Iceland I have seen many examples, in the tops of flows, of the type of columnar jointing observed in the Watchungs, short columns 4 to 10 feet $(1.2-3.1 \mathrm{~m})$ long and 0.5 to $1 \mathrm{foot}$ $(15-30 \mathrm{~cm})$ wide. These columns lie beneath a thin vesicular top, and their attitude is determined by the curvature of the tumuli surface. Curvilinear joints were observed at Detti- 


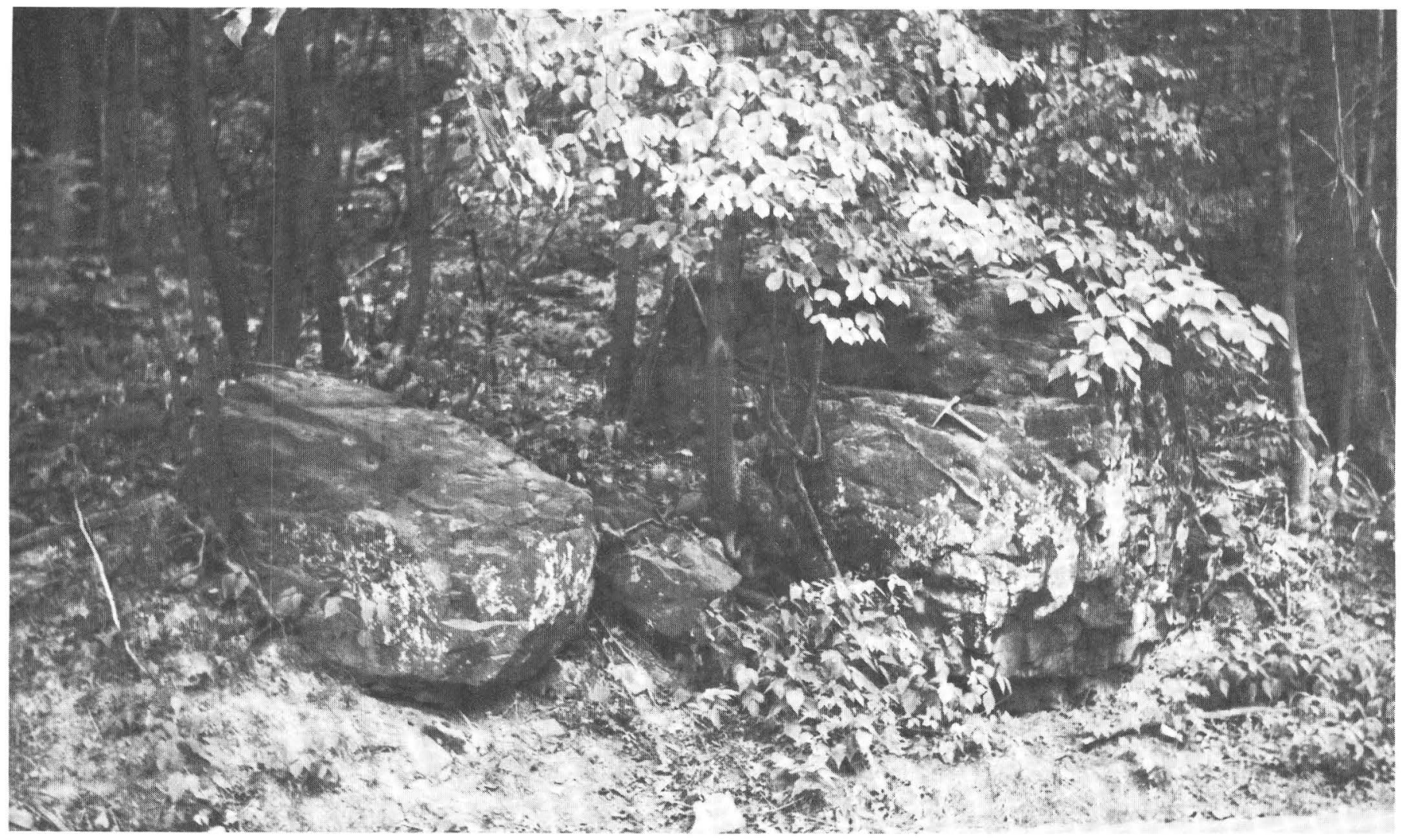

FIGURE 18. Blocks of trap dislodged from their position at the top of the ridge. These were naturally quarried by alternate freezing and thawing which disrupted the jointed ledge and produced a jumble of blocks. When dislodged sufficiently or undermined, they tumble down the scarp slope. Northeast of the intersection of Pine Brook Road and Passaic Avenue Road, Lincoln Park, N.J.

foss, Mývatn, Thingvellir, and elsewhere. Observations in Iceland suggest that if the flow units are thin the blocky zone is absent and the sequence becomes - thin vesicular zone, vesicular grading into the columnar zone, curvilinear zone, and vesicular base.

These observations were made at widely separated outcrops in other basaltic provinces. The identity of the cooling joint systems in the flows of fissure eruptions, wherever observed, with those in the Watchung Basalt flows is significant. It supports my opinion that more detailed studies in these areas will reveal similar patterns and sequences with those in the Watchungs.

\section{TECTONIC JOINTS}

In order to ascribe the cause of the joints produced in the lava flows by tectonism it is necessary to review briefly that portion of the geologic history of the Newark graben that involved them, Faust (1975), and to evaluate the capacity of the several tectonic processes to produce joints. The Watchung lava flows appeared in the Newark graben after the basin was largely filled with sediments. If it is assumed that the Newark Group in New Jersey is 11,800 feet $(3,600 \mathrm{~m})$ thick, then the basin would have been nearly 80 percent filled; if the greater thickness of 25,000 feet $(7,620 \mathrm{~m})$ is assumed, then the basin would have been about 90 percent filled. Over this floor the first eruption from fissures took place. After the completion of the volcanic episode that produced the first Watchung Basalt flow, the two flow units cooled down to earth temperatures, and subsequently they were buried by about 600 feet $(183 \mathrm{~m})$ of sedimentary materials.

Faust (1975) observed at Oakland, N.J., a fanglomerate bed that underlies the base of the second Watchung Basalt flow. Although the contact relations could not be observed, the fanglomerate at the most is about 50 feet $(15 \mathrm{~m})$ below the contact, and it could be much closer. Barrell (1915, p. 29) pointed out that the occurrence of the fanglomerate (conglomerate) beds "indicated a re-growth of the mountains" that supplied the sediments to the basin and that this uplift necessitated a boundary consisting of a fault wall along which renewed movement took place. The presence of the fanglomerate at Oakland, N.J., indicates that faulting, a tectonic process, that could have produced joints in that part of the underlying basalt of First Mountain close to the fault wall. Similarly, after the extrusion of about 750 feet $(229 \mathrm{~m})$ of the second Watchung Basalt flow and its solidification and burial by 1,500 feet $(457 \mathrm{~m})$ of sediment, another fanglomerate 


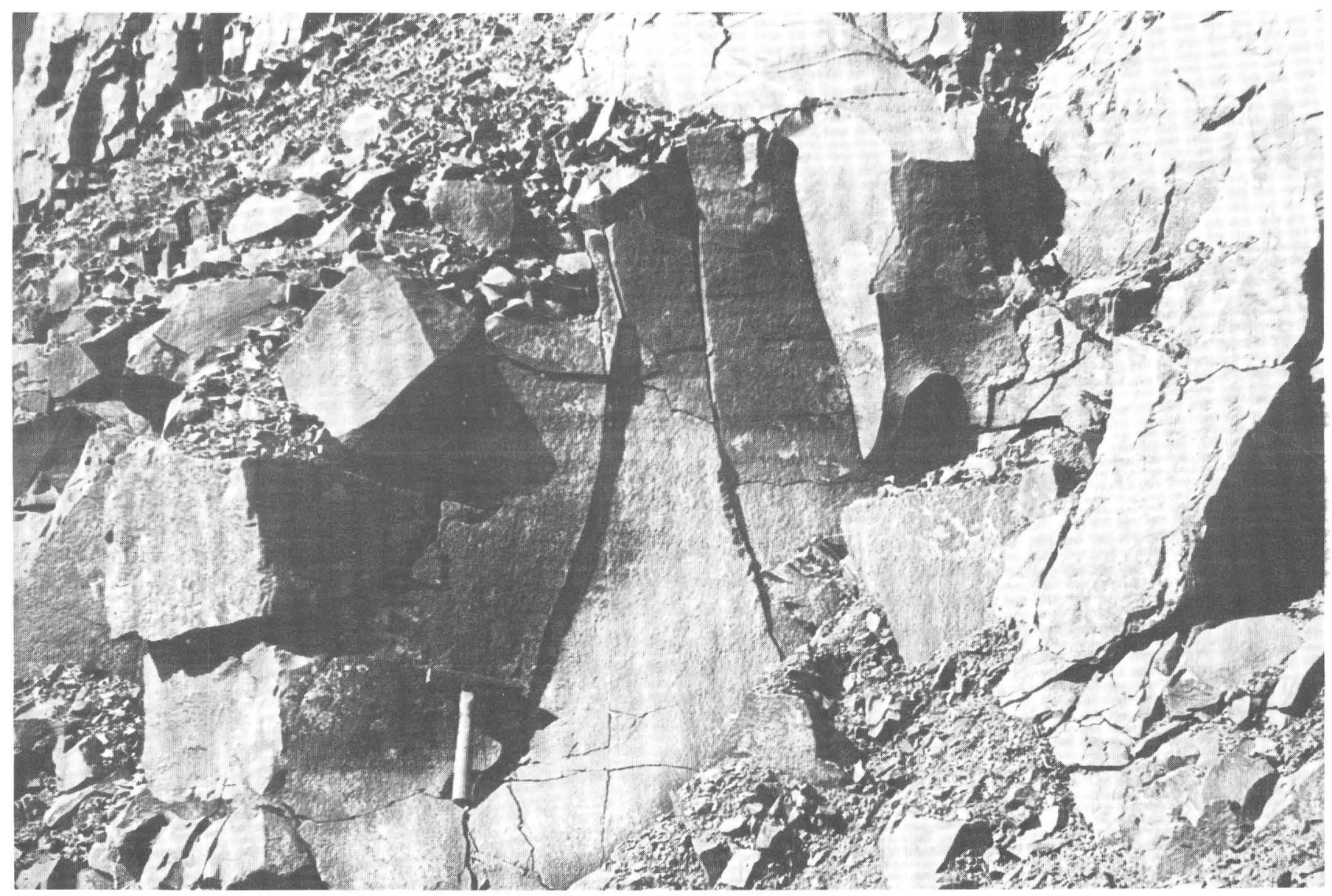

FIGURE 19. Curvilinear joints in trap. "East" wall of the Millington quarry. Note thin layer of the closely jointed blocky zone (upper left hand corner) overlying the curvilinear zone and above this the irregular and hackly broken masses of the blocky zone.

appeared and is evidence of another tectonic event. The sequence was again repeated after 300 feet $(91 \mathrm{~m})$ of the Third Watchung Basalt flow was extruded, cooled, buried under at least 300 feet $(91 \mathrm{~m})$ of sediments and followed by a fanglomerate. These three tectonic events, signalized by the presence of the fanglomerates, were small-scale events and could have produced jointing locally near the walls in these buried flows but for the flows as a whole they were of minor importance.

The deformation of the Newark graben by the tensional forces associated with the drifting apart of the North American plate from the adjoining parts of Pangaea resulted in downfaulting of the graben block. This crustal movement created a space problem and the contents of the graben were folded into a regional arch with border synclines in accord with the model developed by Murawski (1968). This tectonic event was a major process which resulted in extensive jointing in parts of the syncline.

The tectonic joints are best developed in Second Mountain, less so in First Mountain, and they are not very prominent in Third Mountain. In the weathering of the basalt of the Watchung Mountains the tectonic joints are emphasized and their extended planar boundaries tend to overshadow cooling joint boundaries. As a result of this emphasis the eyes of the observer are distracted from other structures in the rocks which are also of a first order of importance.

The tectonic joints in the various zones are described in the following sections.

\section{VESICULAR TOP}

The transverse joints in the vesicular zone are tectonic joints. They may occur in conjugate pairs, and they make an angle of about $45^{\circ}$ with one another.

\section{COLUMNAR ZONE}

The tectonic joints in the columns are not always clearly developed. In some columns they consist of irregular breaks that cut across the columns. In other columns planar basal joints were formed.

\section{BLOCKY ZONE}

Tectonic joints in the blocky zone are essentially perpendicular to the surface of the flow. In some blocks an apparent 


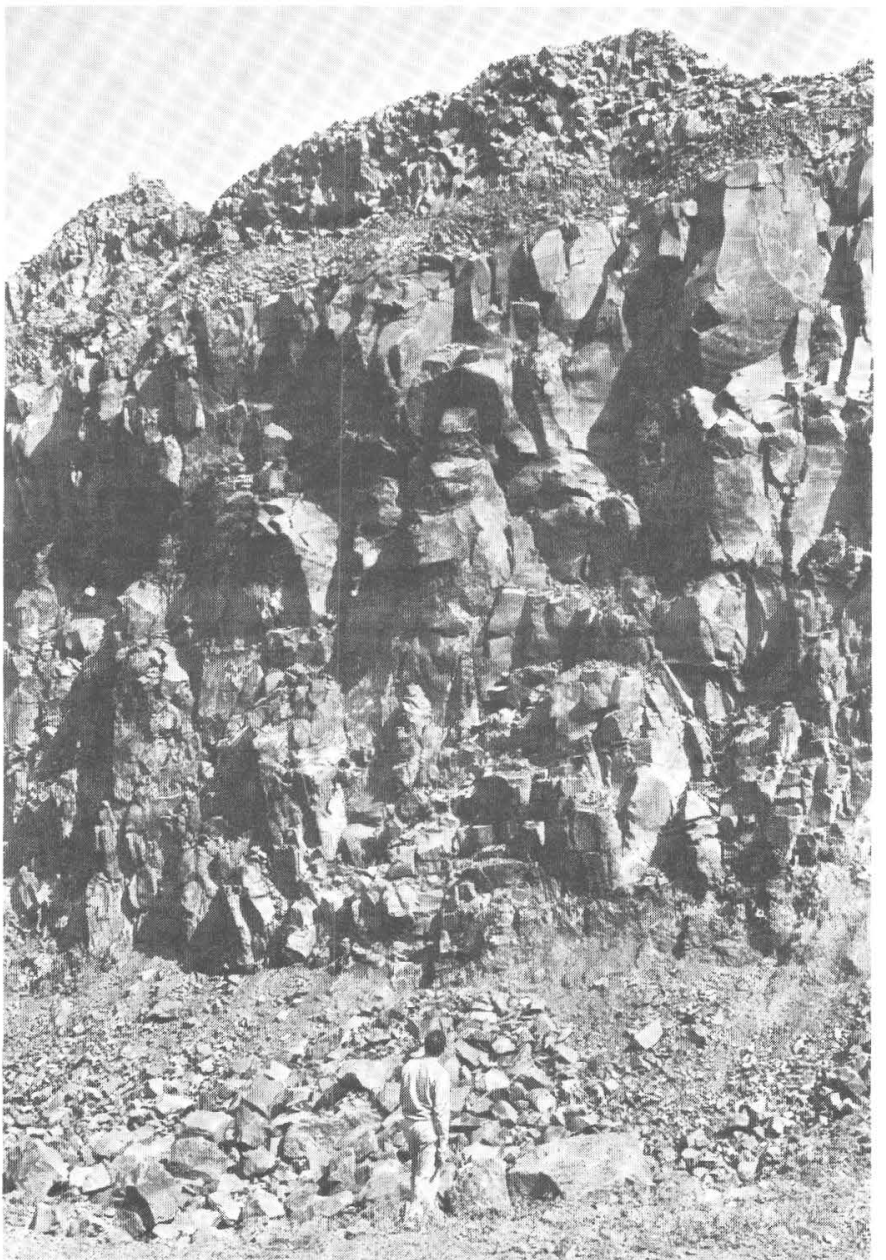

FIGURE 20. A close-up view of curvilinear joints in an old quarry wall. "South' wall Millington quarry. Note that the blocks that have dropped out from the wall are shield shaped and wedge shaped.

single joint may consist of a series of discontinuous parts which form an interrupted linear trace.

At the base of the blocky zone appears what is termed a seam or a layer by the quarrymen, figure 31 . It has a thickness of approximately 2 feet and serves as a marker in the Millington quarry. From a distance it has the appearance of a fissile shale and has been thought by some to be a shaly interbed, see figure 32. A careful examination of the bottom of the blocky zone shows clearly the origin of this subunit, for fine hairlike joints at the base can be traced into the separated joint platelets. The presence of this shear zone is an indication of thrust faulting, and in the Millington quarry the blocky zone jointed at its base as it moved over the curvilinear jointed basalt below it. A similar type of jointing is called a Deckensohle by Cloos (1936, p. 245).

\section{CURVILINEAR ZONE}

Three types of tectonic joints are observed in the curvilinear zone-the first, and most prominent, are the pseudoco- lumnar joints which may extend from the top to the bottom of the zone and are essentially normal to the surface of the flow; the second type are the platy-prismatic joints which are found near the base of the Second Mountain flow, and their abundance is related to the geometry of the syncline; and the third type - the basal platy joints - form very close to the base of the flow, just above the vesicular base and the contact with the Brunswick Formation.

PSEUDOCOLUMNAR JOINTS (TYPE 1)

When one looks at the curvilinear joints from certain directions, they have a distinct columnar aspect. As a result this vertical system of tectonic joints has conveyed to most geologists the impression of a columnar type of jointing. Consequently it has caused confusion in the identification of the cooling joints and has led to the misinterpretation of the jointing. Because of its columnar aspect it is termed here pseudocolumnar jointing. This aspect is produced by a combination of one of the cooling joint systems and a set of parallel planar vertical tectonic joints. These joints have appeared on some of the previous figures, but an attempt was made to select photographs taken to deemphasize this aspect. A photograph typical of the pseudocolumnar joints as seen in older quarries, roadcuts, and power-shovel bumped exposures is shown in figure 33. In contrast the appearance in a freshly blasted exposure is shown in figure 34. Compare figure 34 with figure 22.

\section{PSEUDOCOLUMNAR JOINTS (TYPE 2) - PLATY-PRISMATIC JOINTS (FRACTURE CLEAVAGE)}

Pseudocolumnar joints of a second type were observed by early workers in the Watchungs, who included them in the general classification of columnar joints. These joints are here designated platy-prismatic joints, and their close spacing shows that they are, in fact, a fracture cleavage. Joints of this type have not been observed on Third Mountain proper, but they have been observed in the axis of the syncline composing the New Germantown trap sheet, and they are quite abundant on the scarp slope side of Second Watchung Mountain.

A typical example of this variety of pseudocolumnar habit can be observed in Alward's quarry at the intersection of Pill Hill road and Meeker road about 21/4 miles west of Basking Ridge, see figure 35. An examination of these pseudocolumns shows that they are made up of a fracture cleavage superimposed on the preexisting cooling joints of the curvilinear zone. Well-developed curvilinear joints may be seen about 10 feet above the top of the pseudocolumns shown in this photograph. According to Hartmann's Law (see Nevin, 1931, p. 23-24), the acute angle of the fracture 


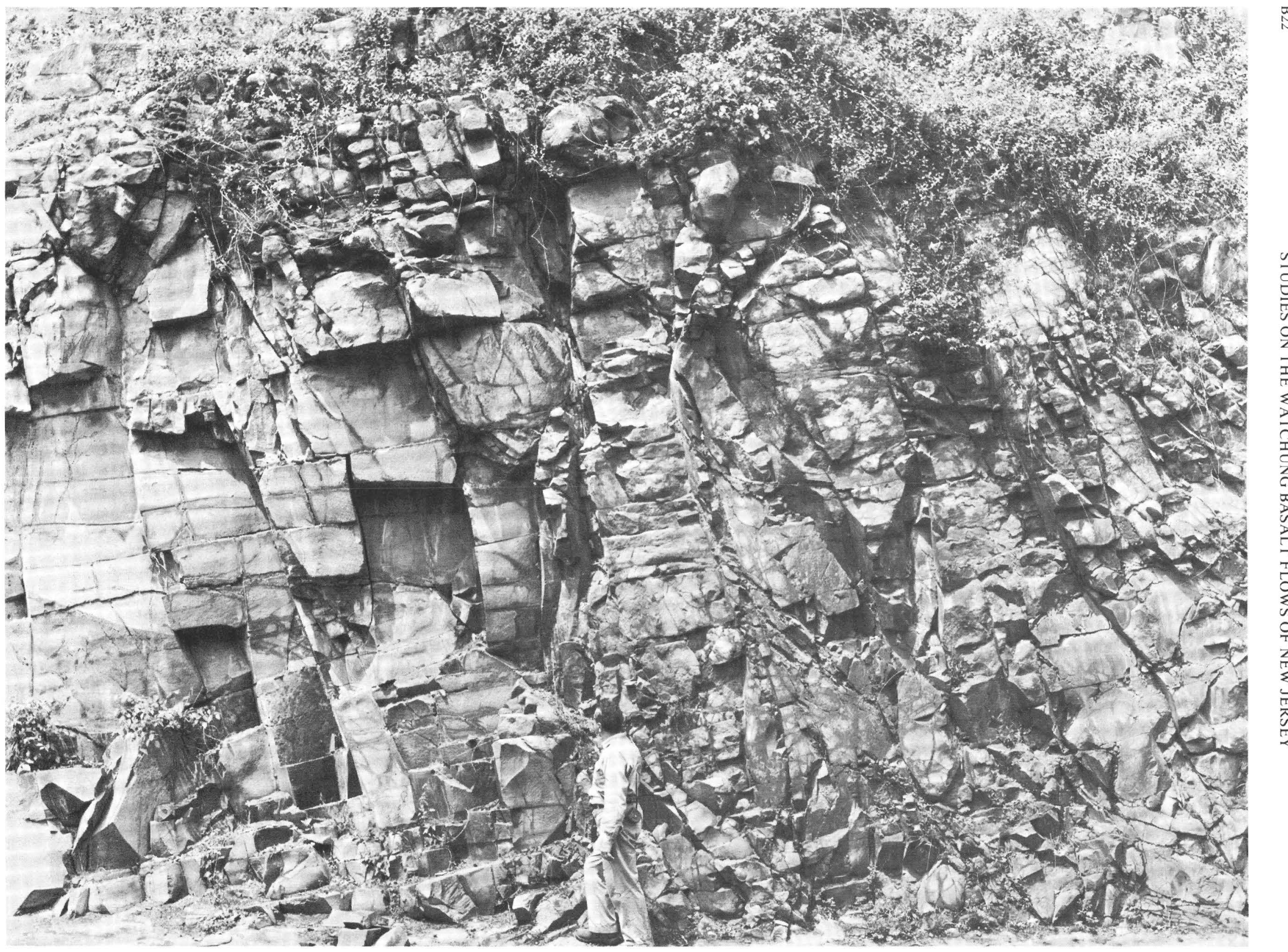

FIGURE 2 I. Excellently developed curvilinear joints in the trap. The roadcut is approximately perpendicular to the strike. The joints across the face of the curved planes are sheeting joints and are not cooling joints. Roadcut on Bloomfield Avenue near its intersection with Hook Mountain Road, Pine Brook, N.J. 


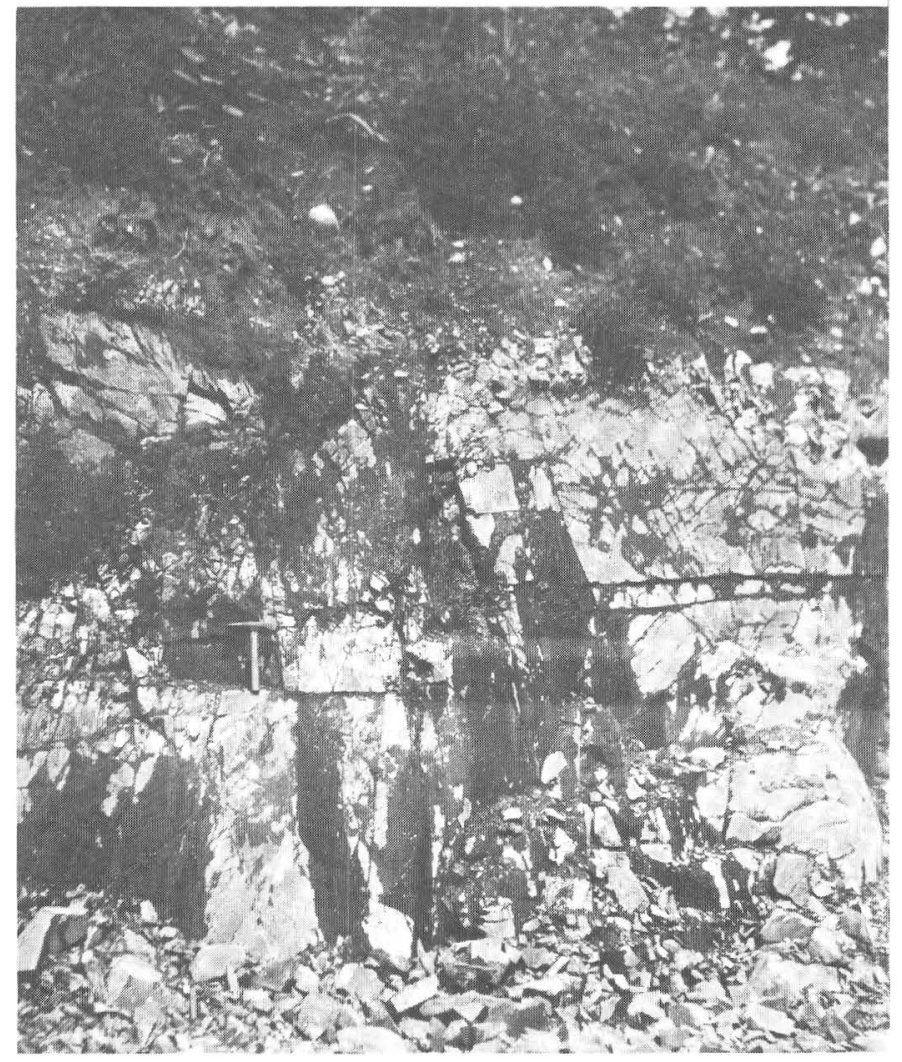

Figure 22. Curvilinear joints in relatively fresh basalt. This rock is very tough and required extra blasting to excavate it. The curvilinear joints are outlined by the shades and shadows. They are clongate approximately perpendicular to the floor of the excavation. Near the surface of the triangular area on the right some checking of the minor joints is apparent. This locality is an excavation at the intersection of U.S. Highway 46 and Hook Mountain Road, Pine Brook, N.J.

cleavage is bisected by the axis of maximum stress, and at Alward's quarry this direction is essentially parallel to the southwest limb of the syncline. A top view of the platyprismatic joints, just described, is identical with the prismatic cross section shown in figure 36 . In the walls of the quarry these platy-prismatic joints exhibit an eminent cleavage and show little evidence of the curvilinear joints arising from the cooling of the sheets. A careful study of the talus pile reveals the curved surfaces on the longer broken prisms, see figure 36 . The loose prism shown in this picture was photographed so as to emphasize the curvature of the joints on the sides.

A type of platy-prismatic jointing, a fracture cleavage, similar to the aforementioned jointing, except that the prisms are curved plates, is found in or near the axial plane of a tightly folded syncline which constitutes the New Germantown trap sheet. These joints were exposed by quarrying.

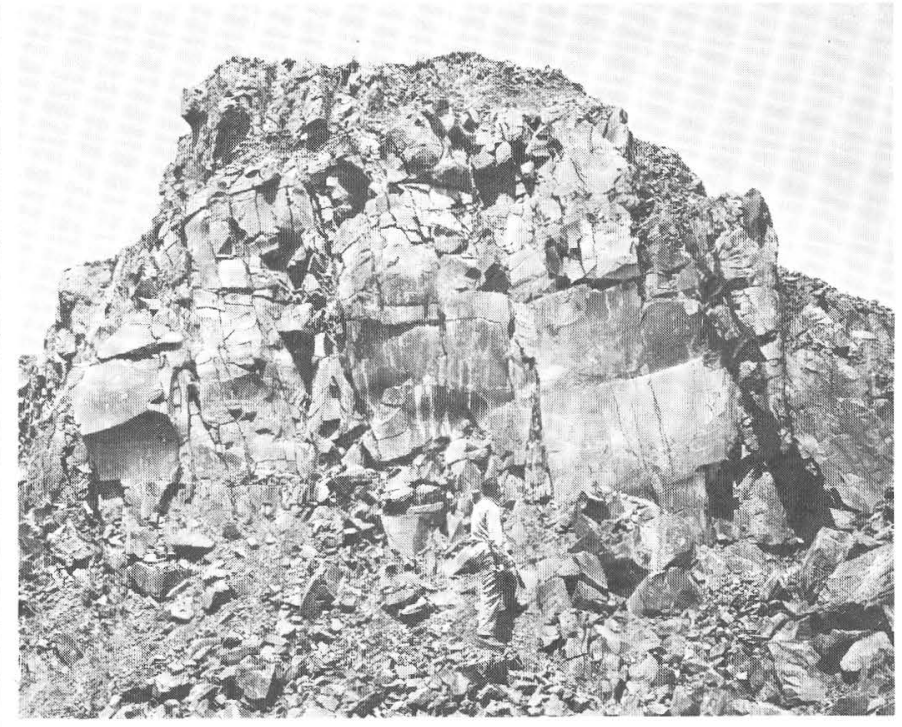

FIGURE 23. A strongly blasted mass of curvilinear jointed trap preserving its characteristic morphology. The picture represents a portion of the "north wall"' at the Millington quarry, Millington, N.J.

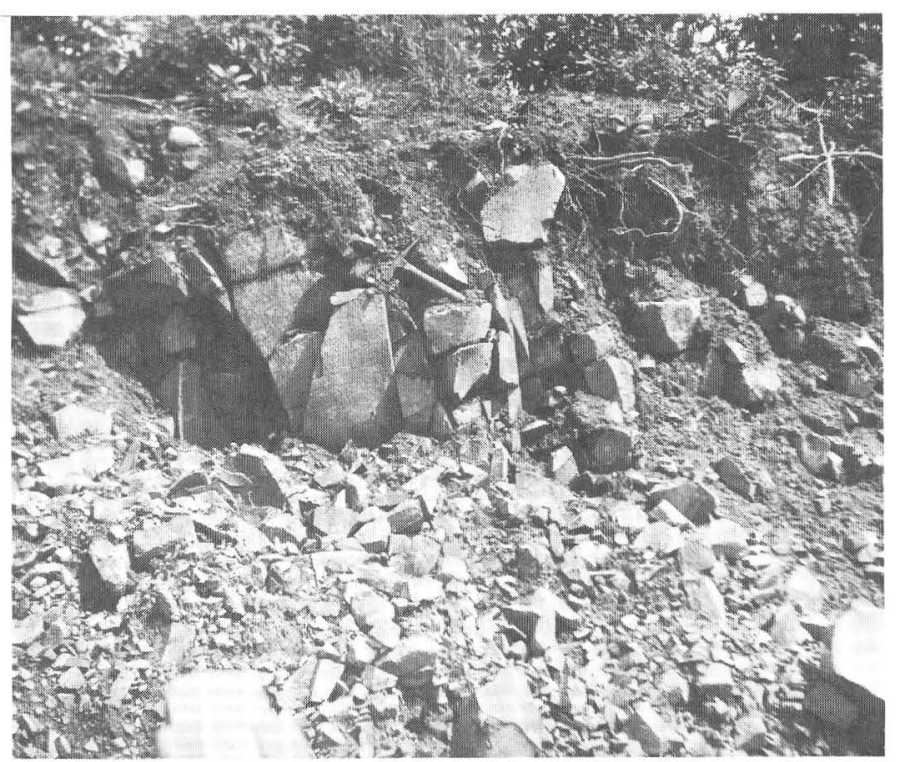

FIGURE 24. Weathered curvilinear joint masses having wedge shapes. This rock is similar to that in figure 22 except that it is from a strongly weathered zone. Excavation at the intersection of U.S. Highway 46 and Hook Mountain Road, Pine Brook, N.J. 


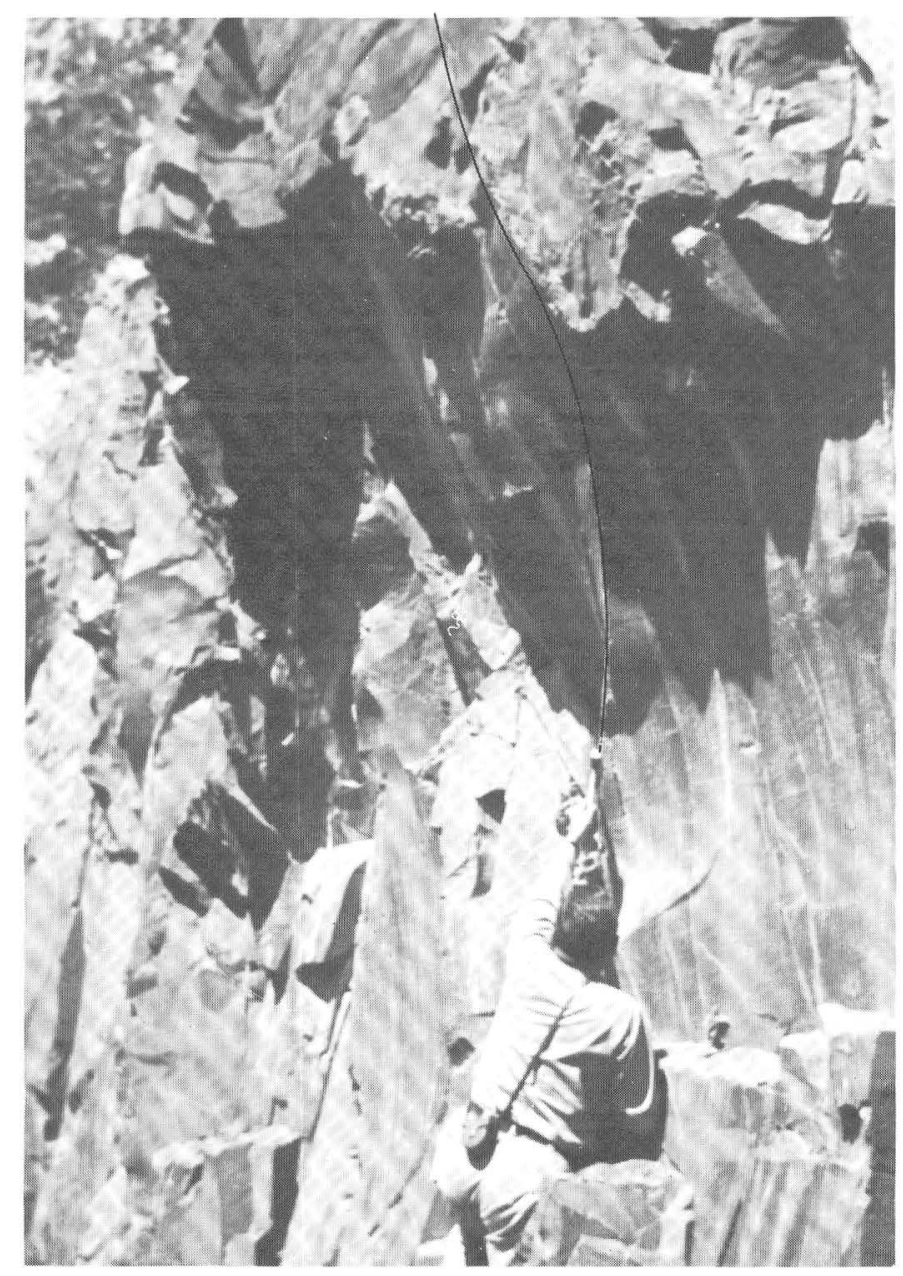

FIgURE 25. Curvilinear joints in the trap of Second Watchung Mountain. Geologists' hammer indicates the position of the trace of the helical path of the curvilinear joint. Gallo's quarry, Mt. Bethel, N.J.
They have an eminent cleavage and are very smooth; in fact, they appear at a short distance from the outcrop to be polished. A view of the platy surface is seen in figure 37; the side view, emphasizing the curvature, is shown in figure 38; and a top view showing the typical prismatic cross section is shown in figure 39 .

The frequency of tectonic joints increases in relation to the geometry of the syncline. Along the limbs the tectonic joints are abundant, but their frequency is greatest in the vicinity of the nose of the syncline, figure 40 .

\section{BASAL PLATY JOINTS}

On the limbs of the syncline, away from the nose, basal platy joints are commonly developed just above the contact with the underlying Brunswick Formation. They may occur

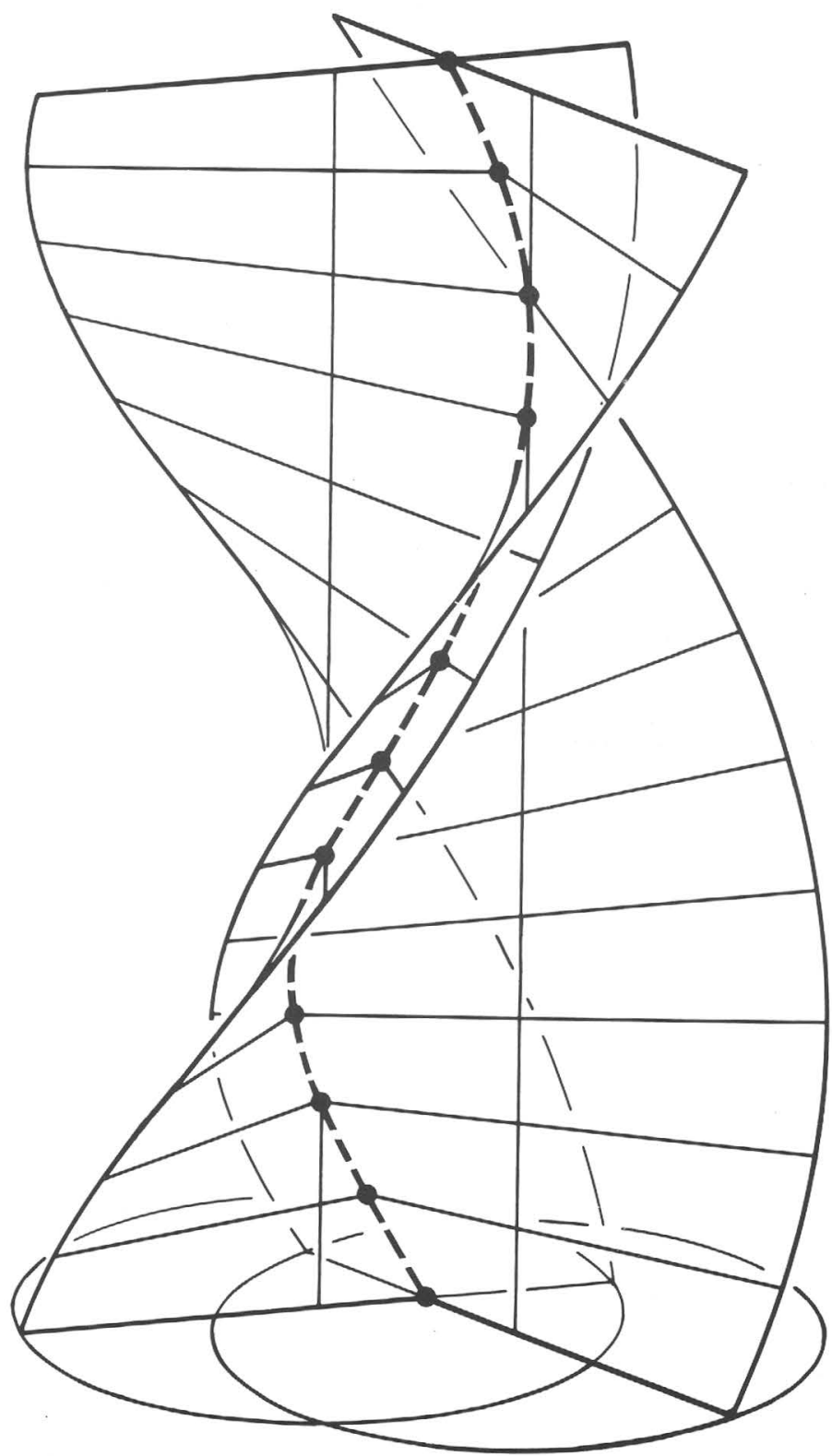

FIgURE 26. Two right helicoids with parallel but displaced directrices (helicoidal axes), with generators of slightly different length, with equal pitches and out of phase by about $155^{\circ}$. The dotted line is the intersection edge. Such edges are similar to those seen in some outcrops.

in a zone of about 10 feet $(3 \mathrm{~m})$ in height above the base, see figure 41 . They are generally spaced about 10 to 12 inches $(25$ to $30 \mathrm{~cm}$ ). They may extend for many tens of feet (many m). It is suggested here that they formed concurrently with the syncline. The interpretation, proposed here, is that the base of the flow and the hornfelsized zone welded to it attempted to behave elastically as a single unit. These joints are developed at the base of Second Mountain. 


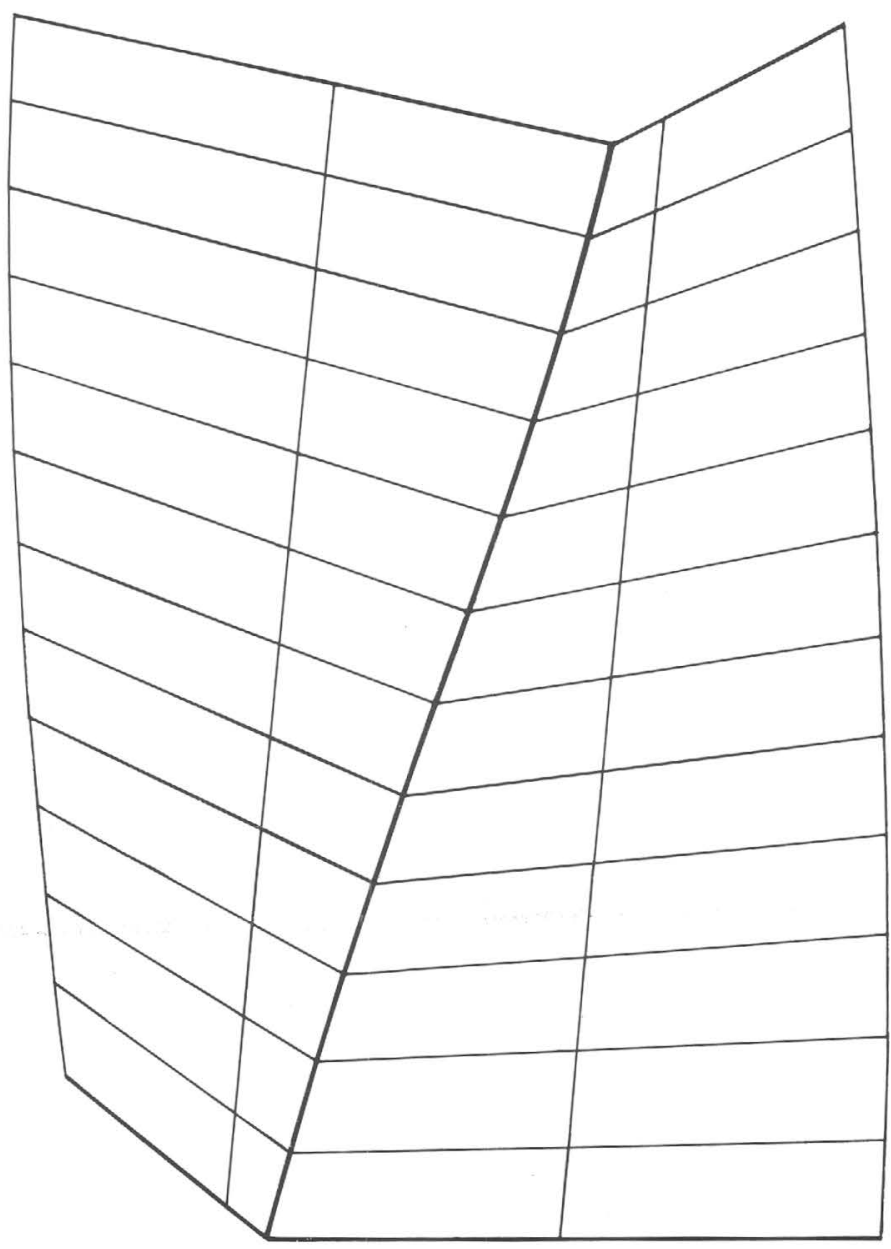

FIGURE 27. Portions of two steep right helicoids, moved parallel to one another graphically, until they intersect.

SHEETING JOINTS

Sheeting joints are a set of parallel, generally closely spaced joints which divide the rock into layers called sheets. These sheets are developed in essential conformity with the topography and where the ground surface is flat or nearly so they are horizontal. Sheeting joints generally form as a result of physical weathering which removes the superimposed load from the rock it exposes, Ollier (1969, p. 5-9). This removal of overburden permits the rock to dissipate its stored strain energy chiefly in the formation of cracks oriented parallel to the ground surface. In this discussion sheeting joints are classified separately from weathering phenomena solely to differentiate these joints from other types of horizontal joints.

At a late stage in the geologic history of the Newark basin the North American ice sheet covered its northern part and

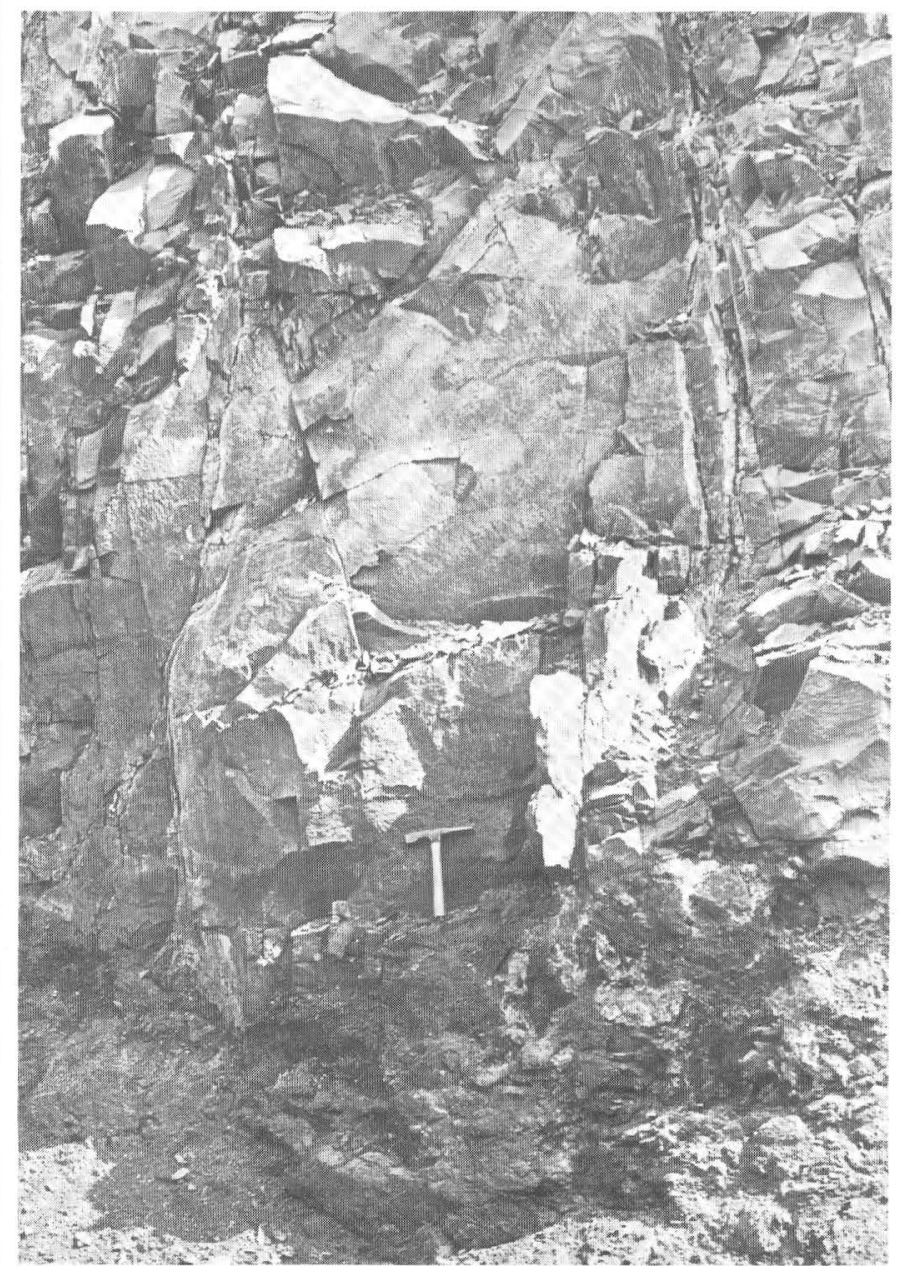

FIGURE 28. Curvilinear jointed trap overlying the vesicular base of the upper flow unit in the Millington quarry. The hammer handle rests on the contact of the two zones. The quarry face in this photograph is nearly perpendicular to the quarry face shown in figure 4 .

loaded the rocks below it with ice. Retreat of this glacier unloaded the rocks but left them strained. Strain relief was accomplished by sheet jointing. In the area north of the terminal moraine, which extends from Summit to Morristown, sheeting has been developed in the basalt. This sheeting conforms to the topography.

Two fine examples of sheet jointing on Hook Mountain are shown in figures 42 and 43 . The outcrop shown in figure 42 is at the southern end of Hook Mountain at Pine Brook. The wall is approximately west-east, and it is a section normal to the strike and cutting through the dip slope. The quarry shown in figure 43 is at the northern end of Hook Mountain near Mountain View. The quarry was opened and excavated in the dip slope, and the photograph is taken in a nearly east-west direction.

The flat, steplike surfaces of the trap in the zone of sheet 


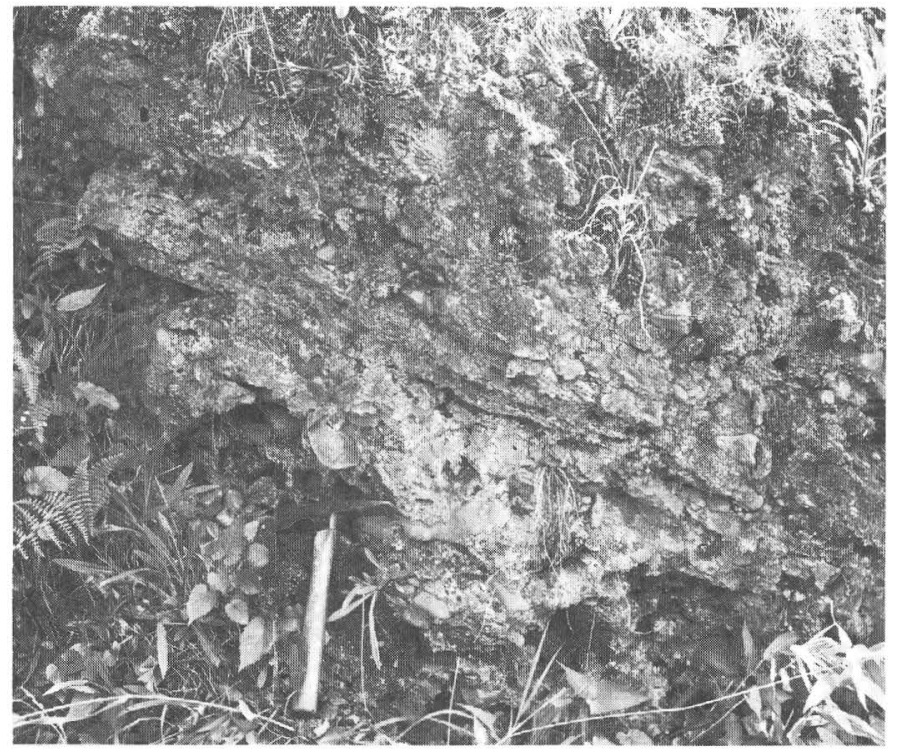

FIGURE 29. Outcrop of flow breccia on south side of Oakland Valley Road, approximately abreast the dam, Packanack Mountain, at Pompton, N.J. This relatively thin layer of flow breccia lies just under the curvilinear jointed lava at the base of the flow.

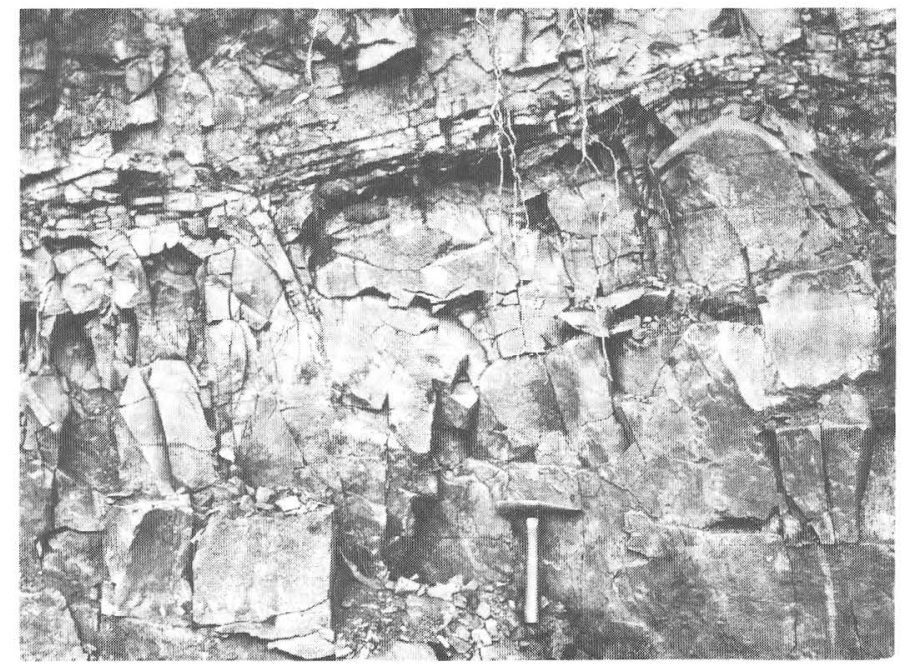

Figure 31 . Tension jointed base of the blocky zone (so-called seam), overlying the curvilinear joint system. Excavation on Northfield Avenue below Valley Road, West Orange, N.J.

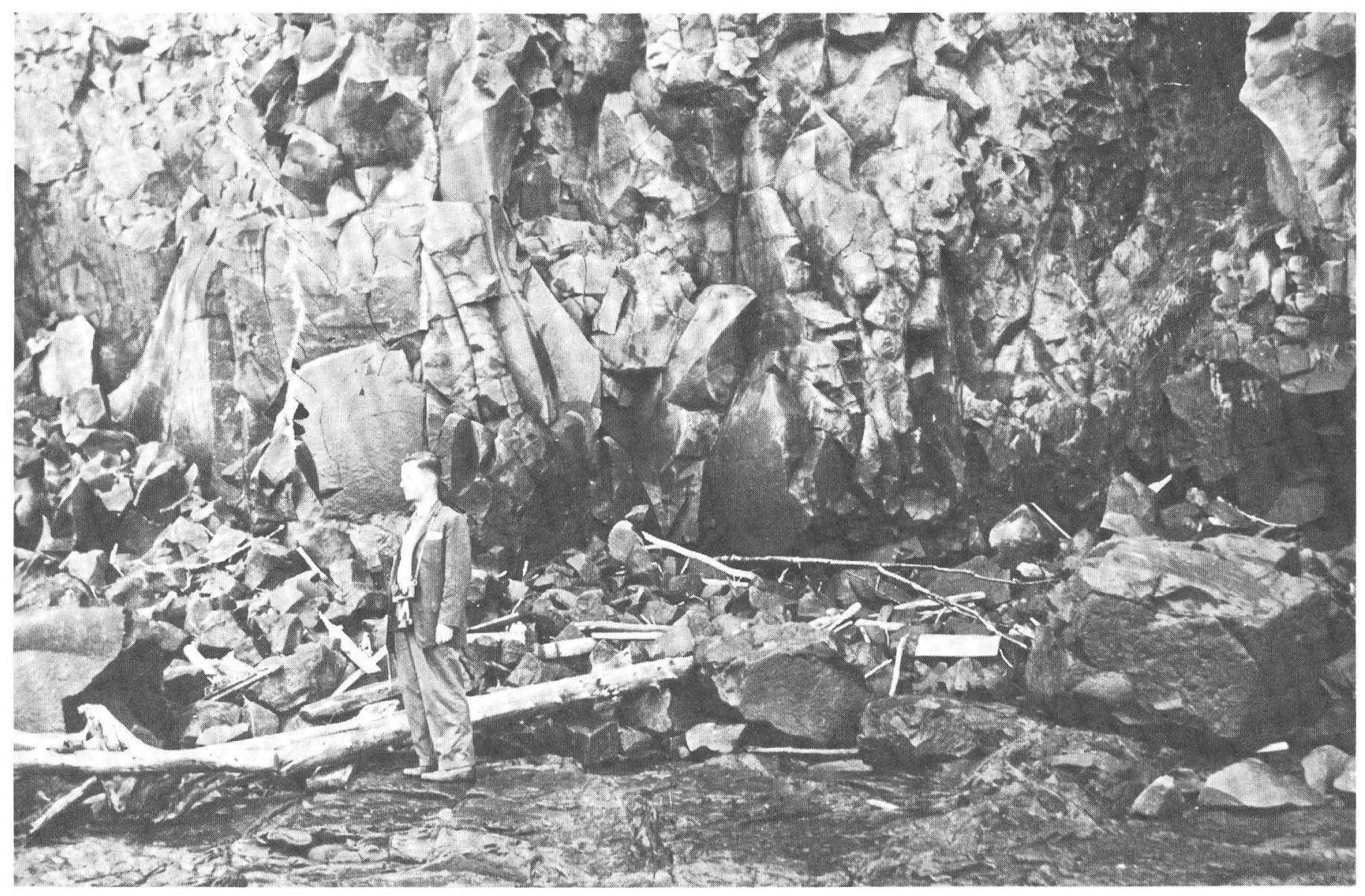

Figure 30. Curvilinear joints in the basaltic lava flow exposed on the Bay of Fundy at Canada Creek, near Black Rock Lighthouse, Nova Scotia. The geologist is standing on the columnar top of the lower flow unit. 


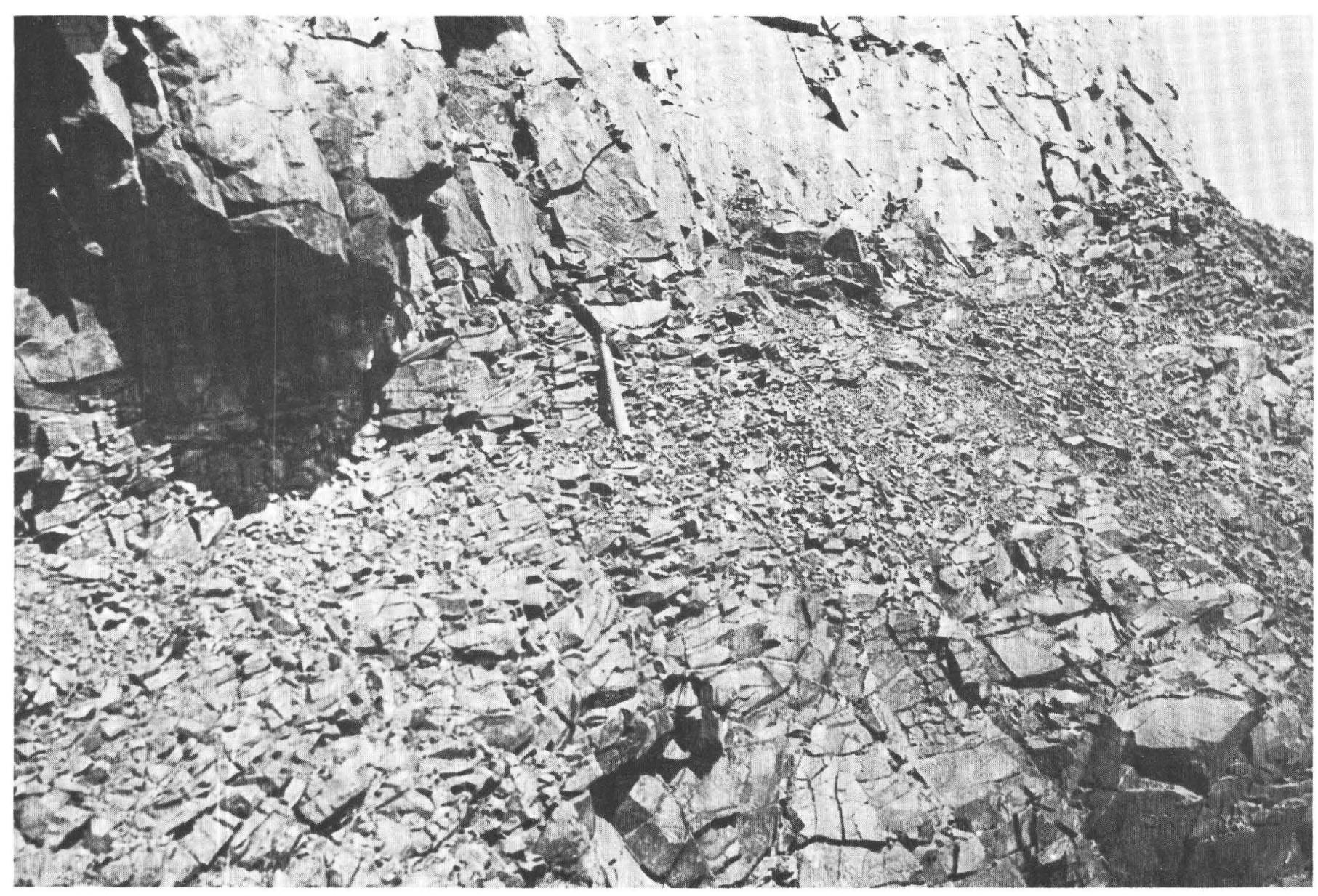

FIGURE 32. Detailed view of the tension jointed base of the blocky layer overlying the curvilinear zone. "East" wall, of the Millington quarry.

joints is well shown in figure 43 , which is a photograph that was taken looking down on the upper surface of the sheet joints. A similar stairlike morphology, developed by erosion on rocks in Sweden gave rise to the name trap from the Swedish "Trappar" (= steps) (Rosenbusch, 1923, p. 440; Kemp, 1929, p. 286).

Curvilinear joints in the quarry at Millington, which is south of the terminal moraine, do not show these planar joints cutting across the curvilinear surfaces. (See figs. 20 and 28.)

\section{WEATHERING JOINTS AND ASSOCIATED PHENOMENA}

\section{SPHEROIDAL JOINTS}

In the upper portion of the columnar zone, in places where weathering has been thorough, a "spheroidal jointing" is commonly observed. I have found zones of spheroidal weathering only below the surface. The symmetry of the weathering pattern, one in which the edges and corners of the columns have been completely destroyed leaving a sequence of concentric shells in successive stages of disintegration surrounding a hard central core, strongly suggests that the alter- ation process is not surficial but takes place below the surface. I have also observed spheroidal weathering in weathered shear zones made up of jointed blocks a foot or so wide and a foot or two long and weathering at a depth of 20 feet $( \pm)$ below the surface. This observation suggests that the symmetry of the joint block may exert a control on the rate of disintegration.

In unworked sections of a quarry where spheroidal weathering can be seen exposed in the walls, "exfoliation boulders," the firmest remnants, may be observed in the talus pile. These consist of the concentric spheroidal layers about a central core. Such "exfoliation boulders" a re also observed in shallow excavations. Eventually these concentric layers peel off leaving a spheroidal corestone. These residual spheroids range in size from 2 to 6 inches in diameter. Locally, they have mistakenly been considered by some people to be spent cannon balls from the Revolutionary War. Such remanants of weathering may be relatively fresh on the inside, see figure 44.

Sosman (1916, p. 229) does not believe that spheroidal weathering is due solely to the rounding off of joint blocks but that some original structure within the columns is also 


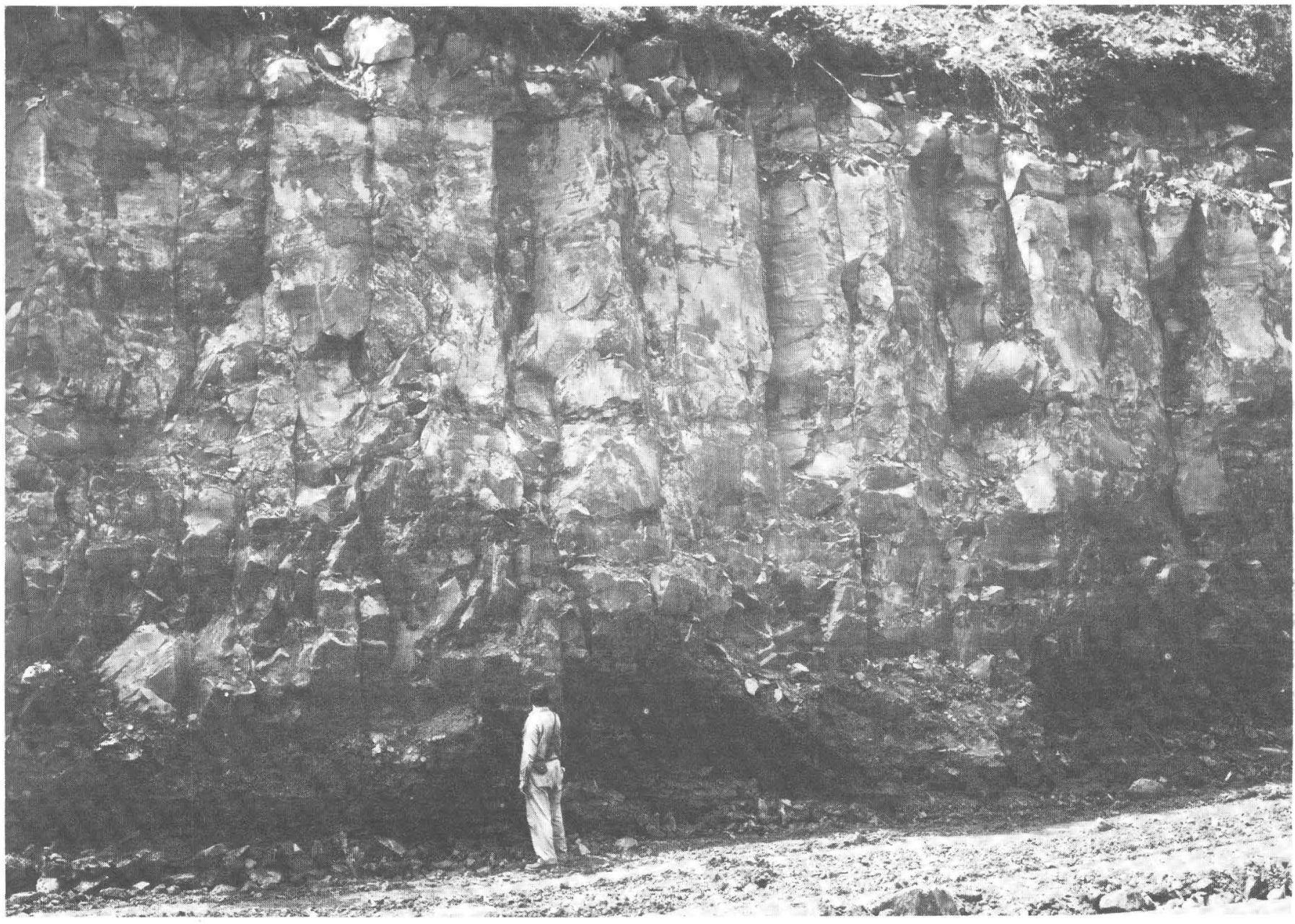

FIGURE 33. Typical pseudocolumnar appearance in the curvilinear zone produced by the superimposition of tectonic planar vertical joints on the curvilinear system. Excavation on Northfield Avenue, below Valley Road, West Orange, N.J.

exerting an influence in determining the shape. This opinion is probably based on the observations of the shells which make up the so-called "spherical joints" described by Lewis (1909) from an occurrence in a quarry, at Stirling, in Second Mountain, shown in figure 45 .

\section{LATE STAGE, UNILADING "PLATY JOINTS"}

A second set of "platy" joints, approximately horizontal, oriented parallel to the present surface are noticed throughout the Watchung flows. These joints are commonly barely visible, and only become so as weathering proceeds, or excavating and quarrying are done. In relatively fresh outcrops many of these joints are probably blind. ${ }^{3}$ In some excavated roadcuts and quarries they are, however, well developed near the surface. This system of joints is of a lower order of magnitude than the previously described basal platy joints of tectonic origin occurring near the base of the flow. They are

They are discontinuous and stop abruptly

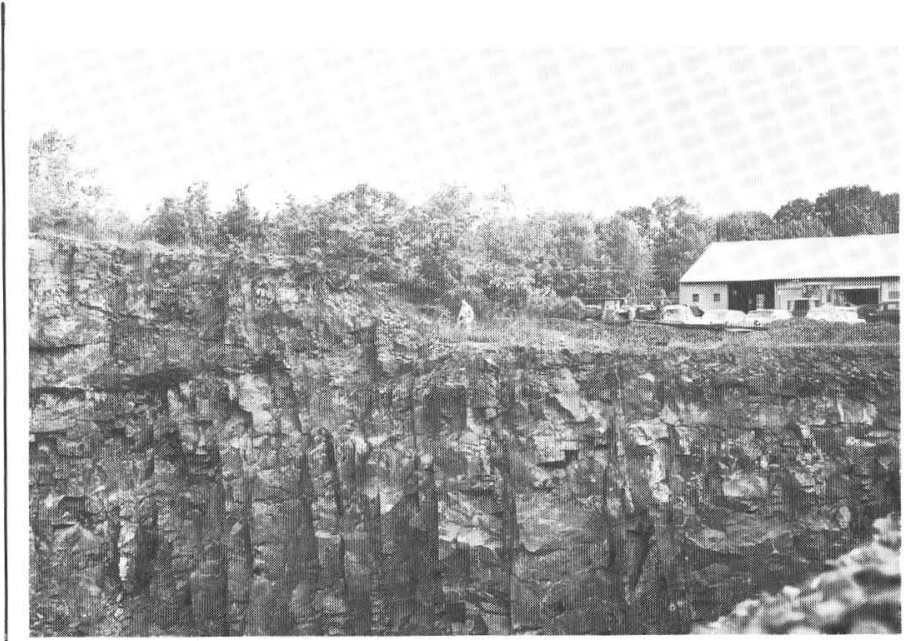

FIGURE 34. Pseudocolumnar joints produced by the superimposition of tectonic joints on the curvilinear jointing system in the north wall of the Millington quarry, Millington, N.J. The tectonic joints are very rare in the overhanging ledge of the blocky systems, in this photograph. This is the appearance of the pseudocolumns in a freshly blasted exposure. 


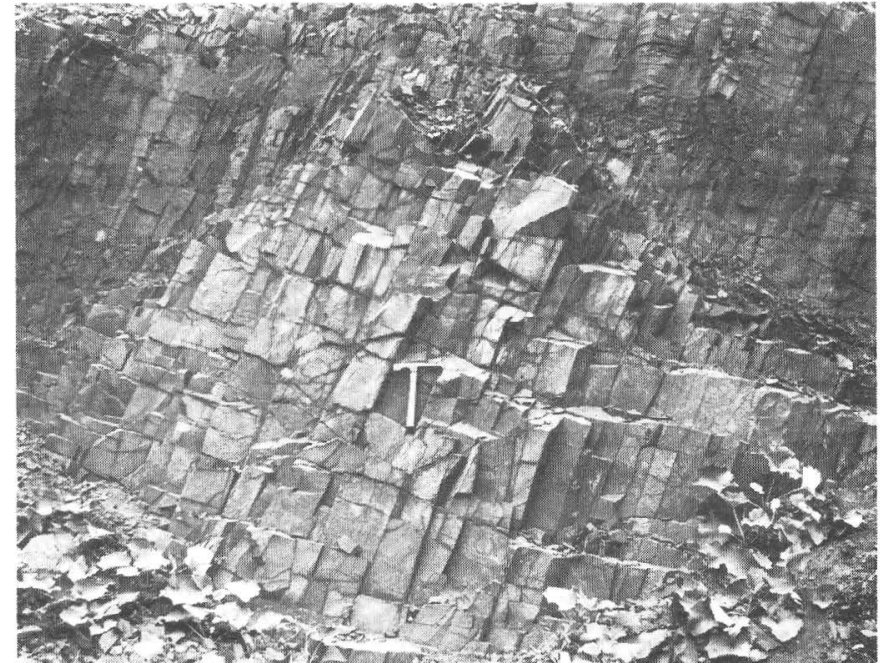

FIGURE 35. Platy-prismatic joints (fracture cleavage) in Second Watchung Mountain. Alward's quarry at the intersection of Pill Hill Road and Meeker Road about $2 \frac{1}{4}$ miles west of Basking Ridge, N.J. These joints are close to the contact with the Triassic sedimentary rocks below.

characteristically short in length, very thin, and some may be slightly curved. Generally they are not as well developed as the typical tectonic joints. Observations, made over a period of years, suggest that many of these approximately horizontal joints were incipient joints. That is they represented areas which had long been in a state of stress. Some of these stresses could have originated totally, or in part, as a result of the local faulting which took place along the walls of the horst at the time the border syncline was formed. When the basalt was exposed by weathering the areas in a state of stress altered more rapidly than the unstressed areas, and this disequilibrium permitted the rocks to separate along planar surfaces to relieve the accumulated stress.

In quarries or in zones of excavation, the removal of the overburden involving much scraping, by power shovels, bulldozers, and other heavy machinery may add additional stress to the already stressed areas near the surface and thus may aid in the formation of these approximately horizontal joints. Blasting and bumping of the quarry walls by the power shovels may also be significant contributory factors in producing or emphasizing these joints. On the "north wall" of the quarry at Millington, N.J., near the surface there are some approximately horizontal joints of this type, figure 46. Their short length is apparent.

\section{SOLIFLUCTION, A DISTORTING AGENT OF JOINTING PATTERNS}

Early in this study of jointing it was noticed that a distortion of the joint systems was sometimes observed on the scarp slope of Third Mountain. Close inspection showed, however, that a supposed change in attitude of the joint prisms on these slopes was unreal and arose from the creep of

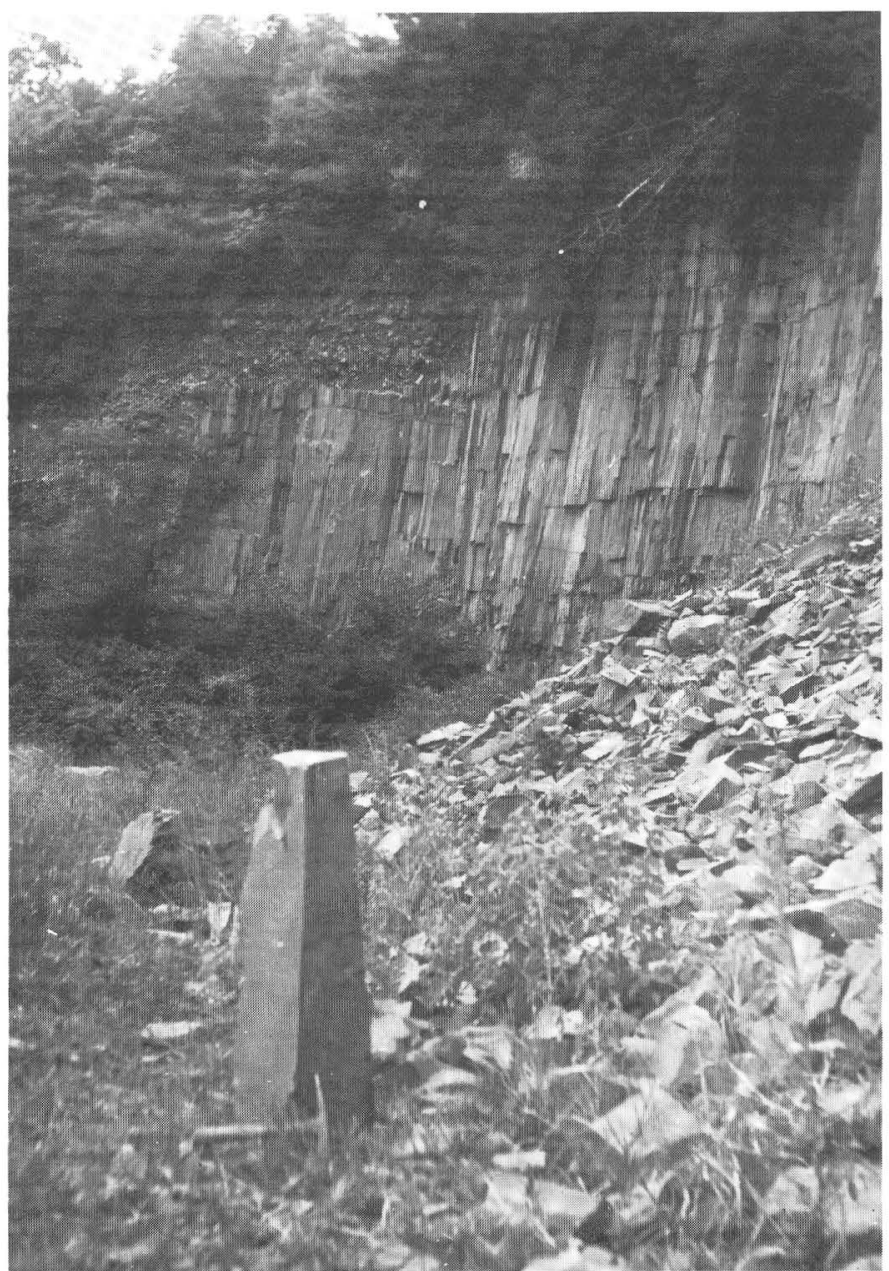

FIGURE 36. A view of the zone of the platy-prismatic tectonic joints on Second Watchung Mountain. Musialowski's quarry on Washington Valley Road, northwest of Martinsville, N.J. Note the curvature of the sides, of the back joint face, in profile. The fracture cleavage here shown in the walls of the quarry has its acute angle bisected by a line parallel to the axis of the major syncline.

the mantle down the steep slope. Such a gradual movement was accomplished by (1) alternate freezing and thawing, (2) alternate wetting and drying, and (3) by a slow movement of the whole system, of joint "blocks," interstitial mud, and water behaving more or less as a unit, down the slope. This type of movement, called solifluction or hill-wash, contrasts with that sometimes observed in quarries along the steep faces especially in areas recently artificially disturbed at the top. Here (1) the rainfall and drainage wash out much of the finer materials in the disturbed top (2) drying conditions remove most of the water and dry out the remaining mud and loose materials which served as an adhesive between the joint "blocks," and (3) the whole loose mass suddenly collapses and tumbles to form a conical pile at the quarry bottom.

In some roadcuts or excavations where small faults, of 


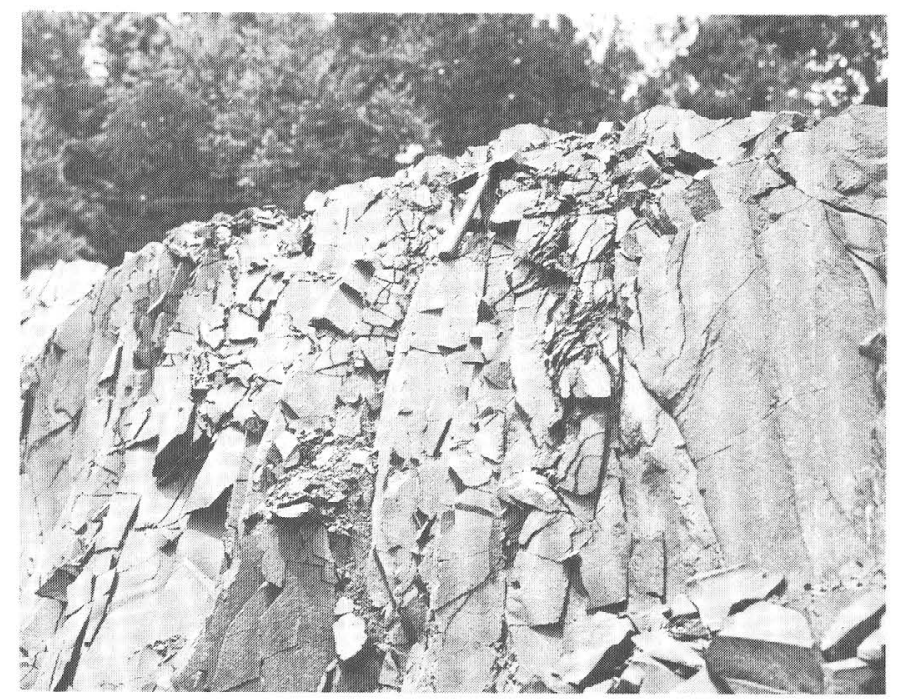

FIGURE 37. The platy surface of the curved platy-prismatic joints (fracture cleavage) developed in or near to the axial plane of the tightly folded syncline in the New Germantown trap sheet, 1.2 miles southwest of Oldwick, N.J.

postglacial age, appear in the unconsolidated sediments on the scarp slopes which overlie the separated joint blocks, the smaller joint "blocks" were observed to have moved out of their primary alinement. All of these occurrences were easily recognized by close inspection at the outcrop to be distortions of the true relationships.

Solifluction probably was enhanced on Third Mountain at the close of the glacial period when the North American ice sheet began to melt and Lake Passaic formed. At this time the waters began to spill over the sides of the scarp slope.

To determine whether the joints on the scarp slope of

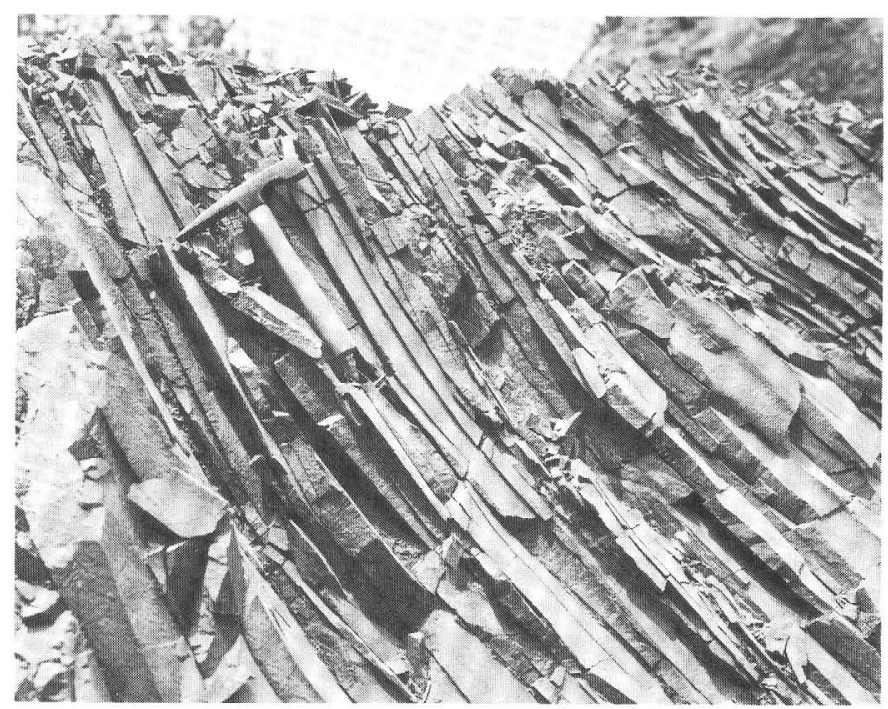

FIgURE 38. Side view of the curved platy-prismatic joints (fracture cleavage) New Germantown trap sheet, 1.2 miles southwest of Oldwick, N.J.

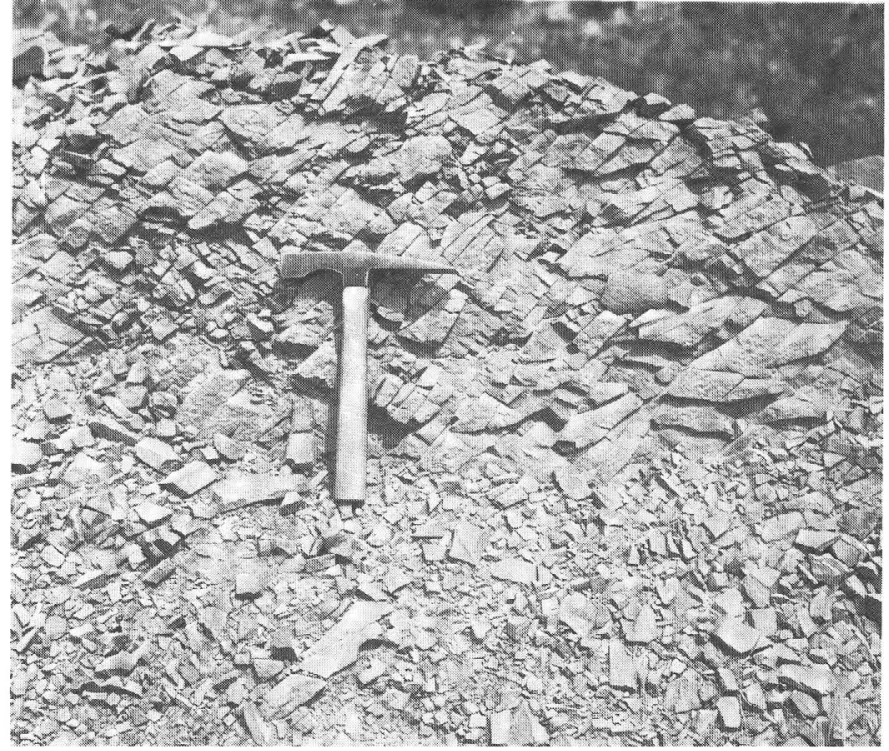

Figure 39. Top view, showing the prismatic cross section of the curved, platy-prismatic joints (fracture cleavage). New Germantown trap sheet, 1.2 miles southwest of Oldwick, N.J

Second Mountain are disturbed is a more subtle and perplexing problem to the observer. These joints can be misleading, they look very natural in exposures on a slope in which only a few feet in depth are seen, and they resemble closely certain aspects of true radial columnar joints as those shown in figures 9 and 10. Close examination of the exposures on the scarp slope, which are limited in depth, discloses a much wider separation of the joint prism than is normally observed, and the presence of finer material in the openings. These criteria suggest movement. The best evidence of movement is seen in an undisturbed wall of a quarry, pit, or excavation, essentially normal to the strike, where the tilting of the columns and their movement "en masse" down the slope is clearly apparent; such a slope is shown in figure 47.

\section{A JOINTING MISCELLANY}

\section{FEATHER-FRACTURE (PLUMOSE FRACTURE) AND OTHER SURFACE PATTERNS ON JOINTS}

Feather-fracture, so-named because of its barblike or plumose structure, was amongst the earliest type of surface feature of joints described in the rocks of Eastern North America. Woodworth (1896, p. 178) in an excellent paper on joint surfaces, particularly their macroscopic features, describes in detail feather-fracture occurring on the joints in the trap of the Somerville quarry at Somerville, Mass. Woodworth $(1896$, p. 165) defined these fractures as follows: The granulations of the surface of a joint-plane when organized take on the form which I have been accustomed in fieldwork to call "feather-fractures" [he states further] Feather-fracture is not limited to true joint-planes, but is traceable on the surfaces of other divisional planes as I shall show below. On the typical 


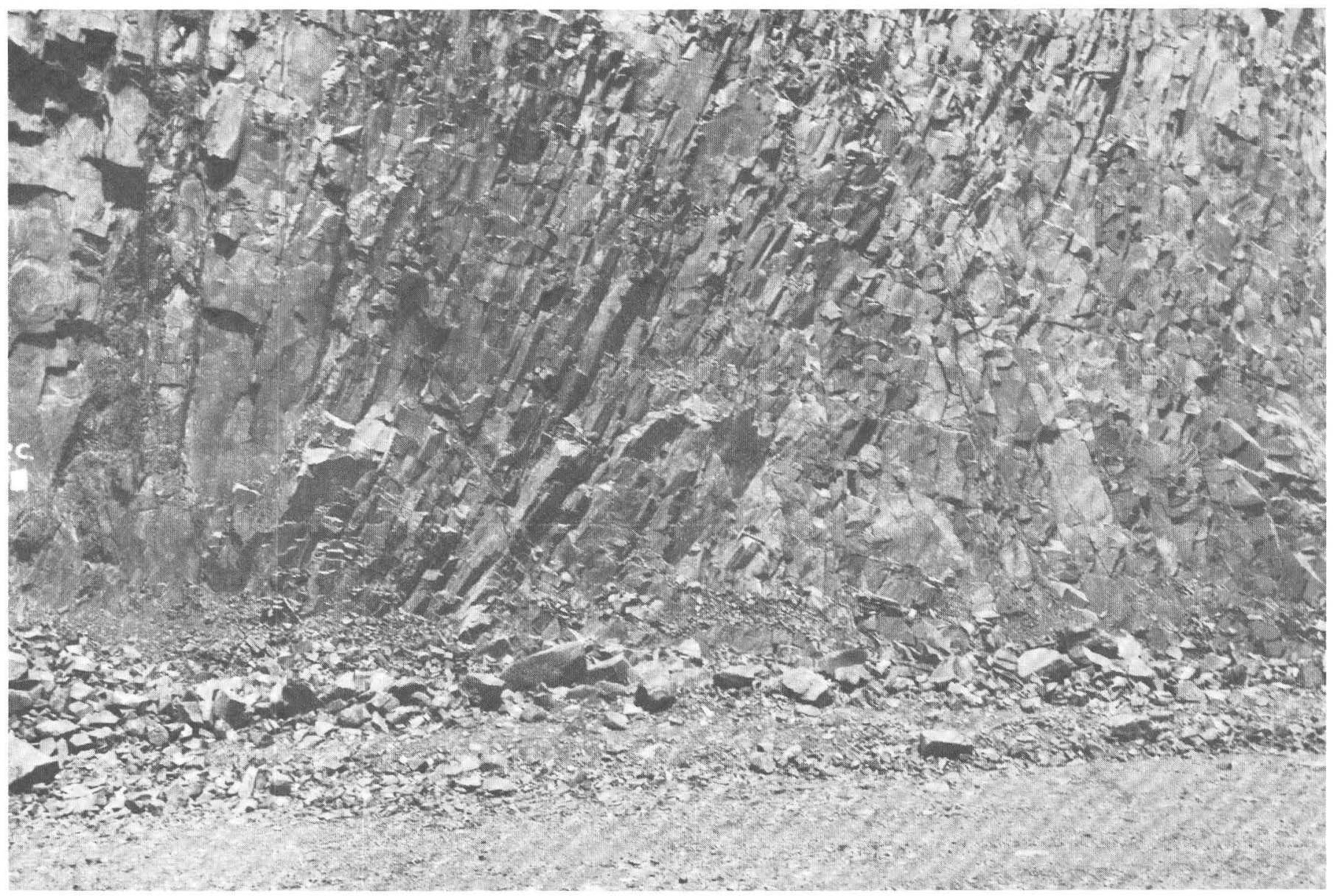

Figure 40. Very abundant platy-prismatic joints on Second Mountain. The conjugate set of tectonic joints are so abundant that it is difficult to recognize the cooling joints. This section was formerly exposed in the cut for U.S. Highway No. 78 near Pluckemin, N.J. The outcrop is just above the contact with the underlying Brunswick Formation.

joint-planes of the Mystic quarry district, ${ }^{4}$ feather-fracture is a delicate tracery of feathery lines diverging from a roughly outlined axis which traverses the face of the joint-block in a plane parallel with the stratification. When the axis of the feather-fracture departs from this plane, it becomes sinuous. In the massive rocks, it is characteristically sinuous. Woodworth also described discoidal joints and percussion rays appearing on specimens of argillite.

Sosman (1916, p. 230) noted the presence of feather patterns on some basalt prisms and suggested that they might be due to contraction. Feather fracture and other surface patterns have recently aroused interest amongst students of rock jointing, and papers by Roberts (1961) and Hodgson (1961) have modified and developed the approach of Woodworth (1896). Price (1966, p. 120-126) and Bankwitz $(1965,1966)$ give further data and interpretation.

I have seen excellently developed feather fractures in the curvilinear layer of the upper flow unit of Third Mountain at

\footnotetext{
+ Cambrian slates.
}

Pine Brook, N.J., and in both the upper and lower flow units of Second Mountain at many localities. The fractures are commonly 2 square feet or more in area. A fine example is shown in figure 48 . Here the axis of the fracture was oriented vertically.

Other types of surface patterns are occasionally observed, but most were too incomplete to describe. A particularly well-developed surface pattern on a curvilinear surface was found on a joint wedge at the floor of the Millington quarry after a wall had been blasted down. It is shown in figure 49 .

This specimen was part of a larger joint surface, and it was not possible to trace its former position in the quarry wall, so that there is no knowledge of its orientation and location except that it came from the zone of curvilinear joints. A description of this rather large individual is given here because of the unusual clarity of its details. The fracture surface occupies an area of $17 \times 25 \mathrm{~cm}$. It is a warped surface, best described as billowy. The surface itself is contained in a volume, roughly a parallelepiped of $17 \times 25 \times 2 \mathrm{~cm}$. Its whorls 


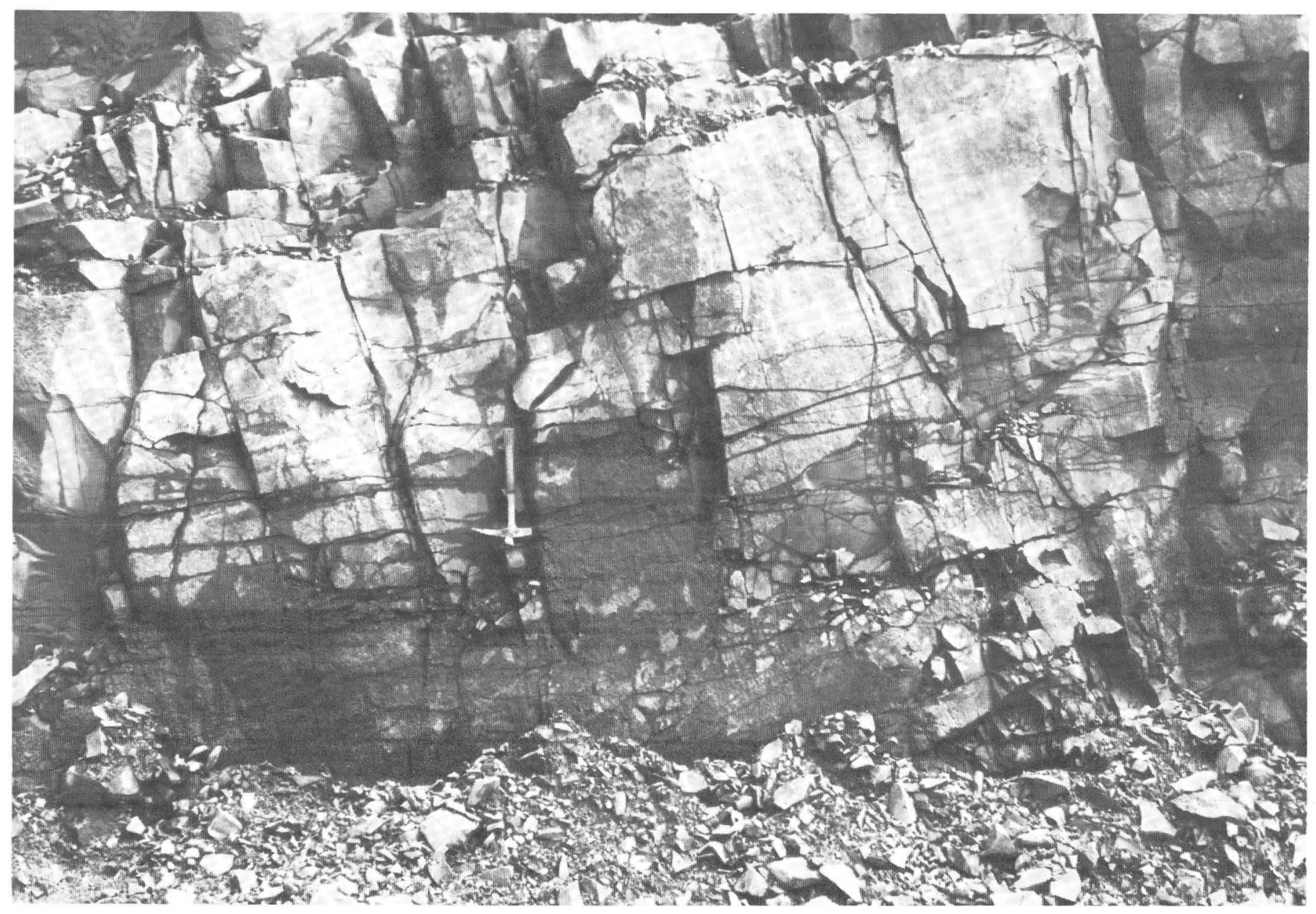

FIGURE 41. Basal platy joints at the base of the curvilinear layer, just above the contact with the hornfelsized Brunswick Formation. In cut, in Second Watchung Mountain, on U.S. Highway No. 280 at its intersection with Pleasant Valley Way, West Orange, N.J.

widen counterclockwise so that its direction of obliquity is sinistral. The widest whorl increases from a few millimeters on the left to nearly $2 \mathrm{~cm}$ on the right. If the lowermost portion of the specimen, where there is a decided change in slope, is taken as the shoulder, then the b-planes (borderplanes) of Woodworth and the c-planes (cross fractures) of Woodworth (1896) can be seen at the lower left-hand side of figure 49. The b-planes (called F-joints by Hodgson, 1961) make an angle of about $5^{\circ}$ with the shoulder. The whole surface pattern has a general conchoidal appearance. Woodworth in discussing discoidal joints describes a surface that resembles this one as "The warped surface thus formed may in some specimens be likened to the rim of a soft hat curled up behind and pulled down in front." The whole surface is covered with a brownish patina showing that it represents a former part of an old quarry wall.

Despite the size of this surface, there is not a sufficient amount of critical detail, particularly the presence or absence of a bulb of percussion, to decide whether this repre- sents (1) a type of discoidal joint or (2) a percussion figure developed in the older method of quarrying using bars and sledges, or by blasting. From observations of similar surfaces on the old walls of quarries the evidence given here suggests that this surface may be a part of a percussion ray.

\section{WIDTH OF JOINT OPENINGS}

The width of joint openings is of interest to geologists studying the fracture characteristics of rocks. Such measurements are most significant when the effects of a single process such as the cooling of a lava flow or the effects of a single tectonic event can be evaluated. The width of openings of cooling joints is best made on recent lava flows. The Watchung Basalt flows are of Late Triassic age and have been subjected to some metamorphism-at least to the zeolite facies and possibly to the green schist facies. The cooling joint openings were disturbed by the tectonic deformation of the graben. Some cooling joints were reactivated as tectonic 


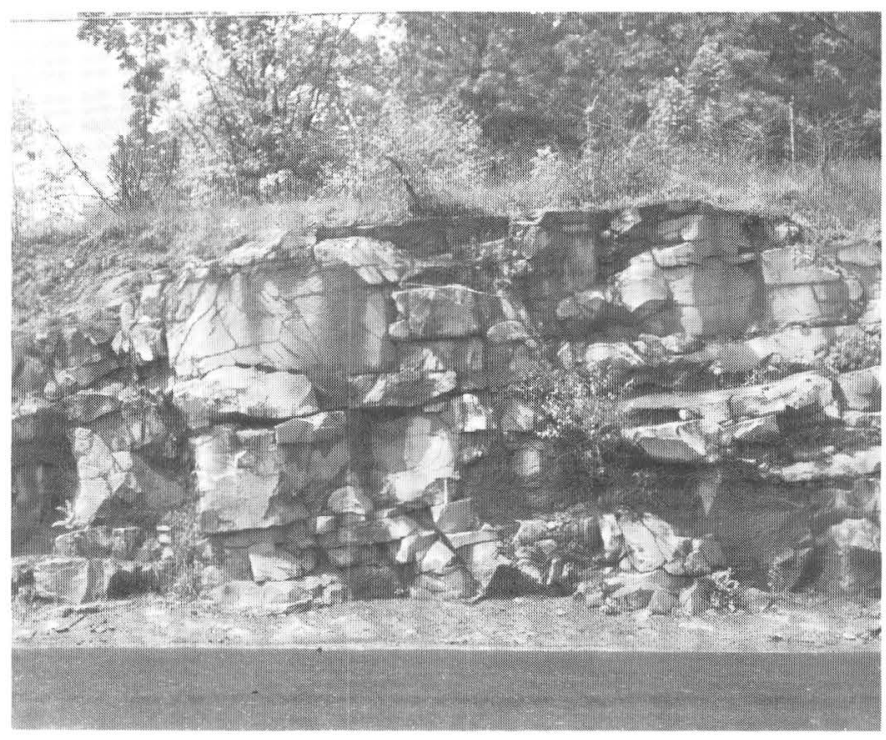

FIGURE 42. Sheeting joints in the transition zone between the blocky and the curvilinear zone of the basalt flow of Hook Mountain. This figure represents a view showing a section essentially at right angles to the strike. The roadcut, on Bloomfield Avenue in Pine Brook, is roughly east-west.

joints. As a result the present-day width of the cooling joints bears little relation to their original width.

To gain some idea of the order of magnitude of cooling joint widths in a relatively recent lava flow $(8,000$ years \pm ) measurements were made, in 1971, on the fault wall of the flow at Thingvellir, Iceland. ${ }^{5} \mathrm{~A}$ mechanics gage with a

Age data-Written communication from Dr. Gudmundur Sigvaldason, Feb. 22, 1974

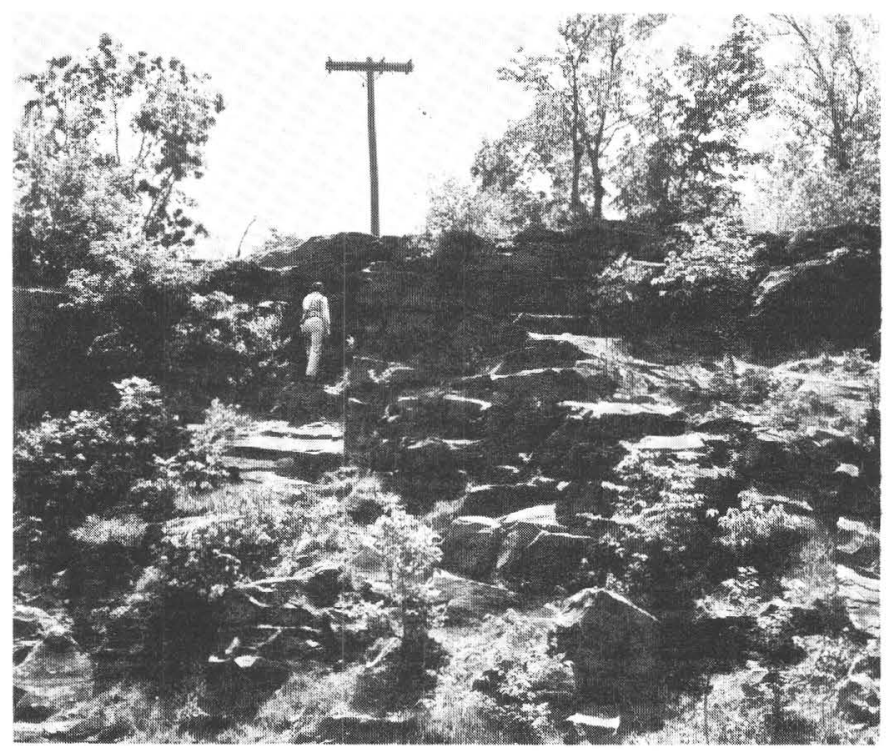

FIGURE 43. Sheeting joints in the blocky and curvilinear jointed trap of Hook Mountain. The steplike aspect is clearly evident. Quarry near the northern end of Hook Mountain near Mountain View, N.J.

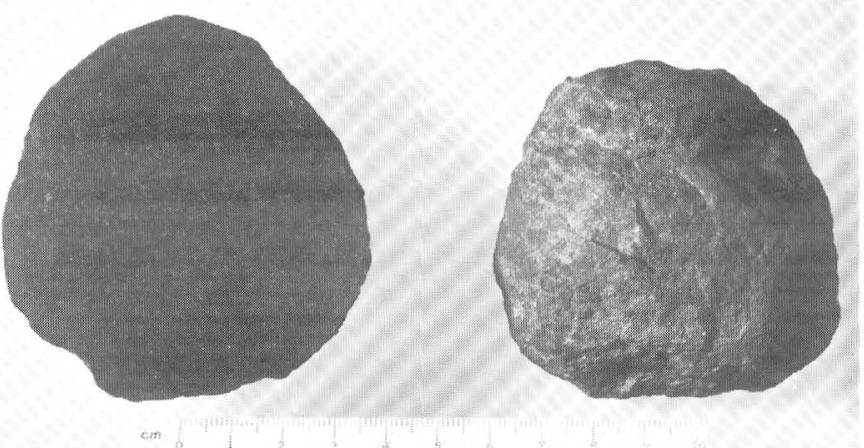

FIGURE 44. Spherical balls found in the deeply weathered columns of trap, near the surface. A ball 3 inches, $7.5 \mathrm{~cm}$, in diameter was cut and polished to show the "fresh" character of the minerals.

minimum thickness of 0.0015 inch $(0.0381 \mathrm{~mm})$ was used to make the measurements. Good quality joints, 111 in all, were measured. A group of 54 joints were found that were smaller than the smallest element of the mechanics gage -0.0015 inches $(0.0381 \mathrm{~mm})$. These joints ranged from those just thinner than 0.0015 inch $(0.0381 \mathrm{~mm})$ down to those very thin joints that were closed by a thin film of altered material. A total of 57 joints were found to be in the range of $(+) 0.0015$ inch $(0.0381 \mathrm{~mm})$ up to those having a width of $0.0240 \mathrm{inch}$ $(0.610 \mathrm{~mm})$. If we assume that the distribution of joints less than 0.0015 but greater than zero is similar to the distribution of the joints between 0.0015 and $0.0240(0.610 \mathrm{~mm})$, then an inspection of these data suggests that the joint openings yield a flat symmetrical curve with a nearly perfect assortment of joint widths. This distribution curve was unexpected. The sample may be too small and the inclusion

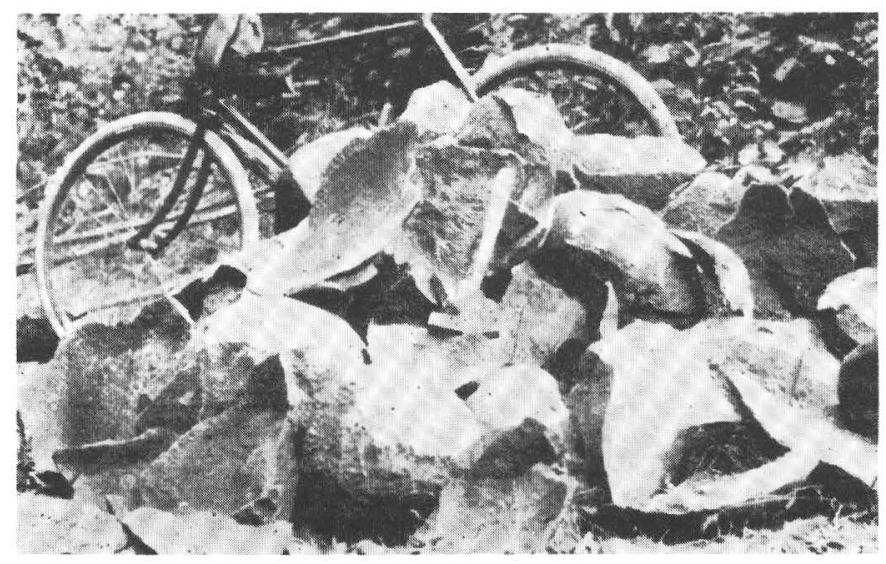

FIGURE 45. "'Spherical jointing"' in basalt produced by weathering. Quarry 21/2 miles south of Stirling, Second Mountain. Taken from Lewis (1908, pl. 38, fig. 1). 


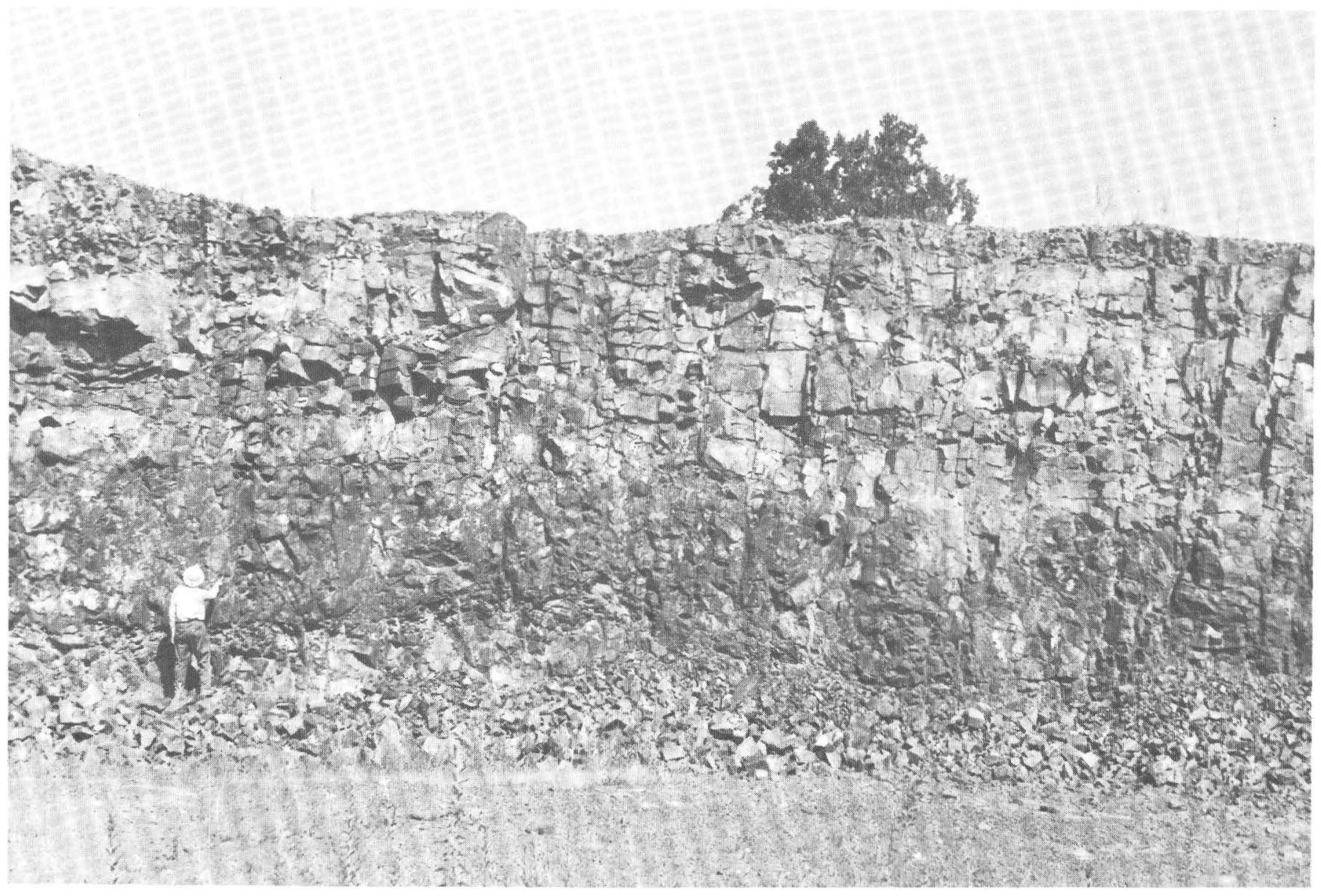

FiguRE 46. Late stage, unloading joints, probably developed in prestressed areas close to the surface of the earth. Their development may have been aided by weathering processes relieving stress, by man induced stresses inherent in blasting, excavating, and machine scraping or bumping operations. "North wall," Millington quarry and plant of the Houdaille Industries, Inc.

of the weathered closed joints may have biased the interpretation. Nevertheless, these data do suggest the order of magnitude of the pristine joint widths.

The measurements of the cooling joints at the Thingvellir in Iceland suggest the probable order' of magnitude of the openings of the cooling joints in the Watchungs. In the Watchungs many of these joints which now appear tight were actually once open but water percolating along them has altered them and closed them. It is commonly possible to see some evidence of alteration indicated by a border zone of a different color and frequently a bleached appearance.

The width of opening of the tectonic joints reached larger values up to one-half inch $(1.2 \mathrm{~cm})$. Good evidence of the width of opening of tectonic joints is to be observed in the widths of the mineralized veins that fill them. Detailed measurements on these veins have been made in all three of the Watchung basalt flows.

The width of opening of weathering joints is generally much larger than that of the other types of joints. In weather- ing zones alternate freezing and thawing in the winter season and heating and cooling in the summer season spring apart the joint blocks producing ever wider gaps.

Geologists, hydrologists, geological engineers, and civil engineers are interested in the width of joint openings as they exist at the time of the "joint survey." Such measurements may give valuable information on the permeability of a rock and on the stability of rock slopes.

\section{QUASI-GEOLOGIC JOINTS AND NONGEOLOGIC PSEUDOJOINTS AND FRACTURES}

The rocks close to the surface of the earth are commonly in some state of stress, Hast (1967), Voight (1966, 1969a, b). Hooker and Johnson (1967) measured the "in situ" stress in several distant parts of the Newark graben particularly in the Triassic diabase at Nyack, N.Y., St. Peters, Pa., and Rapidan, Va., at depths of 0.5 feet $(15 \mathrm{~cm})$ to 4.9 feet $(1.5 \mathrm{~m})$ and 


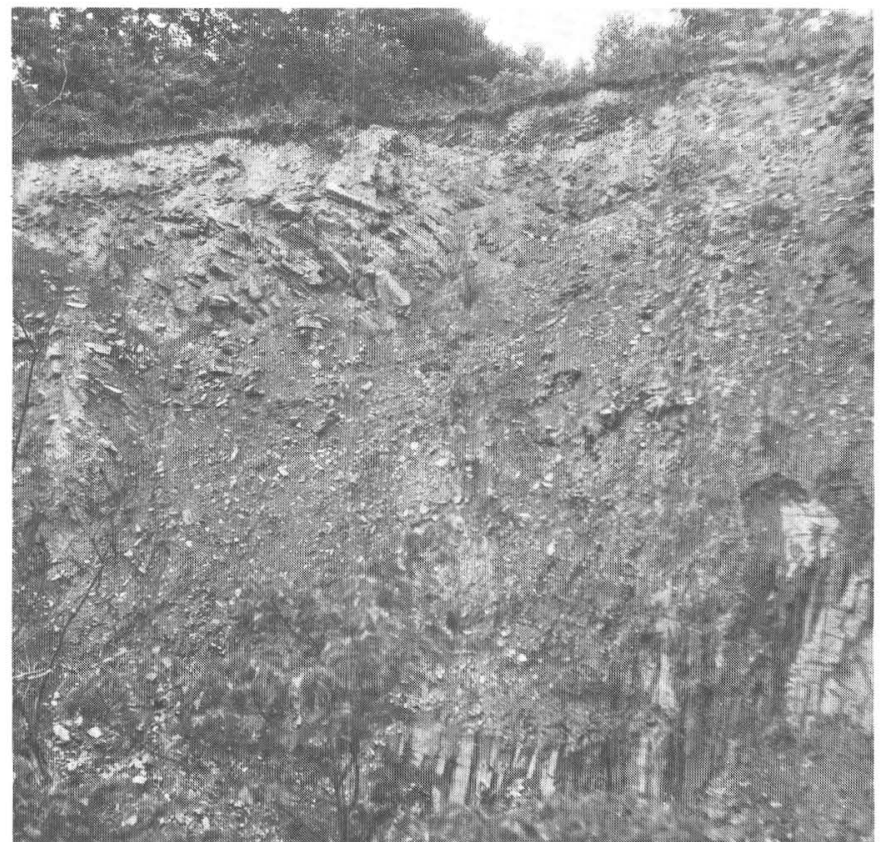

FIGURE 47. Effects of solifluction are shown in the wall, which is essentially normal to the strike. This is shown in Tullo's quarry on Washington Valley Road, near Martinsville, N.J. The creep of the mantle down the slope has tilted the pseudocolumns, from their normal position shown at the base, to head downslope.

found secondary stresses that are compressive with values of $173 \mathrm{psi}\left(12.2 \mathrm{kgf} / \mathrm{cm}^{2}\right)$ to $1,660 \mathrm{psi}\left(117 \mathrm{kgf} / \mathrm{cm}^{2}\right)$. The existence of stress in the Triassic sandstones of Connecticut was dramatically demonstrated in the early development of the

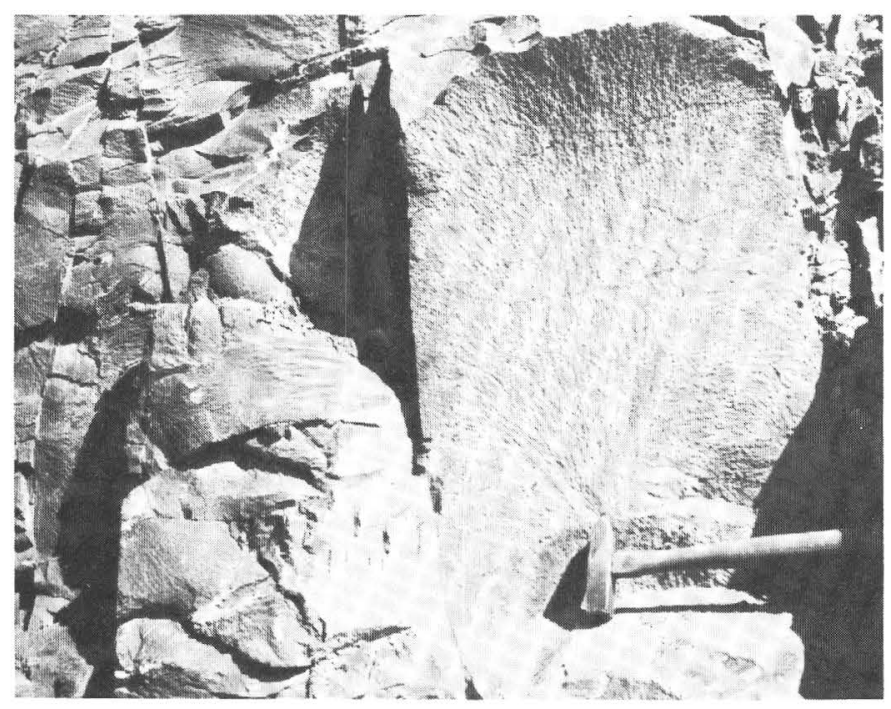

FigurE 48. Feather fracture developed on a curvilinear joint surface. Upper flow unit, Hook Mountain of Third Mountain, Pine Brook, N.J. The sharp end of the hammer is at the basal point of the feather.

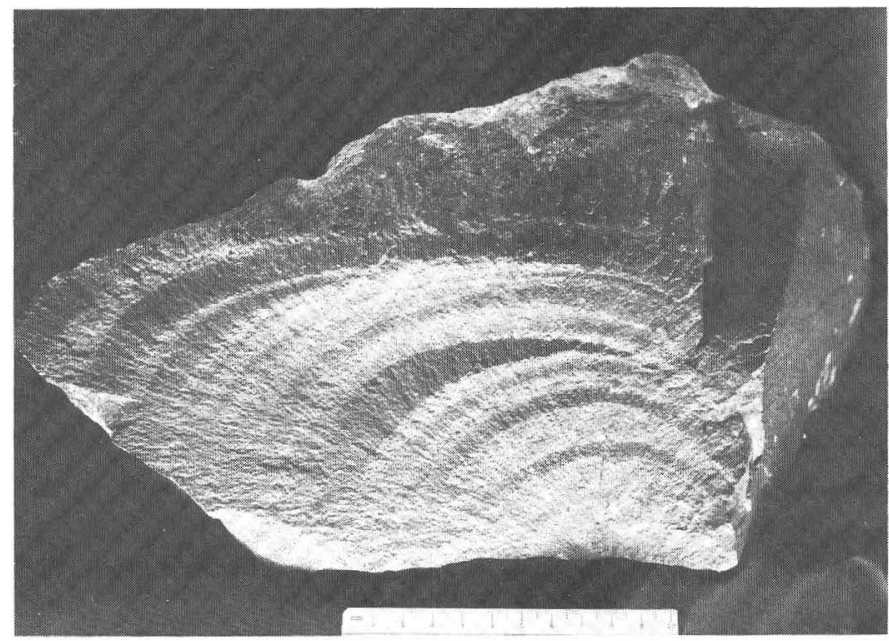

FIGURE 49. Fracture pattern on a joint wedge broken out of the curvilinear zone at the Millington quarry (Houdaille Industries, Inc.), Millington, N.J. The scale is $10 \mathrm{~cm}$ long.

"Brownstone" quarrying operations in Portland. Johnston $(1854$, p. 285,286$)$ describes the instantaneous release of the stress as follows:

The first instance observed occurred some two or three years ago, and occasioned some alarm among the workmen. The excavation had then reached the depth perhaps of one hundred and twenty feet from the original surface of the ground; and a beginning was to be made in the stratum then constituting the bottom of the cavity that had been formed. For this purpose the workmen were directed to cut with their picks a channel or groove, a foot or more wide, quite through the stratum, and some fifty or eighty feet in length. To facilitate the operation, the work was begun by the side of one of the natural joints or seams that occur at intervals, crossing the strata nearly at right angles; and as several workmen commenced upon it at the same time, all along the line it was made to sink with about the same rapidity, the loose fragments being thrown out as they were separated by the instrument. The stratum was found to be about six or seven feet in thickness, and it happened that the channel or groove was cut in an east and west direction. When the channel inad been sunk to within about nine or twelve inches of the bottom of the stratum, suddenly the remaining stone at the bottom was crushed to fragments with a loud report by an enormous lateral pressure, and the men in alarm leaped from the excavation they had made. By examination it was found that the walls of the groove or canal just made had approached each other about three fourths of an inch, the stratum through which they had cut having on one side slidden this distance in its ancient bed!

These observations in the rocks of the Triassic basins indicate that the rocks are in a state of stress above that to be expected from the lateral component of stress associated with gravitational loading. The magnitude of this stress is, by itself, incapable of producing joints but it may produce regions of incipience.

The application of stress by various engineering operations may provide the small amount of energy necessary to climb over an energy barrier and thus open up the incipient joints in these rocks. These joints may be very difficult to recognize in very shallow cuts but in somewhat deeper cuts these joints may be visible, and it may be possible to observe a reduction in the frequency with an increase in depth in the 
section, and this observation may permit an evaluation of the effect. I have observed such differences in quarries.

In making frequency counts it is necessary to discriminate between joints arising from geologic processes and those caused by the works of man. Incipient joints opened up by the works of man I classify as quasi-geologic joints. ${ }^{6}$ Since some of these joints develop in a large volume of rock and are not limited to the surface of the outcrop they must be formed as a result of the application of a significant stress acting throughout a large volume. Such a stress could be generated in blasting operations.

Nongeologic pseudojoints and fractures are produced, in response to stresses developed generally from sudden shock, in the course of engineering, mining, quarrying, and construction operations. They may be produced by the action of percussion machinery-pneumatic drills and hammers, or the accidental dropping of the buckets of power shovels, etc. They may also be produced by the crushing and abrasion occasioned by the movement of heavy excavating equipment over the exposed rock or by its brushing against the walls. These pseudojoints and fractures are commonly short in length, a few inches (a few centimeters), and they may fade out into hairline cracks. They may radiate out from a burred area where the concentrated force was applied. A grouping of several fractures may produce a local hackly appearance. These pseudojoints and fractures are all confined to a thin surface layer, and in this respect they differ completely from the quasi-geologic joints. They should be tallied separately from the other joints in a joint survey. Piteau (1973) has presented methods of characterizing joints for joint surveys in engineering practice and discusses errors in measurement and gives an extensive interpretation of the data.

FREQUENCY OF COOLING AND TECTONIC JOINTS IN ONE OF THE LEAST DEFORMED PARTS OF THE BORDER SYNCLINE

The roadcut for U.S. Highway No. 80 at Pine Brook passes through the lower end of Hook Mountain, a part of Third Watchung Mountain. The roadcut for U.S. Highway No. 280 passes through the Second Watchung Mountain in the vicinity of Livingston, and through First Watchung Mountain at West Orange. These three cuts lie on a line that is nearly perpendicular to the strike of the Watchungs and at a position that is near the center of the syncline and nearly parallel to its minor axis (see figure 2, note line extends from Pine Brook to West Orange).

The joint frequencies measured along the walls of the roadcuts, for 50 feet intervals, are contained in table 1 . Most of the values are averages. All of the joints recorded are the result of geologic processes. The frequencies of the cooling

"In the discipline of Rock Mechanics stresses developed as a result of geologic processes are referred to as "virgin stresses," whereas those developed as a result of engineering operations are referred to as "induced stresses" (Oliveira, 1971). joints are not significantly different for the several joint systems within the three Watchung Mountains. The tectonic joints on the other hand show that the frequency of the tectonic joints in Second Mountain is a different order of magnitude from the frequency values in Third and First Mountains.

These data give a quantitative estimate of the frequencies of cooling and tectonic jointing. They are only a part of a more complete collection of data obtained on Third and Second Mountains and of a more limited set on First Mountain. When the study of First Mountain is completed, these data will be used in interpreting the structural relations in the border syncline.

It should further be noted that the frequency of the cooling joints in the curvilinear zone of the lower flow unit of Second Mountain is relatively constant except close to the base of the flow, near the contact, where incipient curvilinear joints were emphasized by the tectonic deformation.

\section{SUMMARY OF THE GEOMETRY OF THE COOLING JOINT SYSTEMS}

The cooling joint system of the vesicular zone consists of widely spaced basal joints and short rectangular prisms. This combination gives rise to a platy or tabular aspect. The prism joints are commonly a foot $(0.3 \mathrm{~m})$ apart, and the basal joints, in the longest direction, are of 4 to 10 times, or more, the spacing of the prismatic joints. The basal surfaces tend to be rectangular and not square.

The cooling joint system of the columnar zone, in Third Watchung Mountain, consists of a set of prismatic joints, commonly six or five sided together with capping basal joints which terminate the prisms. Many of the joints resemble hexagonal and pentagonal right prisms, but some are tapered and then seem almost pyramidal in aspect. The dimensions of the columns are variable, but they range from 8 to 10 feet ( 2.4 to $3.0 \mathrm{~m}$ ) high and 6 inches to 1 foot ( 15 to 30 $\mathrm{cm}$ ) wide.

The blocky joints are so-called because of their shape as rectangular parallelepipeds. In size they tend to be greater than $4 \times 5 \times 10$ feet $(1.2 \times 1.5 \times 3.0 \mathrm{~m})$. In some exposures they were as large as $10 \times 10 \times$ several tens of feet long $(3.0 \mathrm{x}$ $3.0 \times$ many tens of meters).

The curvilinear joints are quite variable in shape, but they all have curved faces. These curved faces are warped surfaces. They are here interpreted as helicoidal surfaces. When the large helicoidal surfaces are broken, they break up into shieldlike, wedge-shaped, and sphenoidal volumes, whose faces are curvilinear polygons. These curvilinear surfaces may vary from a few feet ( \pm meter) to 20 or more feet $(6.1 \mathrm{~m})$ in height and 5 feet $(1.5 \mathrm{~m})$ in breadth.

In making joint frequency counts it is necessary to be able to rapidly identify the type of joints being counted. One of the complicating problems arises in excavated cuts for highways, and it is important to point out these modifications introduced by the works of man. The columnar zone 
TABLE 1.-Joint frequencies in the Watchung Mountains along a line nearly normal to the strike and extending from Pine Brook on Third Watchung Mountain to near West Orange on First Watchung Mountain

\begin{tabular}{|c|c|c|c|c|c|}
\hline \multirow{2}{*}{ Flow unit } & \multirow{2}{*}{\multicolumn{2}{|c|}{ Cooling joints }} & \multirow{2}{*}{ lectonic joints } & \multicolumn{2}{|c|}{ Length of traverse } \\
\hline & & & & Feet & Meters \\
\hline \multicolumn{6}{|c|}{ Third Mountain } \\
\hline \multirow[t]{4}{*}{ Upper ----------- } & Blocky zone -- & 6 joints in 50 feet $(6 / 15 \mathrm{~m})$ & 9 joints in 50 feet $(9 / 15 \mathrm{~m})$ & 213 & 65 \\
\hline & Curvilinear zone & 72 joints in 50 feet $(72 / 15 \mathrm{~m})$ & 16 joints in 50 feet $(16 / 15 \mathrm{~m})$ & 175 & 53 \\
\hline & -_- do _-_-_-- middle to base & 56 joints in 50 feet $(56 / 15 \mathrm{~m})$ & 3 joints in 50 feet $(3 / 15 \mathrm{~m})$ & 60 & 18 \\
\hline & Vesicular base & a few indistinct joints & a few indistinct joints _... & 21 & $6+$ \\
\hline \multirow{2}{*}{ Lower ----------- } & Vesicular top -- & a few indistinct joints & 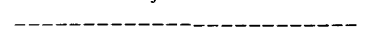 & 19 & 6 \\
\hline & Columnar zone & 20 columns in 19 feet $(20 / 5.8 \mathrm{~m})$ & 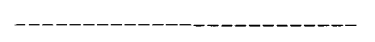 & --- & --- \\
\hline \multicolumn{6}{|c|}{ Second Mountain } \\
\hline \multirow[t]{6}{*}{ Lower --_-------- } & Curvilinear zone --- top & 45 joints in 50 feet $(45 / 15 \mathrm{~m})$ & 14 joints in 50 feet $(14 / 15 \mathrm{~m})$ & 400 & 122 \\
\hline & --- do $----{ }_{-}$middle ---- & 25 joints in 50 feet $(25 / 15 \mathrm{~m})$ & 91 joints in 50 feet $(91 / 15 \mathrm{~m})$ & 800 & 244 \\
\hline & --- do & 73 joints in 50 feet $(73 / 15 \mathrm{~m})$ & 150 joints in 50 feet $(150 / 15 \mathrm{~m})$ & 450 & 137 \\
\hline & --_ do & - & o & --- & --- \\
\hline & _-_ do _-____ joints _-_-_ & --_- - - - - - - - & 10 joints in 12 feet $(10 / 3.7 \mathrm{~m})^{\prime}$ & 12 & 37 \\
\hline & $\begin{array}{l}\text { Shale and sandstone of the Brunswick } \\
\text { Formation below Second Mountain. }\end{array}$ & -n-n-n & 7 to 10 joints in 50 feet $(7-10 / 15 \mathrm{~m})$ & 100 & 30.5 \\
\hline \multicolumn{6}{|c|}{ First Mountain } \\
\hline \multirow[t]{5}{*}{ lower -------- } & "Blocky zone" (Massive)2 & 3 joints in 100 feet $(3 / 30 \mathrm{~m})$ & 10 joints in 50 feet $(10 / 15 \mathrm{~m})$ & 260 & 79 \\
\hline & Columnar zone & 62 columns in 50 feet $(62 / 15 \mathrm{~m})$ & (3) & 1091 & 333 \\
\hline & Curvilinear zone $_{---}$top to middle & 57 joints in 50 feet $(57 / 15 \mathrm{~m})$ & 2 joints in 50 feet $(2 / 15 \mathrm{~m})$ & 780 & 238 \\
\hline & -_- do _-__-_- middle to bottom & 72 joints in 50 feet $(72 / 15 \mathrm{~m})$ & 5 joints in 50 feet $(5 / 15 \mathrm{~m})$ & 365 & 111 \\
\hline & Vesicular base & at few indistinct joints & 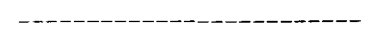 & --- & --- \\
\hline
\end{tabular}

These are cut by joints nearly normal to them, and this normal set is about 18-20 inches apart.

This zone was much disturbed. It contained in addition 125 sigmoidal shears in 260 feet $(125 / 79 \mathrm{~m})$, equivalent to 24 per 50 feet $(24 / 15 \mathrm{~m})$

'Slipping along columns probably took place during the period of tectonic deformation. 
although infrequently observed is almost always easy to identify. The chief difficulty arises in the distinction between the blocky and curvilinear zones.

The recognition of the blocky zone is usually an easy task, but its identification may be complicated by weathering, by glacial processes, by tectonic deformation, or by quarrying and excavation. Weathering may remove the sharp edges and give rise to some rounding of edges, and it may accentuate the joints; but the general rectangular pattern, the presence of few curved joints, and the presence of well-defined parallel joints usually leave no doubt as to zonal identity. It tends to preserve its massive character to a remarkable degree. When blocky joints are bumped and gouged by heavy buckets of power shovels, they usually develop a pseudocolumnar structure, for this operation tends to emphasize the tect onic joints, many of which are incipient in character. The blocky zone is, however, very hard to excavate, and it tends to jut out beyond the curvilinear zone below it. Further, the fact that the internal structure of the blocks resembles an assemblage of closely packed elongate polyhedra is a very helpful criterion in making a decision.

These estimated sizes for the joints are only average values and in some areas they may be larger and smaller. In Second Mountain huge curvilinear joints as much as $15 \times 20$ feet $(4.6$ to $6.1 \mathrm{~m}$ ) were observed.

\section{SUMMARY OF THE GEOMETRY OF THE TECTONIC JOINT SYSTEMS- \\ WITH A CONTRAST OF THE TWO TYPES}

The tectonic joints consist principally of (1) systems of parallel joints occurring in bands from a few inches (few centimeters) to 10 or more feet ( $3 \mathrm{~m}$ or more) apart and usually oriented normal to the surface of the flow, (2) sigmoidal joints (S-shaped) ${ }^{7}$ which may be quite long and oriented normally or transversely to the surface of the flow, (3) a conjugate set of closely spaced joints which appear near the base of the flow and are oriented normally or nearly so, and (4) a set of basal platy joints which are developed as a zone 10 to 12 feet $(3-4 \mathrm{~m})$ thick, parallel to and at the base of the flow just above the vesicular zone. These basal platy joints may be difficult to see in weathered exposures where slumping has occurred.

The occurrence of cooling joint systems and tectonic joint systems differ in the following ways:

1. cooling joints are always present whereas the occurrence of tectonic joints varies in any particular outcrop from very rare to extremely abundant;

2. the cooling joints are limited to certain zones in the flow and appear in a definite sequence;

3. the frequency of cooling joints does not change as the structure of the sheet changes, except for the quasi-geologic joints, whereas the abundance of the tectonic joints is directly related to the stress trajectories; see table 1;

\footnotetext{
For a discussion of the use of the term sigmoidal jointing, particularly applied to sedimentary
} rocks, see Engels (1956).
4. some of the tectonic joint systems having been produced by the deformation of the graben during arching when the border synclines were formed, are characterized by a pronounced conjugate relationship, (as for example the pseudocolumnar joints (type 2));

5. some of the tectonic joint systems consist of planes extending without interruption from the top to the base of a zone and having a uniform attitude, (as for example the pseudocolumnar joints (type 1)).

\section{A NOTE ON THE PAUCITY OF ZEOLITE DEPOSITS} IN THE TRAP FLOWS OF THIRD WATCHUNG MOUNTAIN

The field study of Third Mountain has shown that the occurrence of zeolites and other minerals of the same or similar paragenesis is rather local in areal extent and relatively small in quantity. It is observed chiefly in the following modes of deposition:

1. mineralized veins

2. mineralized joint surfaces

3. breccia zones

4. cavities - generally located near the top of the flow (these cavities were formerly occupied by gases).

This field study has not disclosed any pillow lavas in Third Mountain and this confirms the earlier findings of Lewis (1915). The normal vesiculated bottom is only rarely mineralized and the chief mineral species appears to be calcite. The vesiculated base of Third Mountain thus does not show the great mineralization observed in First Mountain. These observations support Fenner's (1908) theory for the relationship of the large zeolite zones with extrusion of lava flows into shallow bodies of water, chiefly playa lakes, forming pillow lavas in which the mineralization took place.

Schaller $(1932$, p. 8, 9) also contrasted the behavior of the lavas flows that poured over ordinary sediments with those that flowed over lake beds and commented on the condition and appearance of a "lava flow that came to rest quietly over dry sediments and crystallized to a normal compact basalt" with that of a lava that "flowed into water and acquired a spheroidal or boulder like structure." (Pillow lava). His study of the crystal cavities of the zeolite region in First Watchung Mountain showed that "the crystal cavities appear only in the lower spheroidal phase." (That is the pillow lavas).

Joints in the basalt were of minor importance compared to pillow lavas as sites for deposition of the zeolite mineral association.

\section{SUPPLEMENTARY TOPICS}

Implied in some of the descriptions of joint systems are some geometric concepts that may not be familiar to all readers of this paper, and they have been added here for those who wish to read them. In order that the usage given or implied herein will be clear a section entitled "Glossary of terms and definitions," and a section on "The character of 
helicoida! surfaces" have been subjoined. In addition Preston's (1904) classic description of "Isothermal surfaces and lines," and a section on "The phenomenological evidence for isothermal surfaces and the direction of heat flow" have been included.

\section{GLOSSARY OF TERMS AND DEFINITIONS}

A system is anything which we wish to isolate for purposes of study.

A bounded system is a system which is closed by a single surface, such as a sphere, or by the intersection of several surfaces such as a parallelepiped. All points in a bounded system are described by the restrictions on the a nalytical expressions of the surfaces. Thus, for a sphere every point $x y z$, on or within it is described by the family of equations $x^{2}+y^{2}+z^{2}$ $=a^{2}$ and for a bounded system $a^{2}<r^{2}$, where $r$ is the radius of the sphere.

A closed form encloses space and examples are a sphere, a cube, or a parallelepiped.

Open forms cannot by themselves enclose space since they extend to infinity. Examples of open forms are the cylinder, a prism, or a cone. Open forms may be terminated by other open forms. Thus, a cylinder may be terminated by basal planes.

A surface may be defined as a boundary, real or imagined, that separates two contiguous volumes. A single equation such as $F(x, y, z)=0$ represents a surface.

A plane is defined as a surface which meets the requirement that any straight line joining any two points in it lies entirely in the surface.

A curved surface fails to meet the above relation and therefore no part of it is a planar surface. Familiar examples of curvilinear surfaces, i.e. those that consist of curved lines, are the cylinder, cone and sphere.

Curvilinear polygons are polygons whose sides are curved lines and whose surfaces are curved. Note this definition excludes planar surfaces with curved sides.

A quadric surface is any surface defined by an equation of the second degree in $x, y, z$, Osgood and Graustein $(1921, \mathrm{p}$. 548).

The sphere and the quadric cylinders, cones, and surfaces of revolution are special types of quadric surfaces, Osgood and Graustein (1921, p. 548).

General types of quadric surfaces are ellipsoids, hyperboloids, and paraboloids.

Ruled surfaces are those on which straight lines may be drawn. "There are three classes of ruled surfaces: I, Planes; II, Single curved surfaces; III, Warped surfaces" Schumann (1946, p. 223).

"A warped surface is one generated by a straight line moving so that no two consecutive positions lie in the same plane," Schumann (1946, p. 264).

Warped surfaces are not developable surfaces, because they cannot be unrolled into a plane.

\section{CHARACTER OF HELICOIDAL SURFACES}

Helicoids are geometric surfaces that are rarely described in modern texts on analytical geometry and so are not too well known. For this reason several definitions are given here, and references to the pertinent literature have been added. Helicoids are defined in slightly different ways by mathematicians (differential geometers) and engineers (descriptive geometers), but their operations generate identical surfaces. The mathematician is interested in an analytical treatment of the surfaces; the descriptive geometer is concerned with the accurate graphical representation of geometric objects and with the solution of problems relating to the shape of objects and their disposition in space. The mathematician Frost (1886, p. 218) defines a helicoid as follows:

The helicoid is a scroll generated by the motion of a straight line which intersects at right angles a fixed axis, about which it twists with an angular velocity which varies as the velocity of the point of intersection with the axis.

Schumann (1946, p. 223, 282-289) gives an especially clear presentation of the approach to these surfaces from descriptive geometry. The following definitions are taken from his text:

A surface is generated by the continuous motion of a line (straight or curved) called the generatrix, having a relationship to a fixed line called the directrix. The consecutive positions of the generatrix are elements of the surface. A surface is not a solid but is a boundary of a solid.

The helicoid is a warped surface generated by a straight line moving so that it constantly touches a helix and its axis and makes a constant angle with that axis.

When the generatrix makes an angle of $90^{\circ}$ with the axis the helicoid is right. This surface is also a surface of two nappes.

When the generatrix makes an angle with the axis other than $90^{\circ}$, the helicoid is oblique. It consists of two nappes*** [See figure $50 \mathrm{~A}$.]

A nappe is a surface, or a portion of a surface, forming a continuous sheet. [See figure 50B.]

The general analytical expression for a helix and a helicoid provide a means of grasping the significance of their properties. The following discussion is based on the treatment of Eisenhart (1909) and Graustein (1935). The parametric equations defining a helix are: $x=u \operatorname{Cos} v, y=u \operatorname{Sin} v$ and $z=a v$ where $z$ is the axis of a right cylinder, $x$ and $y$ the coordinate axes, $v$ is the angle between the radius of the right cylinder to a point $P$ and the positive $x$ axis, and $a$ is a constant. The pitch of the helix, $h$, is equal to $2 \pi a$, and the tangent of the helical angle is $\tan \sigma=\frac{h}{2 \pi u}$. The tangent relation shows that as the angle of the helix increases the pitch, $h$, increases.

The parametric equations for the helicoid are commonly referred to the orientation with $z$ as the axis of rotation and the meridians defined as the planes through the $z$ axis, then the equation of the helicoidal surface is:

$$
x=u \operatorname{Cos} v, y=u \operatorname{Sin} v, \text { and } z=\phi(u)+a v
$$



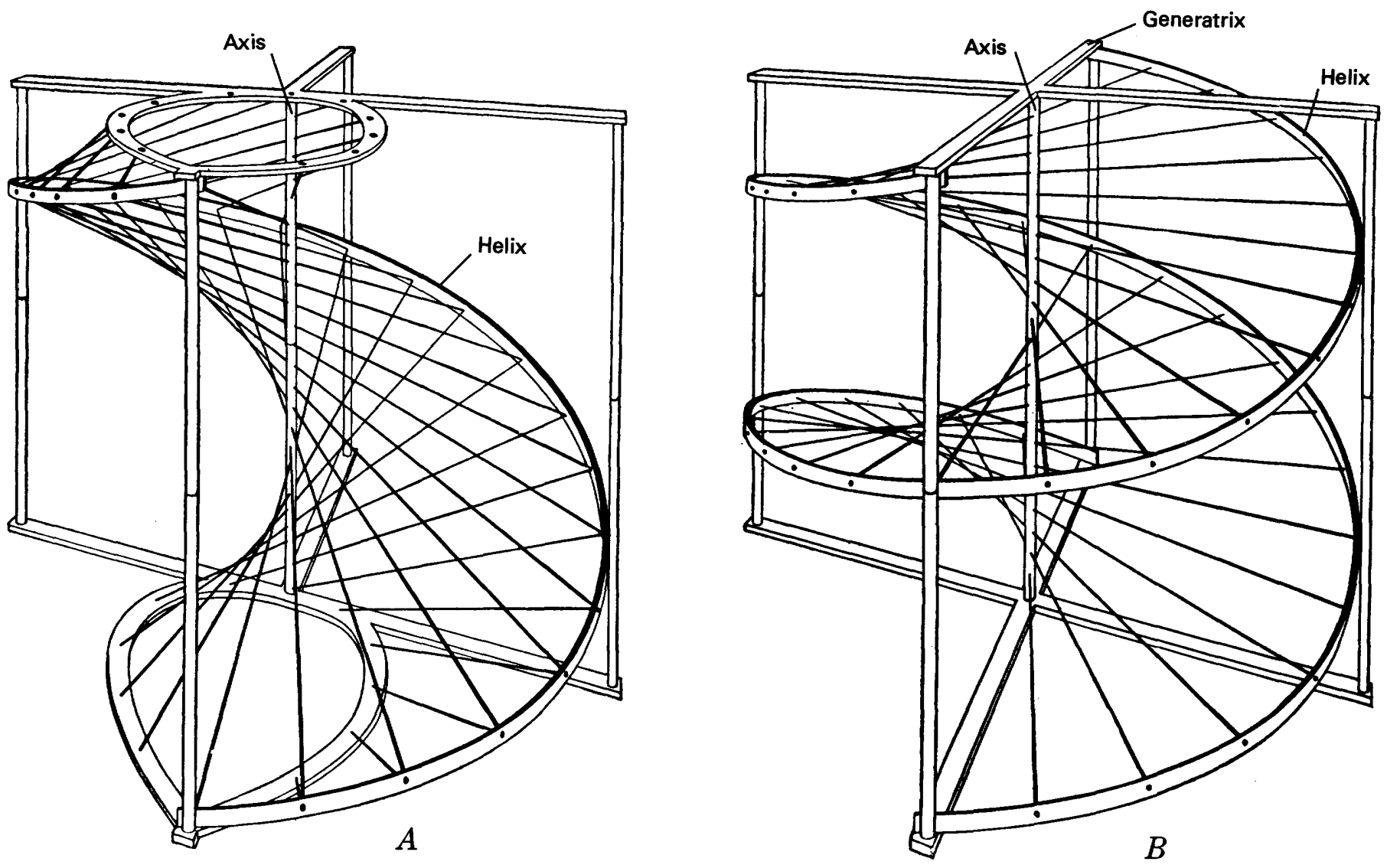

FIGURE 50. A, A string model of Oblique Helicoid prepared by Olivier of Paris. "A helix and its axis as directrices; elements making an acute angle with the axis." $B$. A string model of Right Helicoid. "A helix and its axis as directrices; elements making a right angle with the axis." From Schumann (1946) (Published by permission of D. Van Nostrand Co., Inc.)

where

$z=\phi(u)$ is the generating curve;

$u=$ the perpendicular distance of a point from the $z$ axis;

$v \quad=$ the angle of the meridian plane through the point to the $Z X$ plane;

$a=$ constant, the parameter of helicoidal motion; and

$2 \pi a=$ the pitch of the helicoidal motion.

In these equations it can be noted that:

1. if $\phi(u)=$ constant, then the curves $v=$ constant are straight lines (rulings) perpendicular to $z$ and the surface is a right helicoid.

2. if $a=0$, then the equations define a surface of revolution. 3. from the method of construction it follows that the curves $v=$ constant are the rulings and curves $u=$ constant are circular helicies on the helicoids.

4. if the pitch, $h$, is variable or the length of the generatrix is variable more general types of helicoids are generated. Wellman $(1948$, p. 219$)$ points out that in such cases "the angle between the generatrix and the axis is also variable."
From these definitions we may further observe that helicoids can be right-handed or left-handed depending on whether they twist to the right or to the left, see figures 50 and 51. A right-handed helicoid advances away from the end of the helical directrix in a clockwise direction and a lefthanded helicoid advances in a counterclockwise direction. Helicoids are warped surfaces because successive positions of the generatrix do not lie in the same plane and if the surface is unrolled onto a plane it will not lie flat but will have a warp in it. Helicoids have also been called screw surfaces because of their obvious relations to these objects.

For an analytic treatment of helicoids the reader is referred to the works of Eisenhart (1909), Frost (1886), Graustein (1935), Hilbert and Cohn-Vossen (1932), and Scheffers $(1901,1902)$. For a descriptive geometric approach reference is made to the treatments of Schumann (1946), Von Sanden (1960), Watts and Rule (1946), and Wellman (1948).

\section{ISOTHERMAL SURFACES AND LINES}

According to Preston (1904, p. 663),

In the general case the temperature at any point of a body will be a function 


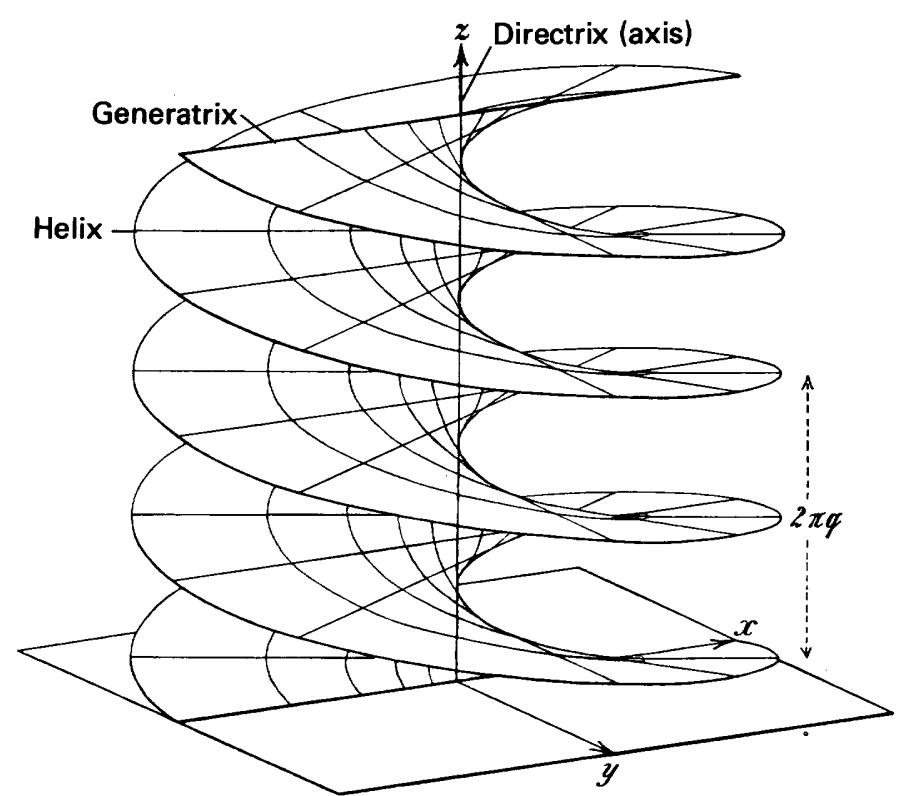

FIGURE 51. Two left-hand, right helicoids. The vertical distance $2 \pi q$ is the pitch of one helicoid where $q$ equals a constant and it represents the vertical distance traversed in one complete revolution $\left(360^{\circ}\right)$ of the generatrix. Scheffers (1902, v. 2, p. 60-61).

of the co-ordinates, $x, y, z$, of the point and of the time $t$, so that the general expression for $\theta$ at any point will be of the form

$$
\theta=f(x, y, z, t) \text {. }
$$

Hence, if we write

$$
f(x, y, z, t)=a,
$$

where $a$ is a constant, we obtain the locus of all the points at which the temperature has the same value $a$ at the time $t$. These points lie on a surface, determined by the function $f$, and named an isothermal surface because it is one of equal temperature. When the flow has become steady the temperature at any point remains steady, and therefore does not involve the time. In this case, then, the isothermal surfaces are fixed in shape and position, each separating those parts of the body which are hotter than a certain temperature from those which are colder. In the variable state, on the other hand, the shape and position of an isothermal surface corresponding to a definite temperature will in general vary with the time.

If a system of such surfaces be supposed drawn within the body, the temperature of each differing, by $1^{\circ}$ suppose, from that which immediately precedes or follows it, the whole body will then be divided into a system of layers or shells such that the temperature of one face of each layer exceeds that of the other by $1^{\circ}$, and a flow of heat will proceed through the shell from the hotter face to the colder. The direction of the flow at each face will also be perpendicular to the surface, for since the temperature is constant all over each isothermal, it follows that there can be no flow along such a surface.

It follows then that the direction of the resultant flow at any point of a body is along the normal to the isothermal surface passing through that point, so that if a line be drawn cutting the whole system of surfaces orthogonally, the direction of the flow at every point of this line will be along the line. For this reason a line drawn so as to cut each of the system of surfaces at right angles is termed a line of flow.

The whole body may thus be imagined to be divided into a system of infinitely thin shells by a system of isothermal surfaces, and the infinite system of lines which can be drawn cutting these shells orthogonally are the lines of flow.

One property of these systems is that no two isothermal surfaces, or no two lines of flow, can intersect each other, for no point can possess two dif- ferent temperatures at the same time, nor can the flow at any point be at once in two different directions.

\section{THE PHENOMENOLOGICAL EVIDENCE FOR ISOTHERMAL SURFACES AND THE DIRECTION OF HEAT FLOW}

Geologists established long ago the relation of the columnar joint systems in lava flows and dikes and observed that in vertical dikes the columnar joints were horizontal whereas in flat-lying lava flows the joints were vertical. They further observed that in curved contacts with the country rock that the joints tilted to conform to a normal position to the contact. They also noted that in pahoehoe tops and other curved surfaces in lava tops that the joints tilted in conformity with the surface. From this they concluded that the isothermal surfaces were parallel to the tops of flows and the walls of dikes and that the direction of heat flow was normal to the isothermal surfaces. Their conclusion was reinforced by the observations in the furnace practices of their day.

Iddings (1886; 1909, v. 1, p. 320-322) studied the columnar jointing in the famous O'Rourke quarry at West Orange, N.J. He made a theoretical study of the heat flow relations and jointing in which he assumed that the joints formed in the cooling lava along surfaces perpendicular to the isothermal planes. Tomkeieff $(1940$, p. 121-135) worked out the cooling relations and formation of joints for his study of basalt of the Giant's Causeway district of Northern Ireland. He defined (p. 129) the fracture isotherm as that particular isotherm at which fracture takes place and suggested "that the rate of advance of the fracture isotherm will determine the nature of the jointing, while, the amount of accumulated stress will determine its magnitude."

These model studies of heat transfer relations, by conduction, to the geometry of the jointing produced in a solidifying lava sheet have been calculated for only very simple cases. The calculation of the heat conduction relations, including the corner and edge corrections of Langmuir, Adams, and Meikle (1913) can only be made for simple solids. For more complex shapes the mathematical solutions become formidable, and a graphical method, based on geometrical principles was developed by Awbery and Schofield (1929) and Schofield (1930). It has been found very useful by Ingersoll, Zobel, and Ingersoll (1954, p. 200-203) in analyzing "steady-state heat conduction in two dimensions, involving the construction of an isotherm and flow-line diagram." Numerical methods used in conjunction with a computer may yield solutions for yet even more general problems, Myers (1971).

\section{ACKNOWLEDGMENTS}

Richard C. Erd, U.S. Geological Survey, worked closely with me in the mapping of much of Third Watchung Mountain, and I am indebted to him in many ways in the testing of the ideas regarding the jointing patterns in the trap flows. The late Theodore Woodward, John R. Houston, and the late Charles Minard, former members of the U.S. Geological 
Survey, served as assistants in the field studies on Third Watchung Mountain. Many of the photographs were specially taken for this study by John P. Marble, Jr., formerly of the U.S. Geological Survey and Dr. Gudmunder E. Sigvaldason, then of the Dept. of Industrial Testing and Research, Reykjavik, Iceland, who from 1959 to 1961 was a visiting research scientist at the U.S. Geological Survey under sponsorship of the National Academy of Sciences. I am also indebted to the many property owners, quarry companies, and quarry managers in the area. The standard reference section for Third Watchung Mountain was set up in the Millington quarry and accordingly, I am particularly grateful to the late Thomas J. Stewart, former superintendent, of the Millington Plant of Houdaille Industries, who aided me in many ways and who constantly encouraged me.

The names given to the abandoned quarries were obtained in part from former owners and in part from local residents. The late Clyde L. Wolfe of Bernardsville was knowledgeable and helpful on this subject.

In order to gain a knowledge of jointing in other basaltic provinces and to make comparisons, brief field excursions were made to them with geologists familiar with the areas. This provided the opportunity to study the possible influence of the nature of the underlying rocks on the character of the jointing in the basalt flows above them. I wish to thank the following colleagues who are members of the U.S. Geological Survey for showing me jointing phenomena in the basaltic rocks of the areas of study-Henry $\mathrm{R}$. Cornwall and Walter S. White in the Michigan copper district, Albert E. Weissenborn in the flows of the Columbia River Basalt Group south of Spokane, Wash., and John K. Adams in the Table Mountain basalt near Golden, Colo. In Europe I was shown jointing in the basalt flows of Iceland at Thingvellir and elsewhere by the late Professor Tómas Tryggvason of the University Research Institute of Reykjavik, in the Vogelsberg Mountains in Hesse, Germany, by Professor Hans Hentschel of the Hessische Landesamt fur Bodenforschung in Wiesbaden, Germany. Professor K. Hans Wedepohl of Göttingen University, showed me the basaltic plugs in the vicinity of the University and Professor Sigmund Koritnig took me to the "Blaue Kuppe" bei Eschwege and to the Hoher Meissner. The later flow was famous in the controversy of the Neptunists and the Vulcanists, Johannsen (1937, p. 264). The late Professor Sergei I. Tomkeieff of King's College, University of Durham, showed me the Whin Sill and discussed his jointing studies on the Giant's Causeway district, Northern Ireland. Niels Óskarsson, of the University of Iceland assisted me in the measurement of joint widths at the fault wall at Thingvellir and for which help I thank him.

My colleague Howard T. Evans very kindly prepared the complex illustrations of the geometrical models of the various helicoidal surfaces. Dallas L. Peck and Thomas L. Wright discussed related problems in the lavas of Hawaii and the Columbia River flows.
An early version of this manuscript was critically reviewed by my colleagues Gudmunder E. Sigvaldason, Harry W. Smedes, and Robert L. Smith, and this version by Rosalind L. Helz, Ray E. Wilcox, and David R. Wones, all of the U.S. Geological Survey.

\section{LITERATURE CITED}

Awbery, James H. and Schofield, Francis H., 1929, Effect of shape on heatloss through insulation: Congress on Refrigeration, 5th Internat. Proc., 1928, pt. 3, p. 591-596.

Bankwitz, Peter, 1965, Über Klüfte-I. Beobachtungen im Thüringischen Schiefergebirge: Geologie, Zeitschr. für das Gesamtgebiet der Geologischen Wissenschaften, Jahrg. 14, p. 241-253.

1966, Über Klüfte-II. Die Bildung der Klüftflache und seine Systematik ihrer strukturen: Geologie Zeitschr. fur das Gesamtgebiet der Geologischen Wissenschaften, Jahrg. 15, p. 896-941.

Barrell, Joseph, 1915, Central Connecticut in the geologic past: Connecticut Geol. and Nat. History Survey Bull. 23, 44 p.

Bingham, James W., and Grolier, Maurice J., 1966, The Yakima Basalt and Ellensburg Formation of south-central Washington: U.S. Geol. Survey Bull. 1224-G, p. G1-G15.

Bond, John G., 1963, Geology of the Clearwater embayment: Idaho Bur. Mines and Geology Pamph. No. 128, 83 p.

Bucher, Walter H., and Kerr, Paul F., 1948, Excursion to the First Watchung Basalt at Paterson, New Jersey: Geol. Soc. America Guidebook of Excursions, 61 st Ann. Mtg., New York, N.Y., 1948, p. 109-119.

Cloos, Hans, 1936, Einführung in die Geologie: Lehrbuch der inneren Dynamik: Berlin, Verlag Gebrüder Borntraeger, p. XII +515 .

Eisenhart, Luther P., 1909, A treatise on the differential geometry of curves and surfaces: New York, Ginn and Company, p. xiv +474 . Reprinted by Dover Publications, Inc., N.Y., 1960.

Engels, Bruno, 1956, Zur Deutung der Querplattung (Sigmoidalklüftung): Hamburg geol. Staatsinst. Mitt. Heft 25, p. 5-25.

Faust, George T., 1975, A review and interpretation of the geologic setting of the Watchung Basalt flows, New Jersey: U.S. Geol. Survey Professional Paper 864-A, 42 p.

Fenner, Clarence N., 1908, Features indicative of physiographic conditions prevailing at the time of the trap extrusions in New Jersey: Jour. Geology, 16, p. 299-327.

Frost, Percival, 1886, Solid geometry: London, Macmillan and Company, $3 d$ edition, p. xxiv +408 .

Geike, Archibald, 1893, Textbook of geology: London, Macmillan and Co., 3d ed., rev., p. xvi +1147.

Graustein, William C., 1935, Differential geometry: New York, Macmillan and Company, p. $x i+230$.

Hast, Nils, 1967, The state of stress in the upper part of the earth's crust: Eng. Geology, v. 2, no. 1, p. 1-17.

Hilbert, David, and Cohn-Vossen, Stephen, 1932, Anschauliche Geometrie: Berlin, Julius Springer, 254 p. Translated by Nemenyi, P., 1952, Geometry and the Imagination, New York, Chelsea Pub. Co., p. ix + 357.

Hodgson, Robert A., 1961, Classification of structures on joint surfaces: Am. Jour. Sci., v. 259, p. 493-502.

Hooker, Verne E., and Johnson, Charles F., 1967, In situ stresses along the Appalachian Piedmont: Proc. 4th Rock Mechanics Symposium, Ottawa, p. 137-154.

Iddings, Joseph P., 1886, The columnar structure in the igneous rocks of Orange Mountain, New Jersey: Am. Jour. Sci., ser. 3, 31, p. 321-331. _1909, Igneous Rocks: New York, N.Y., John Wiley and Sons, v. 1, p. $\mathrm{xi}+464$.

Ingersoll, Leonard R., Zobel, Otto J., and Ingersoll, Alfred C., 1954, Heat conduction with engineering, geological and other applications: Madison, Wisconsin, Univ. Wisconsin Press, p. xiii +325 . 
Jaeger, John C., 1968, Cooling and solidification of igneous rocks: in Hess, Harry H., and Poldervaart, Arie, Basalts-The Poldervaart Treatise on rocks of basaltic composition: New York, N.Y., Interscience, v. 2, p. 503-536.

Johannsen, Albert, 1937, A descriptive petrography of the igneous rocks: Chicago, The University of Chicago Press, v. III, p. xiv +360 .

Johnston, John, 1854(1855), Notice on some spontaneous movements occasionally observed in the sandstone strata in one of the quarries at Portland, Connecticut: Amer. Assoc. Adv. Sci. Proc., v. 8, p. 283-286.

Kemp, James F., 1929, A handbook of rocks: New York, N.Y., D. Van Nostrand Co., Inc., p. $x i+300$.

Krynine, Paul D., 1950, Petrology, stratigraphy, and origin of the Triassic sedimentary rocks of Connecticut: Connecticut Geol. and Nat. History Survey Bull. 73, 239 p.

Langmuir, Irving, Adams, Elliot Q., and Meikle, George S., 1913, Flow of heat through furnace walls: The shape factor: Am. Electrochem. Soc. Trans., v. 24, p. 53-84.

Lewis, J. Volney, 1908, Petrography of the Newark igneous rocks of New Jersey: Geol. Survey New Jersey, Ann. Rept. State Geologist for 1907, p. 99-167.

1909, Building stones of New Jersey: New Jersey Geol. Survey Ann. Rept. for 1908, p. 53-124.

1915. The pillow lavas of the Watchung Mountains: New Jersey Geol. Survey Bull. 16, Ann. Adm. Rept. State Geologist of N.J. for 1914, p. 51-56.

Mackin, J. Hoover, 1961, A stratigraphic section in the Yakima Basalt and the Ellensburg Formation in south-central Washington: Washington Div. Mines and Geol. Rept. Inv. no. 19, 45 p.

Murawski, Hans, 1968, Tektonik, a chapter in "Vom Erdkern bis zur Magnetosphere": Frankfurt am Main, Germany, Umschau Verlag, p. 6783.

Myers, Glen E., 1971, Analytical methods in conduction and heat transfer: New York, McGraw Hill Book Co., p. xvii + 508 .

Nevin, Charles M., 1931, Principles of structural geology: New York, John Wiley and Sons, Inc., p. xii +303.

Oliveira, R. A. M., 1971, Nature of stresses: Internat. Symposium on the detm. of stresses in rock masses, Lisbon, 1969, Proc. vol., p. 34-36.

Ollier, Clifford D., 1969, Weathering: New York, American Elsevier Pub. Company, Inc., p. vii +304 .

Osgood, William F., and Graustein, William C., 1921, Plane and solid analytic geometry: New York, The Macmillan Company, p. xvii +614 .

Piteau, Douglas R., 1973, Characterizing and extrapolating rock joint properties in engineering practice: Rock Mechanics, Supplementum 2, p. 5-31.

Preston, Frank W., 1930, Ball and socket jointing in basalt prisms: Royal Soc. London, Proc. pt. b, v. 106, p. 87-93.

Preston, Thomas, 1904, The Theory of Heat [2d ed., revised by J. Rogerson Cotter]: London, Macmillan and Co., Ltd., p. xix +838 .
Price, Neville J., 1966, Fault and joint development in brittle and semibrittle rock: Oxford, England, Pergamon Press, p. $x+176$.

Roberts, John C., 1961, Feather fracture, and the mechanics of rock jointing: Am. Jour. Sci., v. 259, p. 481-492.

Rosenbusch, Harry, 1923, Elemente der Gesteinslehre: Stuttgart, Germany, E. Schweizerbart'sche Verlag, p. $x+779$.

Salisbury, Rollin D., Kummel, Henry B., Peet, Charles E., and Knapp, George N., 1902, The glacial geology of New Jersey: Final Rept. State Geologist, 5 , p. xxvii +802 .

Schaller, Waldemar T., 1932, The crystal cavities of the New Jersey zeolite region: U.S. Geol. Survey Bull. 823, p. vii +90 .

Scheffers, Georg, 1901, Einführung in die Theorie der Curven in der Ebene und in Raume: Leipzig, Verlag von Veit and Company, v. 1, p. $x+360$ : 1902, Einführung in die Theorie der Flachen: v. 2, p. $x+518$.

Schofield, Francis H., 1930, The heat-loss from a plate embedded in an insulating wall: Phil. Mag., ser. 7, v. 10, p. 480-500.

Schumann, Charles H., Jr., 1946, Descriptive geometry: New York, D. Van Nostrand Company, Inc., 4th ed., p. xi +338 .

Sosman, Robert B., 1916, Types of prismatic structure in igneous rocks: Jour. Geology, v. 24, p. 215-234.

Spry, Alan, 1962, The origin of columnar jointing, particularly in basalt flows: Geol. Soc. Australia Jour., v. 8, pt. 2, p. 191-216.

Tomkeieff, Sergi I., 1940, The basalt lavas of the Giant's Causeway district of Northern Ireland: Bulletin Volcanol., ser. II, Tome VI, p. 89-143.

U.S. Geological Survey, 1961, Geological Survey Research 1961-Synopsis of geologic and hydrologic results: U.S. Geol. Survey Prof. Paper 424A, p. A77-A194.

1972, Geological Survey Research 1972: U.S. Geol. Survey Prof. Paper 800-A, p. A27.

1973, Geological Survey Research 1973: U.S. Geol. Survey Prof. Paper 850, p. 36.

Voight, Barry, 1966, Interpretation of in situ stress measurements: Internat. Soc. Rock Mechanics, Proc. Int. Cong., v. 3, p. 332-348.

1969a, A discussion-The state of stresses in the upper parts of the earth's crust: Eng. Geology, v. 3, p. 335-339.

$1969 \mathrm{~b}$, Evolution of North Atlantic Ocean: Relevance of rockpressure measurements: Amer. Assoc. Petroleum Geologists Mem. 12, p. $955-962$.

Von Sanden, Horst, 1960, Darstellende Geometrie: Stuttgart, B. G. Teubner Verlag, p. $115+42$ Abbildungen.

Watts, Earle F., and Rule, John T., 1946, Descriptive Geometry: New York, Prentice-Hall, Inc., p. viii +501 .

Wellman, B. Leighton, 1948, Technical descriptive geometry: New York, McGraw Hill Book Company, Inc., 1st ed., p. xii + 508 .

Woodworth, Jay B., 1896, On the fracture system of joints with remarks on certain great fractures: Boston Soc. Nat. History, Proc. v. 27, p. 163183. 



\section{INDEX}

[Italic page numbers indicate major references]

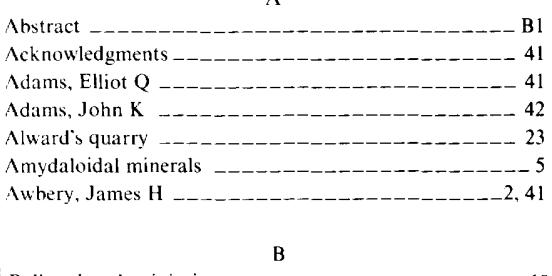

Ball and socket jointing _-_-_-__-_-_-_-_-_-_ 10

Bankwitz, Peter -- Barn, Jo 31

Barrell, Joseph, quoted _-__________-__-_ 19

Bingham, James W ----

Bond John

Brownstone -

Brunswick Formation

$5,16,21$

Bucher, Walter H. quoted

Chos, Hans, cited _---- 21 quoted - 4

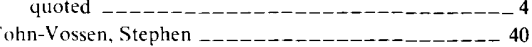
Columbia River Group -_-_-_-_-_-_-_-_-- 18, 42

Cooling joints, blocky zone - columnar zone -
curvilinear zone ---12 in other basaltic provinces rectangular joint systems

Connecticut Triassic Basin _-_-_-_-_-_-_-_-- 17

Cornwall, Henry R

Deckensohle

$-21$

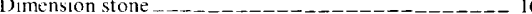

Eisenhart. Luther P _-_-_-_-_-_-_-_-_- 39, 40

Engels, Bruno _-_-_-___-__-_-_-_ 38

England:

Whin Sill

Erd, Richard C

$-42$

Evans, Howard T __...____________ 15, 42

Faust, George T

Feather fracture -_-__-_-_-_-_-_-_-_-_ 30,31

Fenner, Clarence $\mathrm{N}$

Flow, breccias _-_-_-_-_-_-_-_-_-_-_--- 16

Fracture isotherm _- 2, 41

Frost, Percival, cited _._____-_ 40

quoted

Gcike, Archibald, quoted _--

Geometry, cooling joint systems

tectonic joint systems

Germany:

Blaue Kuppe --_-_--_---_------_---_-- 42

Gottingen - -

Hoher Meissner

Vogelsberg -

Glacial pavement

Glossary of terms _._._-_._- 39

Graustein, William C, cited _-_-_-_--_- 40

yuoted --_-_-

Grolier, Maurice J
Hast, Nils _-_- $\mathrm{H}$

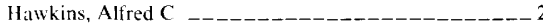

Helicoidal surfaces -

Helicoide -__-_-__-__-__-_ 14

Hel7. Rosalind -

Hentschel, Hans _-_-___-__-____-_-_-_-__-_ 42

Hilbert, David _-_- 40

Hodgson. Robert A _

Hooker, Verne E --_-_-_-_-_-_-_-_-_-_-_- 34

Hornfels zone — 5,24

Houston. John

41

Iceland:

Dettifoss

18.42

Myvatn - 19,42

Thingvellir -_-_-_-_- $19,33,34,42$ Iddings, Joseph P --_-

Ingersoll, Alfred C _-________________-_ 41

Ingersoll, Leonard R _-_-

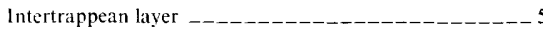

Introduction _......-

Isothermal surfaces

Jacger, John C _... J

Johannsen, Albert --_-_-_-_-_-_-_-_-_---- 42

Johnson, Charles F --

Johnston, John, quoted _-___- 35

Joints, cooling _-_-___-_-__- 36

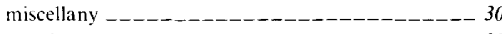

sheeting -

tectonic _-_-_-_-_-_- 19.38

weathering

K

Kemp, James $\mathrm{F}$

K

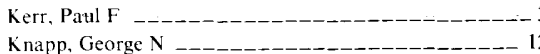

Koritnig, Sigmund _-__-__-___-_-_-_ 42

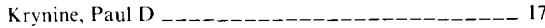

Kummel, Henry B

I angmuir Irving - $-2-5$

I ava flow unit zones, blocky zone _-__________-_ 11

columnar zone

curvilinear zone --_-_-_-_-_-_-_-_-_-_-- 12

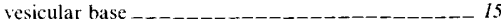

vesicular top --_-_-_-_-_-_-_-_-_-_--_--_ 5

L.cwis, J. Volney

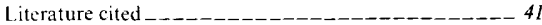

M

Mackin, J. Hoover --_-_-

Marble, John P _-________________ 42

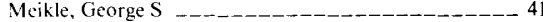

Millington quarry

Minard, Charles _-_-_-_-_-_-___-_-_-_- 4

Murawski, Hans _-_-_-_-_-__-_ 20

Myers, Glen E _-_-_-

Nevin, Charles $M$

Vew Germantown trap sheet

Newark graben, geologic history _-___-__-__-__- 19

Newark Group, thickness _-_-

Nova Scotia-Bay of Fundy
Oliveira, R. A. M., quoted _-_- B36

Ollier, Clifford D _..-_-_-_-_-_-_ 25

O'Rourke quarry _-_-

Osgood, William F., quoted _-______- 39

Oskarsson, Niels _-_

Pahoehoe surface -_-_- $4,5,9,16,41$

Peck, Dallas _-_

Peet, Charles E _-______-_ 12

Pillow lavas _-__-__-_ 3, 16, 38

Piteau, Douglas R _-__-_-_-_ 36

Preston. Frank W _-_- 10

Preston. Thomas, quoted _____________-_ 39

Previous studies _-_-_-_-_-_-_-_-_-_-_-_-_- 2

Price, Neville, J

\section{R}

Riprap $=-2-17$

Road metal

Roberts, John C _-_-_-_-_-_-_-_-__-_ 31

Rosenbusch, Harry _-__-_-_-_ 27

Rule, John T _ _-

$\mathrm{S}$

Schaller. Waldemar T -

Scheffers, Georg -_-__-__-_-_-_ 40

Schufield. Francis H _-___________-__-_ 2,41

Schraubenflache --_-_-_-_-_-_-_-_-_-_- 14

Schumann. Charles H., cited yuoted --_-_- 39 Shecting joints _-

Sigvaldason, Gudmunder _-_-_-__-_-__-_-_-_ 42

Smedes, Harry W -_-_-_-_-_-_-__-__-_ 42

Smith, Robert L _______ 42

Sosman, Robert B______________ 3, 27, 31

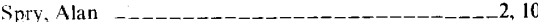

Stewart, Thomas J -

T

Tectonic joints, basal platy

joints. vesicular base
perpendicular joints, blocky zone -14

planar basal joints.

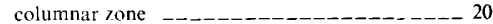

pseudocolumnar joints, curvilinear

hear zone, blocky zone

transverse joints, vesicular

top Trygavason, Tomas $2,3,10,41,42$

$\mathrm{U}, \mathrm{V}, \mathrm{Z}, \mathrm{w}$

U.S. Geological Survey _--_-_-_-_---_--_--- 2

Voight, Barry ______-__-_-_ 34

Von Sanden, Horst

\section{W}

Watchung Basalt flows, sequence of

zones in each unit _-___-__-_ 5

Watts, Earle $F$ -

Weathering joints. late stage.

unloading "platy joints"

solifluction, a distorting agent

of jointing patterns $-29$ 
Weathering joints-Con. spheroidal joints

Wedepohl, K. Hans

Weissenborn, Albert $\mathbf{E}$

Wellman, B. Leighton

White, Walter $\mathrm{S}$

Wilcox, Ray E _.

Width of joint openings

Wolfe, Clyde L

Wones, David R

Woodward, Theodore

Woodworth, Jay B _
Wright, Thomas $\mathrm{L}$ 42 Z

Zeolite deposits in the trap flows of Third mountain ___ B 38 flows of Third mountain
Zobel, Otto J ¿.S U.S Government Printing Office: 1977-261-221/146 